\title{
UAV POWER PLANT PERFORMANCE
}

\section{EVALUATION}

\author{
By \\ ASHWIN RAVI \\ Bachelor of Science in Mechanical Engineering \\ Anna University \\ Chennai, Tamil Nadu \\ 2008
}

Submitted to the Faculty of the

Graduate College of the Oklahoma State University

in partial fulfillment of the requirements for the Degree of

MASTER OF SCIENCE

May, 2010 


\section{UAV POWER PLANT PERFORMANCE \\ EVALUATION}

Thesis Approved:

Dr. Andrew Arena

Thesis Adviser

Dr. Jamey Jacob

Dr. David G Lilley

Dr. A. Gordon Emslie

Dean of the Graduate College 
Nine tenths of education is encouragement

-Anatole 


\section{ACKNOWLEDGEMENTS}

I would like to express the truthful admiration to my advisor Dr. Andrew Arena, who has supported me throughout my thesis with his patience and knowledge whilst allowing me the room to work in my own way. Without his guidance and constant help this thesis would not have been possible. One simply could not wish for a better or friendlier advisor.

I would also like to thank my committee members, Dr. Jamey Jacob, Dr. D G Lilley for being patient and helping me throughout my research at Oklahoma State University.

I convey my sincere thanks to Oklahoma State University, in particular the department of Mechanical \& Aerospace Engineering for helping me finish my masters at the pace I'm comfortable with, for providing the best in class research facilities and resources to finish my research in time.

Finally, I thank my parents and friends for being there for me and supporting me here at Oklahoma State University. 


\section{TABLE OF CONTENTS}

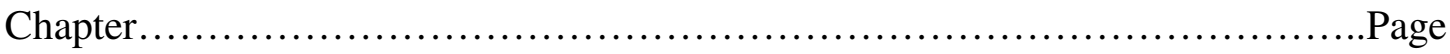

I. INTRODUCTION ................................................. 1

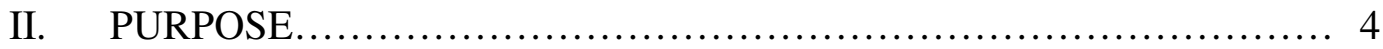

III. LITERATURE REVIEW......................................... 5

3.1.Technology Readiness Level................................. 5

3.2.Evaluation of current propulsion technologies................... 6

3.2.1. 2-Stroke engines...................................... 6

3.2.2. 4-Stroke engines....................................... 11

3.2.3. Wankel engines..................................... 14

3.2.4. Turbines..................................................... 19

3.2.5. Electric motors.............................................. 24

3.2.6. NiMH................................................. 27

3.2.7. Lithium Ion/Polymer.................................... 28

3.2.8. Lithium Sulfur........................................ 29

3.2.9. Hydrogen fuel cells...................................... 30

3.3.Near \& Long term technologies.............................. $\quad 30$

3.4.Comparison of current propulsion technologies.................... 33

3.5.Summary of adv \& dis-adv of propulsion technologies............. 34

3.6. Future propulsion technologies............................... 39

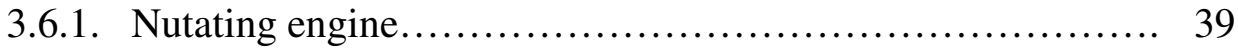

3.6.2. Six-stroke engine..................................... 40

3.6.3. HCCI engine .......................................... 41

3.6.4. Dual fuel engine........................................ 42

3.6.5. Electric diesel hybrid.................................. 43

IV. Dynamometer..................................................... 46

4.1.Thomas dynamometer.................................... 46

4.2.Menon Dynamometer........................................ 47

4.3.Korean Aerospace institute dynamometer..................... 48

4.4.Fuel injection system..................................... 50

4.4.1. Types of fuel injection system............................ 51 
V. Propulsion system survey....................................... 54

VI. Experimental setup............................................ 56

6.1.Rationale for dynamometer................................ 56

6.2.Measurements \& Instrumentation........................... 58

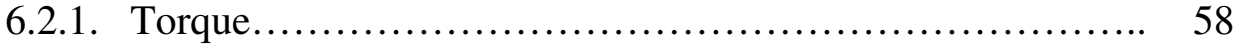

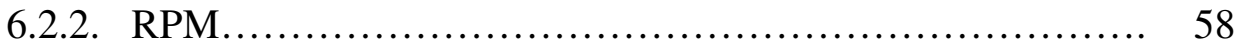

6.2.3. Flow-meter............................................. 59

6.2.4. Thermocouple....................................... 61

6.2.5. Propeller............................................ 61

6.2.6. Control module........................................... 61

6.3.Construction................................................ 62

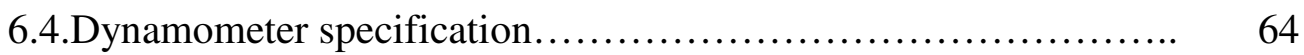

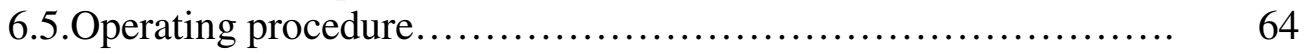

6.6.Construction of 2-stroke FI system......................... 65

VII. Uncertainty analysis........................................... 69

VIII. Results \& Discussions....................................... 73

8.1.Engine data............................................... 74

8.1.1. BME 150 carburetor results.............................. 74

8.1.2. BME 116 carburetor results............................. 78

8.1.3. BME 116 EFI results................................ 82

8.2.Payload vs. Range analysis................................. 85

IX. Conclusion.................................................... 88

X. Future developments............................................ 89

XI. Appendices.................................................. 90

1. FL113 flow-meter calibration chart..................... 90

2. Digital flow meter calibration chart..................... 91

3. Propulsion system survey........................... 93

XII. References...................................................... 95 


\section{LIST OF FIGURES}

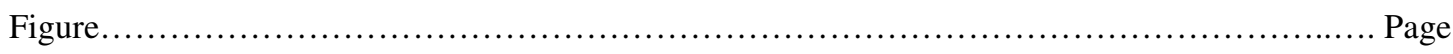

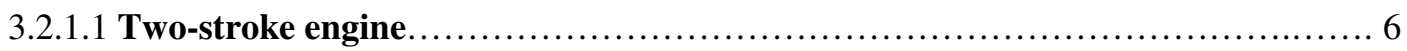

3.2.1.2 Plot of HP vs. Weigh..................................................... 9

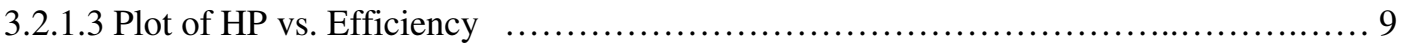

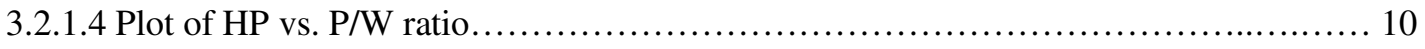

3.2.1.5 Plot of HP vs. SPED ...................................................... 10

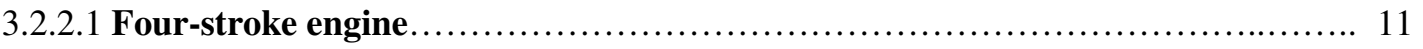

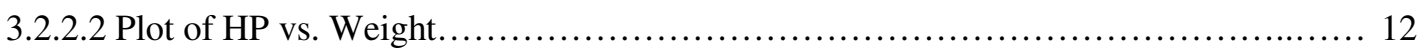

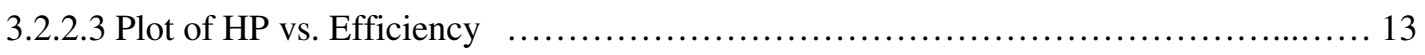

3.2.2.4 Plot of HP vs. P/W ratio................................................... 13

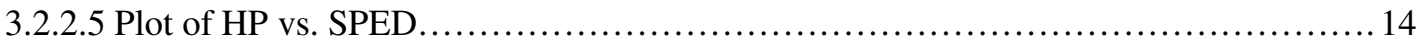

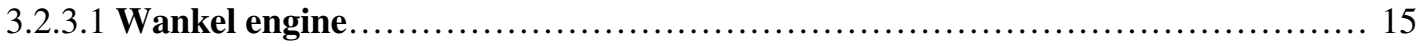

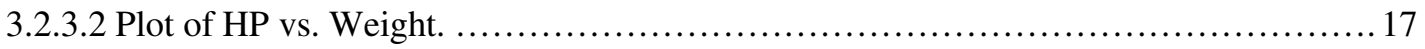

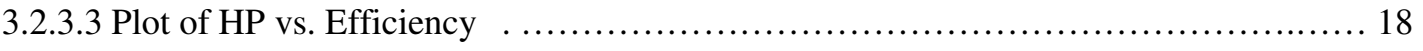

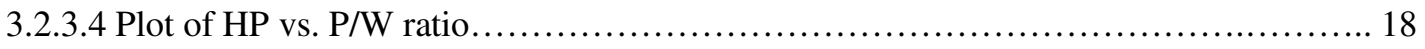

3.2.3.5 Plot of HP vs. SPED .................................................. 19

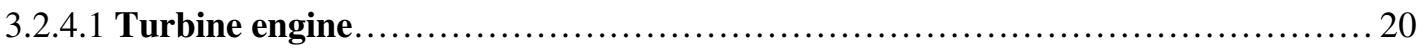

3.2.4.2 Plot of HP vs. Weight..................................................... 22

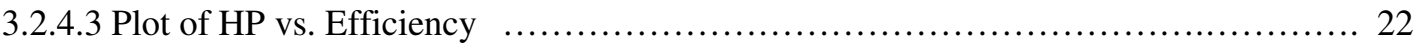

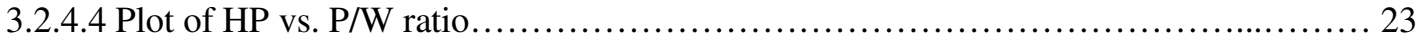

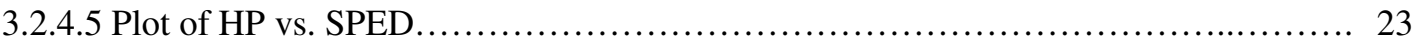

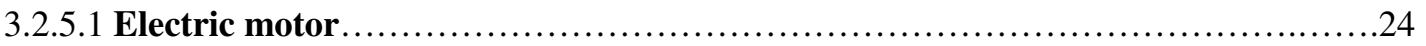

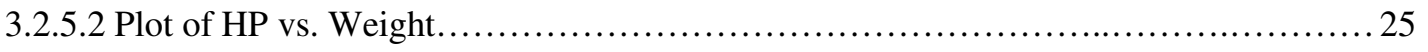

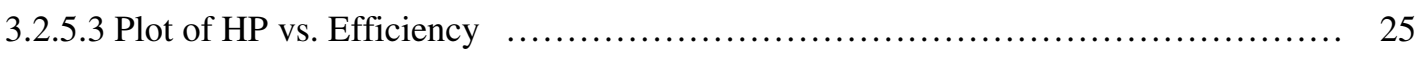

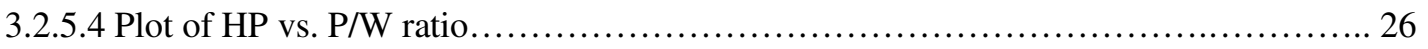


3.2.5.5 Plot of HP vs. SPED ...................................................... 26

3.3.1 Expected growth of small scale propulsion system................................ 31

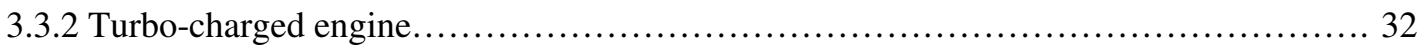

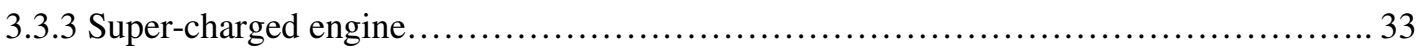

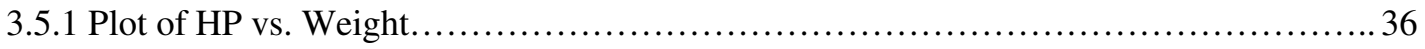

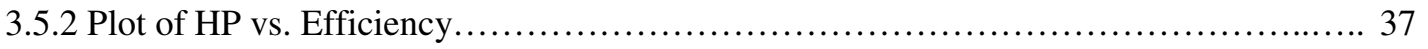

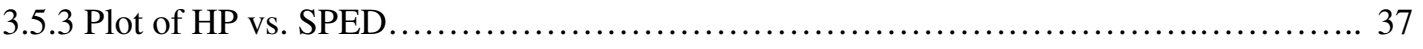

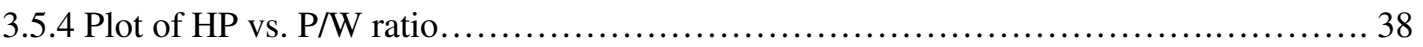

3.5.5 Plot of Specific fuel consumption vs. Power density .............................. 38

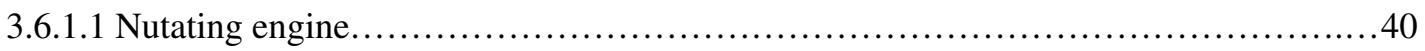

3.6.2.1 Six-stroke engine ......................................................... 40

3.6.3.1 HCCI engine.............................................................. 42

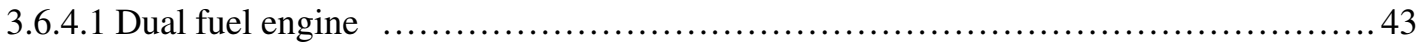

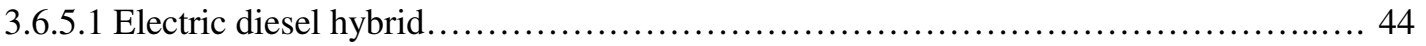

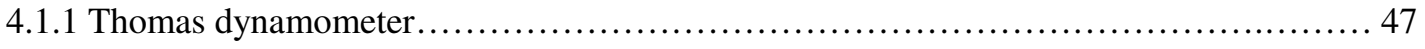

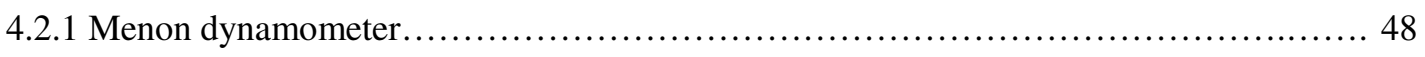

4.3.1 Korean Aerospace institute dynamometer.....................................49

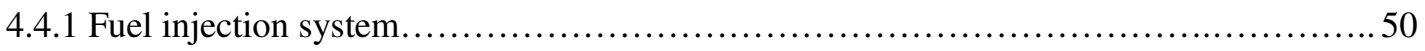

6.2.6.1 Control module of Electronic fuel injection system (EFI) ........................ 62

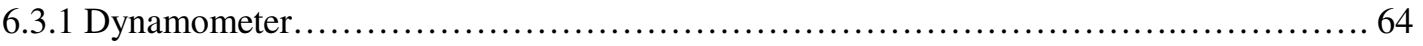

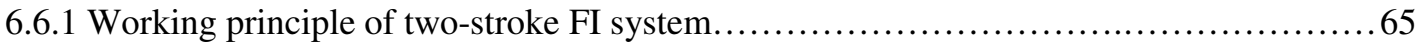

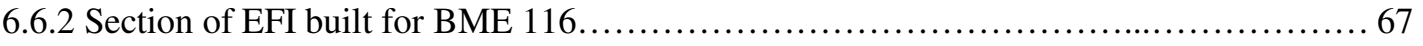

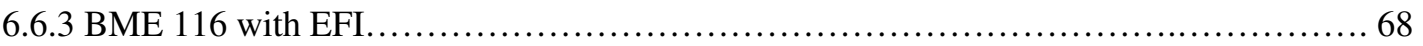

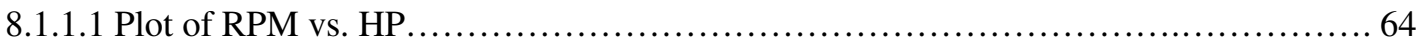

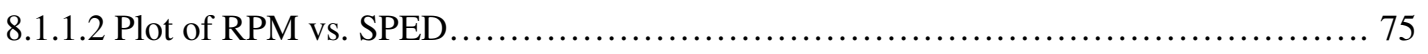

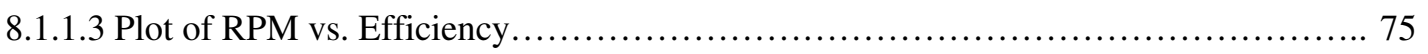




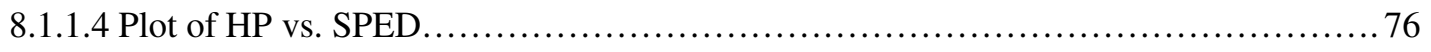

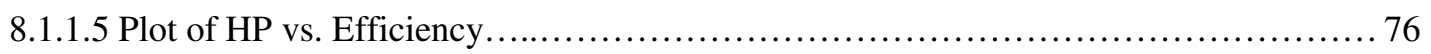

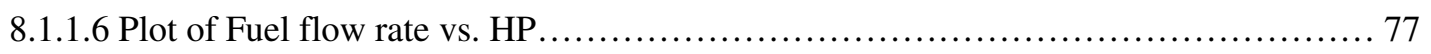

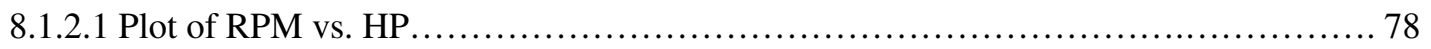

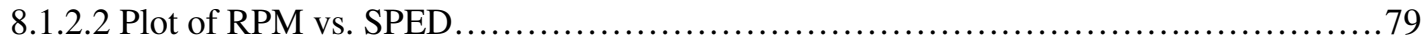

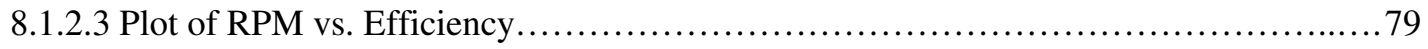

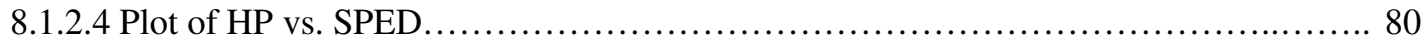

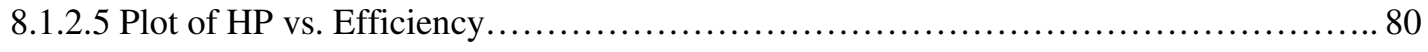

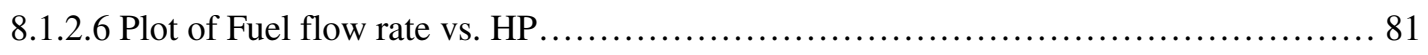

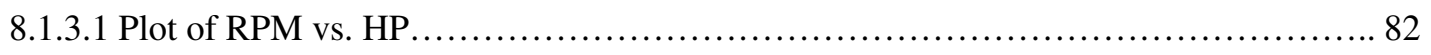

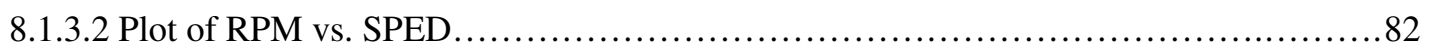

8.1.3.3 Plot of RPM vs. Efficiency.................................................. 83

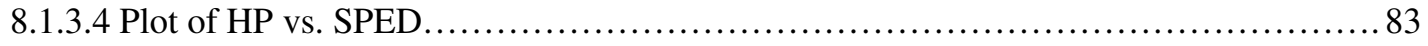

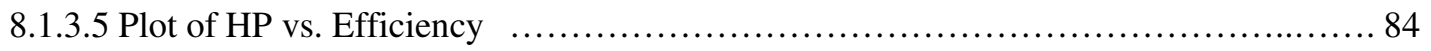

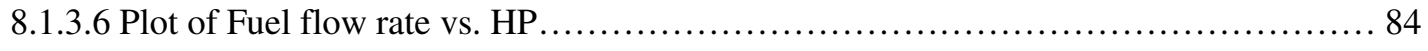

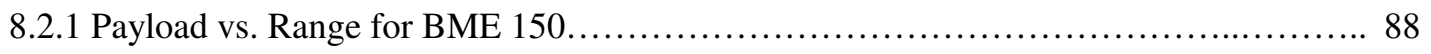

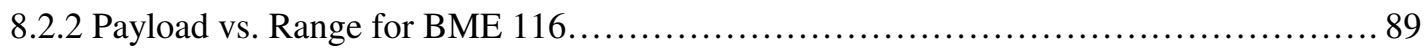

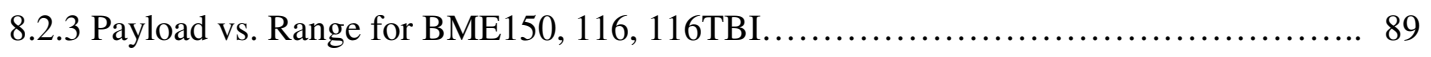

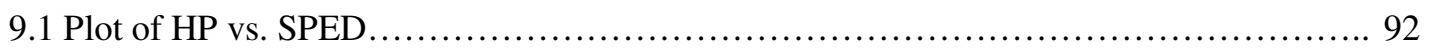

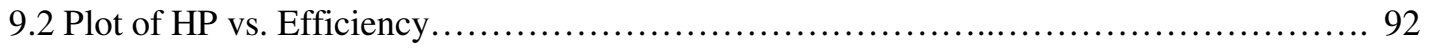

9.3 Plot of Specific fuel consumption vs. Power density .............................. 93

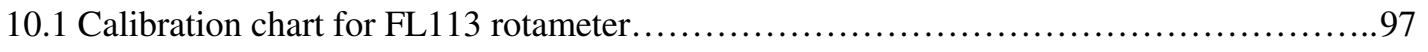

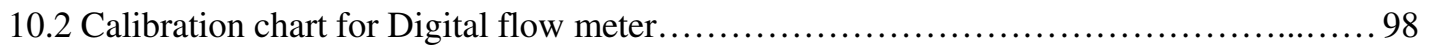

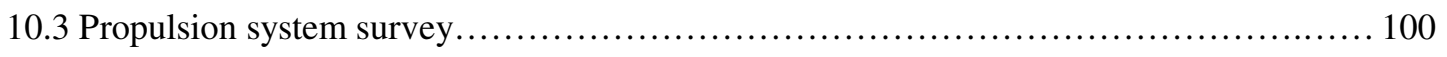




\section{CHAPTER I}

\section{INTRODUCTION}

UAV - uses application and types

An Unmanned Aerial Vehicle (UAV) is remotely piloted or autonomous aircraft that carries sensors and other payloads. UAVs represent a rapidly growing segment of the aerospace industry with huge applications. These vehicles are a significant member of military, civil and commercial aviation due to their applications like high altitude imagery, border patrol, maritime surveillance, law enforcement and media reporting. Major advantages of UAV over manned aircraft are, they are proven to be cost effective and minimize the risk of pilot's life.

Today, UCAV/UAV capabilities can be divided into various categories, in use or under development. They are often classified based on mission requirements. Short range, low altitude, tactical UAVs operate at altitudes up to $10000 \mathrm{ft}$ with a range of about $500 \mathrm{~km}$ (4 hours). A good example is the "Silver Fox", developed for the US Navy by Advanced Ceramics Research Inc. UAVs that operate at altitudes from 25000 to $40000 \mathrm{ft}$ with a range of about 150-1500 km (5-25 hours) are known as medium altitude long endurance UAVs. Example includes the MQ-5B Hunter developed by Northrop 
-Grumman. The ones that operate above $40000 \mathrm{ft}$ with a range more than $2000 \mathrm{~km}(10$ hours and more) are categorized as high altitude long endurance UAVs. A good example is the Global Hawk RQ-4A with a range of more than $20000 \mathrm{~km}$ and a maximum endurance of about 35 hours. Micro-Air vehicles or MAVs are a smaller fleet of UAV that weigh less than $100 \mathrm{~g}$. They are equipped with a variety of sensors and have an endurance of about 30 minutes. They are intended to serve a variety of military and civilian functions ranging from battlefield reconnaissance to environmental monitoring.

Three main important characteristics pertaining to any UAV/aircraft are, range (how far), endurance (how long) and what can it carry (payload). Most UAVs are balanced in these areas, but suffers in all of them when compared to the performance of their larger counterparts. The factors that determine range, endurance and payload are power, weight and efficiency.

The prime focus of this thesis was on identifying and evaluation of state of the art propulsion technologies for Tiger shark-class UAVs in order to identify areas of future improvement in power, weight and efficiency. In order to achieve this, a detailed survey of all the propulsion technologies in the accepted horse power range was conducted. It includes most of the COTS propulsion system used today. The prime focus was on the 20-30 Hp range; although a wide horse power range of 5-100 was considered in order to identify possible trends in Efficiency or Horse Power or Specific Propulsive Energy Density (SPED)

The data for the survey was obtained by contacting the individual manufactures; since their method of evaluation may vary, a means of quantifying them was necessary. That necessitated the construction of dynamometer. The design of the dynamometer 
along with everything that was learnt during its construction and testing is discussed in the later sections.

Finally, a 2-stroke engine was fitted with fuel injection system and its performance was evaluated. A BME 116.3cc 2-stroke 2-cylinder engine was selected for this purpose as it matched our power range. The Fuel injection system was added to it and its performance features before and after were evaluated and compared using the dynamometer. 


\section{CHAPTER II}

\section{PURPOSE}

- Detailed survey of all the propulsion technologies in the 5-100Hp range.

- Construction of a dynamometer to compare and evaluate engine performance.

- Improve power, weight and efficiency in Tiger-Shark class UAV. 


\section{CHAPTER III}

\section{LITERATURE REVIEW}

\subsection{Technology readiness level}

Technology readiness level (TRL) was originally developed by NASA in the 1980s. TRL was developed to assess the maturity of evolving technologies prior to incorporating that technology into a system or subsystem. This reduces the ambiguity and provides a common understanding of technology status, which helps make decisions concerning transition of technology. The various level of TRL is summarized as follows:

TRL1 Basic principles observed and reported

TRL2 Technology concept and/or application formulated

TRL3 Analytical and experimental critical function and/or characteristic proof of concept TRL4 Component and/or breadboard validation in laboratory environment

TRL5 Component and/or breadboard validation in relevant environment

TRL6 System/subsystem model or prototype demonstration in a relevant environment (ground/space)

TRL7 System prototype demonstration in a space environment

TRL8 Actual system completed and "Flight qualified" through test and demonstration TRL9 Actual system "Flight proven” through successful mission operations 


\subsection{Evaluation of current propulsion technologies}

\subsubsection{Two-stroke engines (TRL9)}

A 2-stroke engine is the type of internal combustion engine that completes a power cycle once every revolution. This large power boost gives the 2-stroke quite an advantage compared to other engines. Since these engines are generally lightweight, they have a high power to weight ration making them attractive for many applications. Machines such as chainsaws, lawnmowers, motocross bikes, ultra lights commonly use 2stroke engines for their small size and large power output.

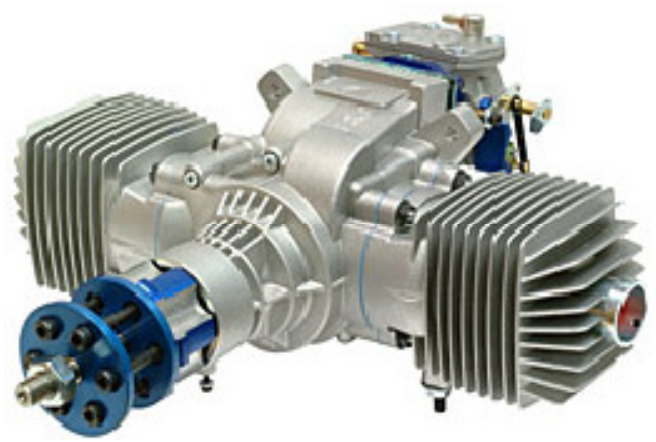

Figure 3.2.1.1 two-stroke engine

In a two stroke engine, the beginning of the compression stroke and the end of the combustion stroke is utilized to perform simultaneously the intake and exhaust functions. This provides strikingly high specific power. Although, the principle of a 2 -stroke engine is simple, it can be implemented in more than one way, depending upon the method of introducing the charge to the cylinder, the method of scavenging the cylinder and the method of exhausting the cylinder.

The working principle is pretty simple in a two stroke engine. Fuel and air in the cylinder are compressed and when the spark plugs fires the mixture ignites. The resulting 
expansion due to the combustion drives the piston downwards. As it moves down, it is compressing the air/fuel mixture in the crankcase. As the piston approaches the bottom of its movement, the exhaust out is known as scavenging. As it moves further down, the intake port is opened, and fuel and air mixture fills the cylinder, displacing the exhaust out. The interesting part of the 2-stroke engine is that, the piston is shaped in such a fashion that the incoming fuel mixture doesn't simply flow right over the top of the piston and out the exhaust port.

Intake, compression, combustion, and exhaust occur in the same chamber in a 2stroke engine making valves, connecting rods, rocker arms, and a camshaft are unnecessary. This simplifies construction and gives these engines the low weight that makes them so attractive. This is not the only factor contributing to their low weight however. In general, 2-stroke engines are air-cooled and have no need for cooling system. Subsequently, there is no need for a separate lubrication system since oil is premixed into the fuel. Consequently, these engines run rather hot resulting in a shortened lifespan and some of the oil is burned off in the process. This makes 2-strokes a higher pollutant engine compared to other internal combustion engines.

Most 2-strokes run on a carbureted system. In a carbureted engine, the amount of fuel released is dependent on the amount of air vacuumed into the cylinder. This is a problem for UAVs required operating in higher altitude settings. Since there is less oxygen per unit of air at higher elevation, the air vacuumed into the carburetor contains a lower amount of oxygen and causes incomplete combustion. With not enough oxygen present to completely combust all the fuel, the resulting effect is lower fuel efficiency. A solution is to this problem is to use a fuel injection system as opposed to the carbureted 
method. With fuel injection, a sensor measures the amount of oxygen in the intake air and releases fuel according to the stochiometric ratio to obtain complete combustion.

Today, several UAVs in operation run on carbureted 2-stroke engines. A few examples are the Marine Corps' Pioneer, the Navy's Neptune UAV, and the XPV-1-tern used by the United States Special Operations Command (SOCOM). While these engines suffice for current operations, a few areas could use some improvement. Since stealth is a crucial requirement for UAVs, reducing the produced noise is a must. Increasing the engine's fuel efficiency is also a high priority since the fuel weight is the bulk of the total aircraft's mass.

Plots comparing Hp vs. weight, Efficiency (\%ๆ), P/W ratio and SPED are made. They are prepared from the data obtained through the survey.

- It can be seen that most part of the HP vs. Weight plot is linear, the weight increases as the output HP increases

- The efficiency is scattered around $10-20 \%$ for most engines

- There is not much of a trend in the HP vs. P/W ratio

- SPED, which gives more idea about the fuel economy per amount of power produced, doesn't follow a trend. It's just scattered from 1-2. A high SPED is optimum 


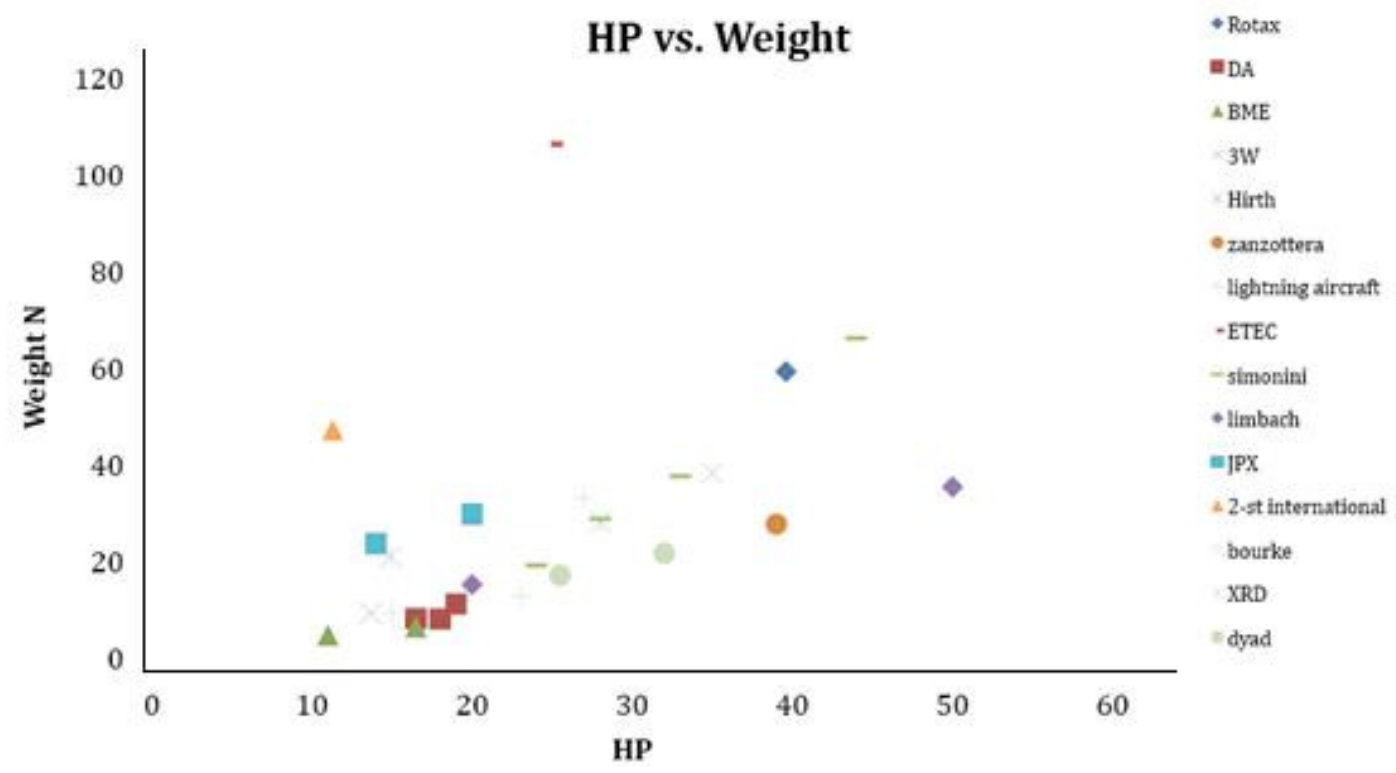

Figure 3.2.1.2 Plot of HP vs. Weight

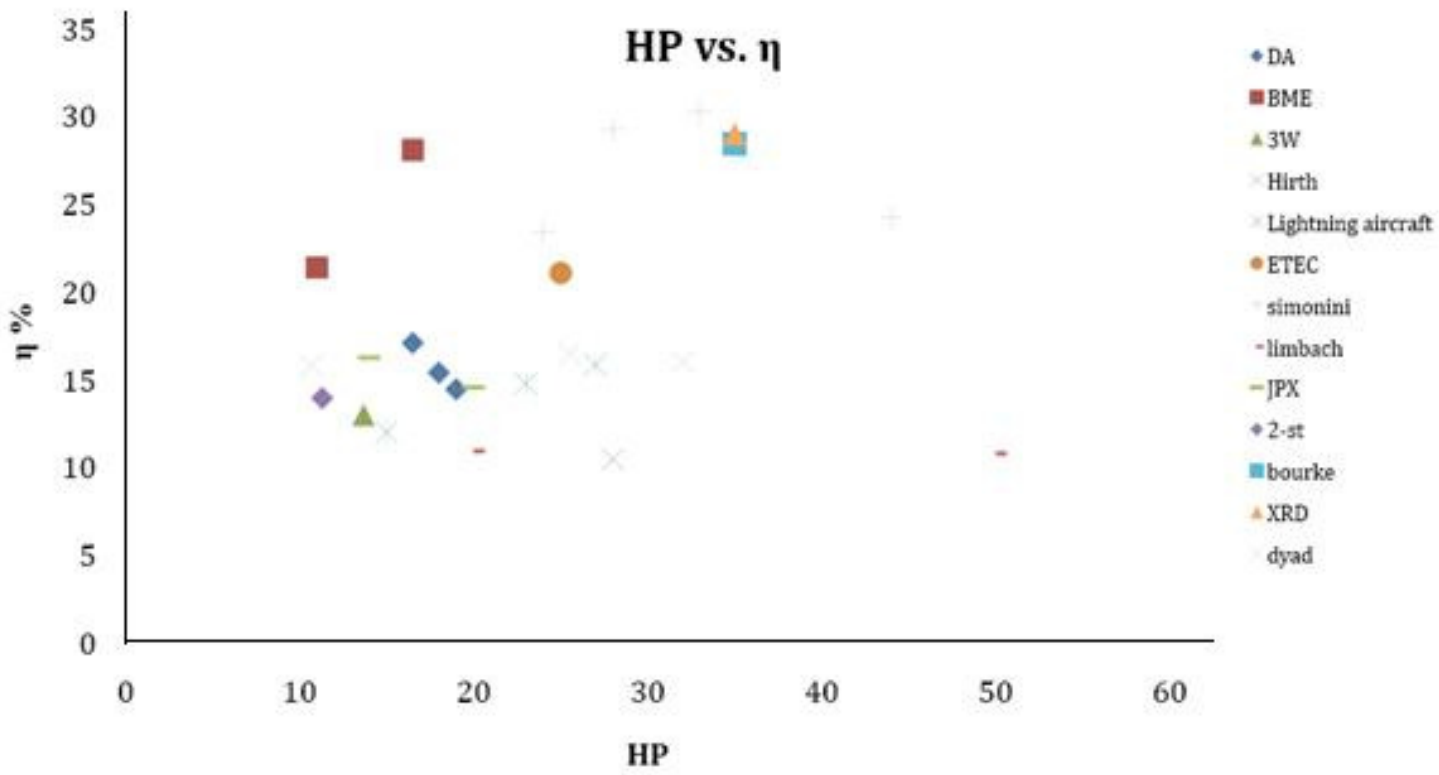

Figure 3.2.1.3 Plot of HP vs. Efficiency 


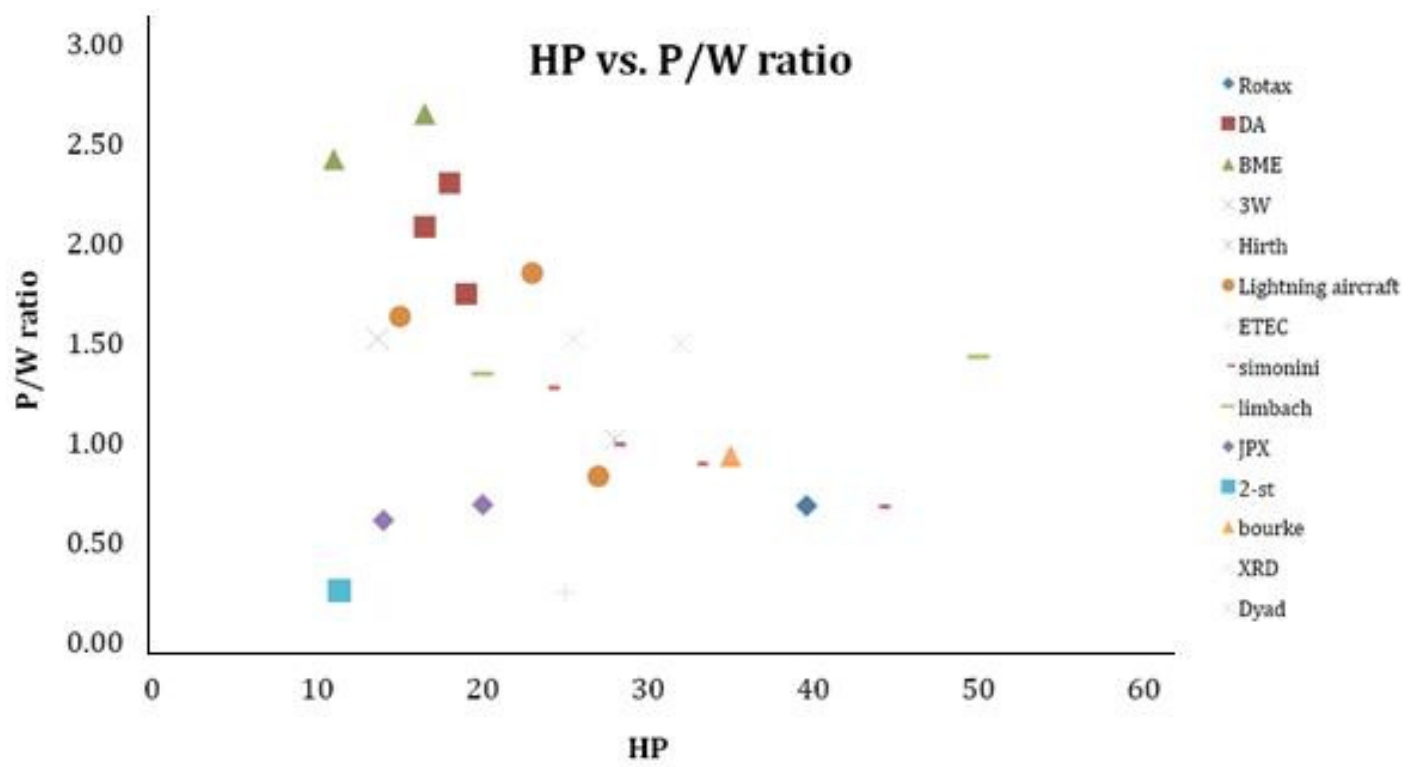

Figure 3.2.1.4 Plot of HP vs. P/W ratio

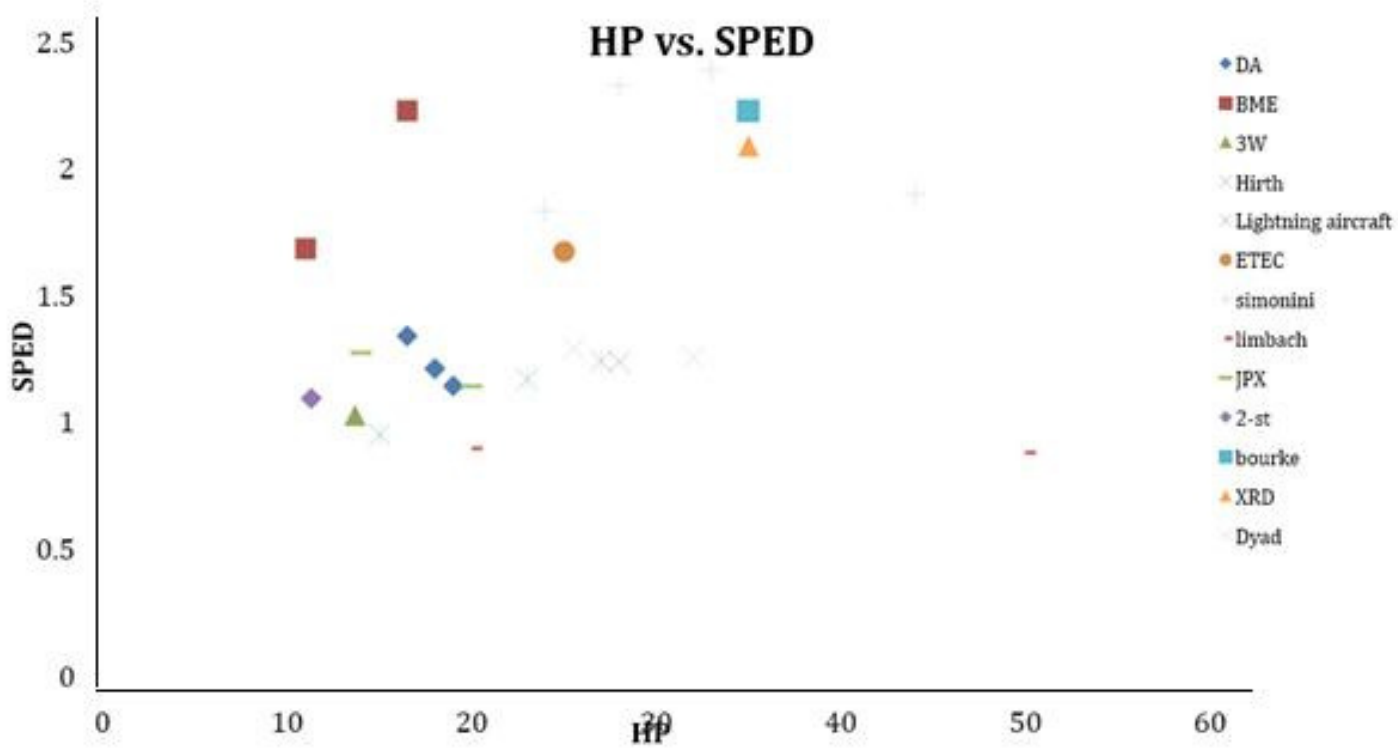

Figure 3.2.1.5 Plot of HP vs. SPED 


\subsubsection{Four stroke engine (TRL9)}

Today, IC engines in cars, trucks, aircraft, construction machinery and many others, most commonly use a four stroke cycle. The four strokes refer to intake, compression, and combustion/power and exhaust strokes that occur during two crankshaft rotations per working cycle of the gasoline engine and diesel engine. Unlike 2strokes, 4-stroke engines fire once every other revolution. They also make use of a valve system that allows the intake and exhaust processes to be timed correctly with the compression and combustion cycles.

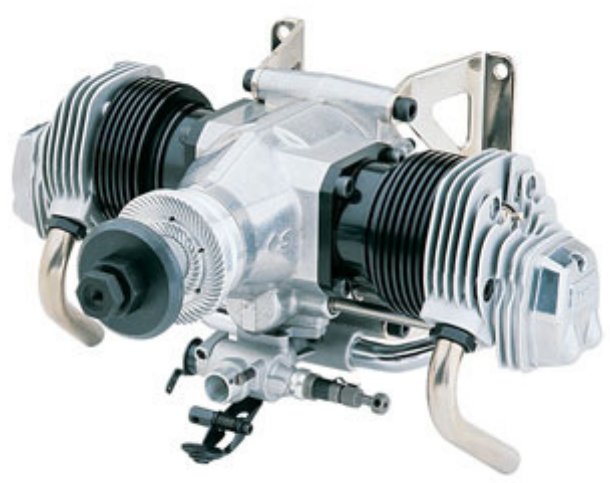

Figure 3.2.2.1 Four stroke engine

This operation requires the use of a camshaft to lift the valves up and down at the appropriate times. Four-stroke engines are more efficient than 2-strokes and last quite a bit longer since they have an efficient cooling system. These engines have a separate lubrication system that does not involve combusting a fuel/oil mixture. Because of this fact, they are less pollutant than 2-strokes as well. However, 4-strokes contain many more moving parts than 2- strokes are consequently quite a bit heavier. There are quite a few 
issues the four stroke engines. They weigh more than two stroke engines and produce less power. They are noisy and not as fuel efficient as other engines like hybrid engines for instance. Four-strokes are currently used by the Air Force in the infamous Predator, by the Army in the I-Gnat-ER, and by DARPA in their A-160.

Plots of HP vs. Weight, Efficiency, P/W ratio and SPED are made. They are prepared from the data obtained through the survey.

- There is not much of a trend for HP vs. Weight plot. This lack of consistency is directly related to insufficient data on UAVs that has 4-stroke engines

- The efficiency is scattered around $10-40 \%$ for most engines

- Power to weight ratio is less compared to 2-stroke engines. The distribution is pretty horizontal around the horse power range

- SPED of 4-stroke engines aren't much higher compared to 2-stroke engines. Its scattered around 1-2

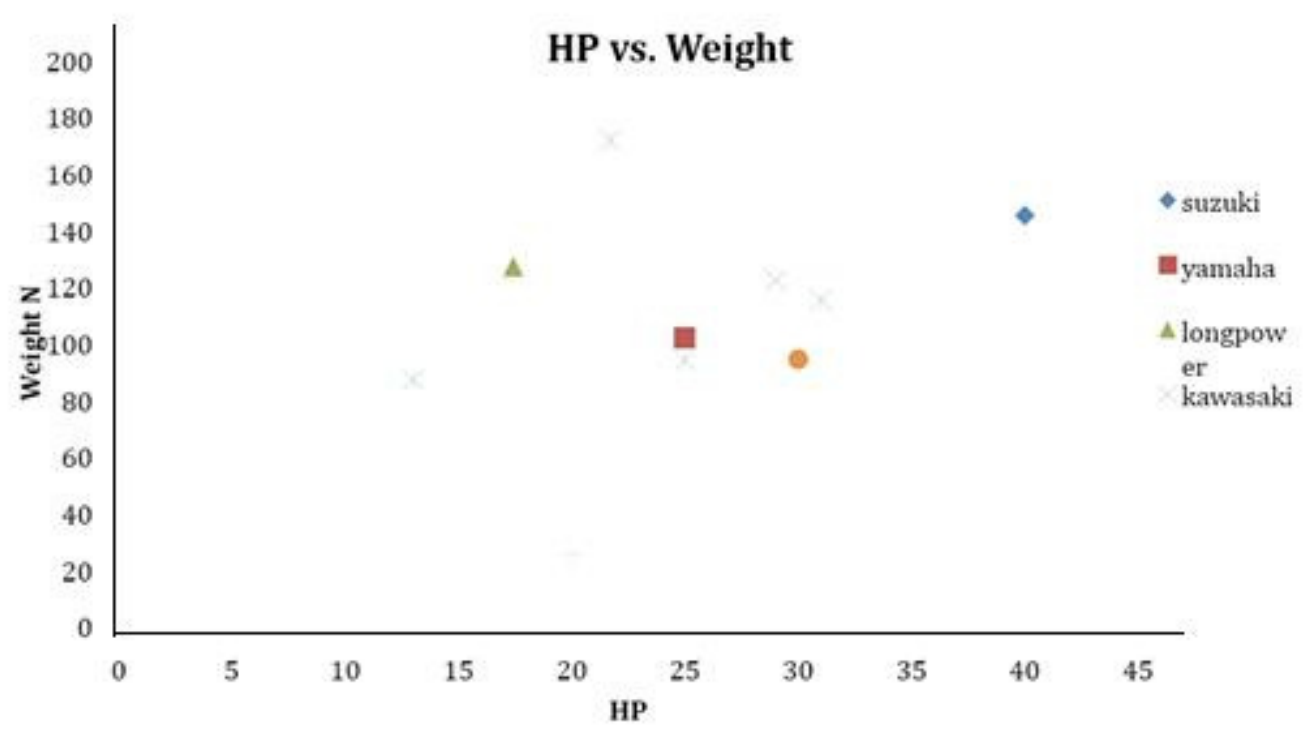

Figure 3.2.2.2 Plot of HP vs. Weight 


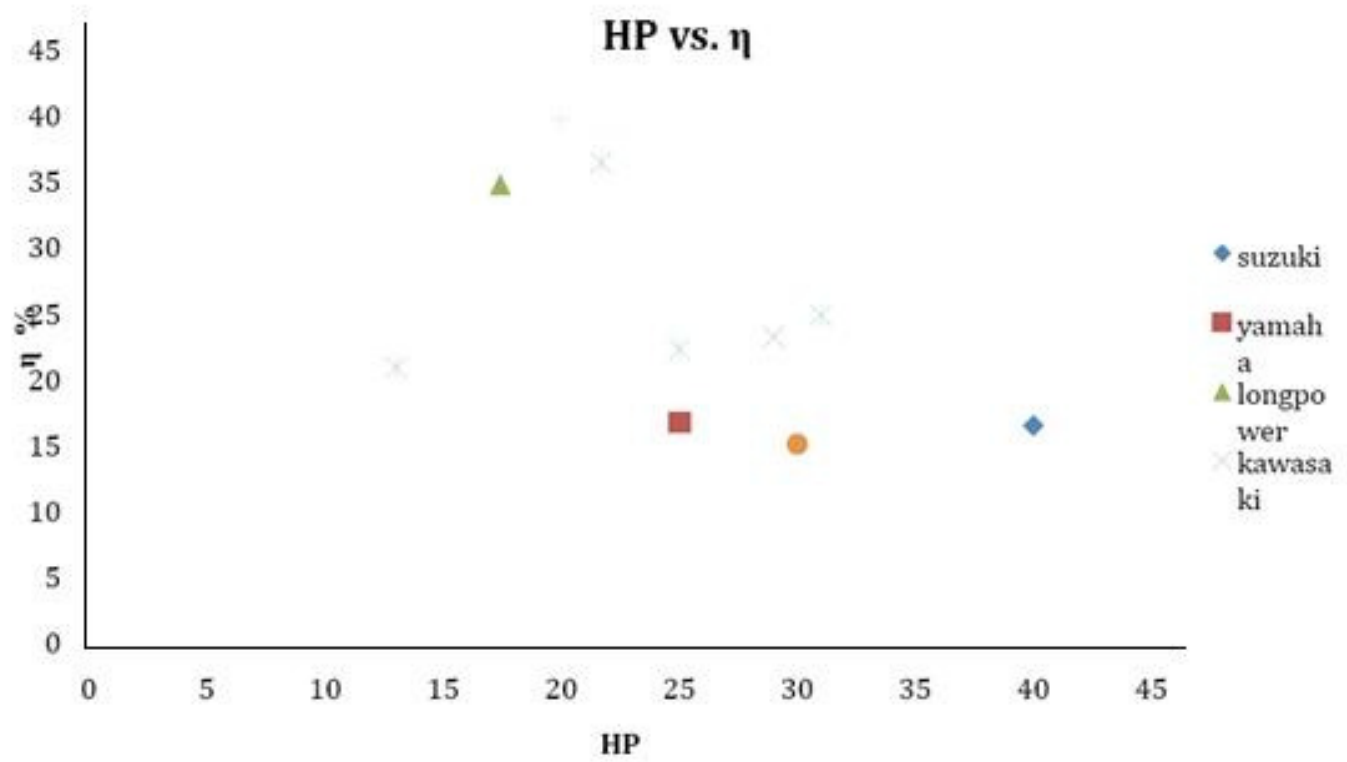

Figure 3.2.2.3 Plot of HP vs. Efficiency

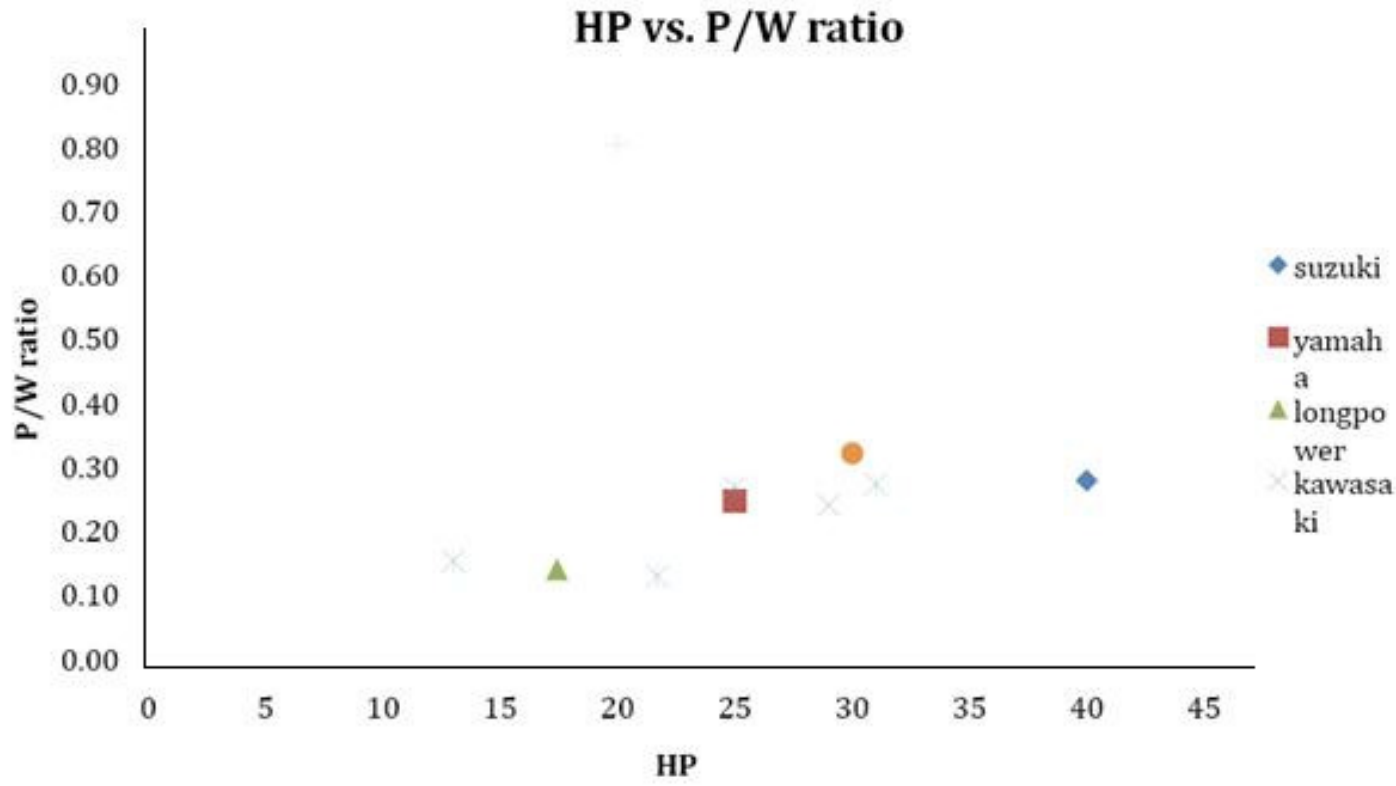

Figure 3.2.2.4 Plot of HP vs. P/W ratio 


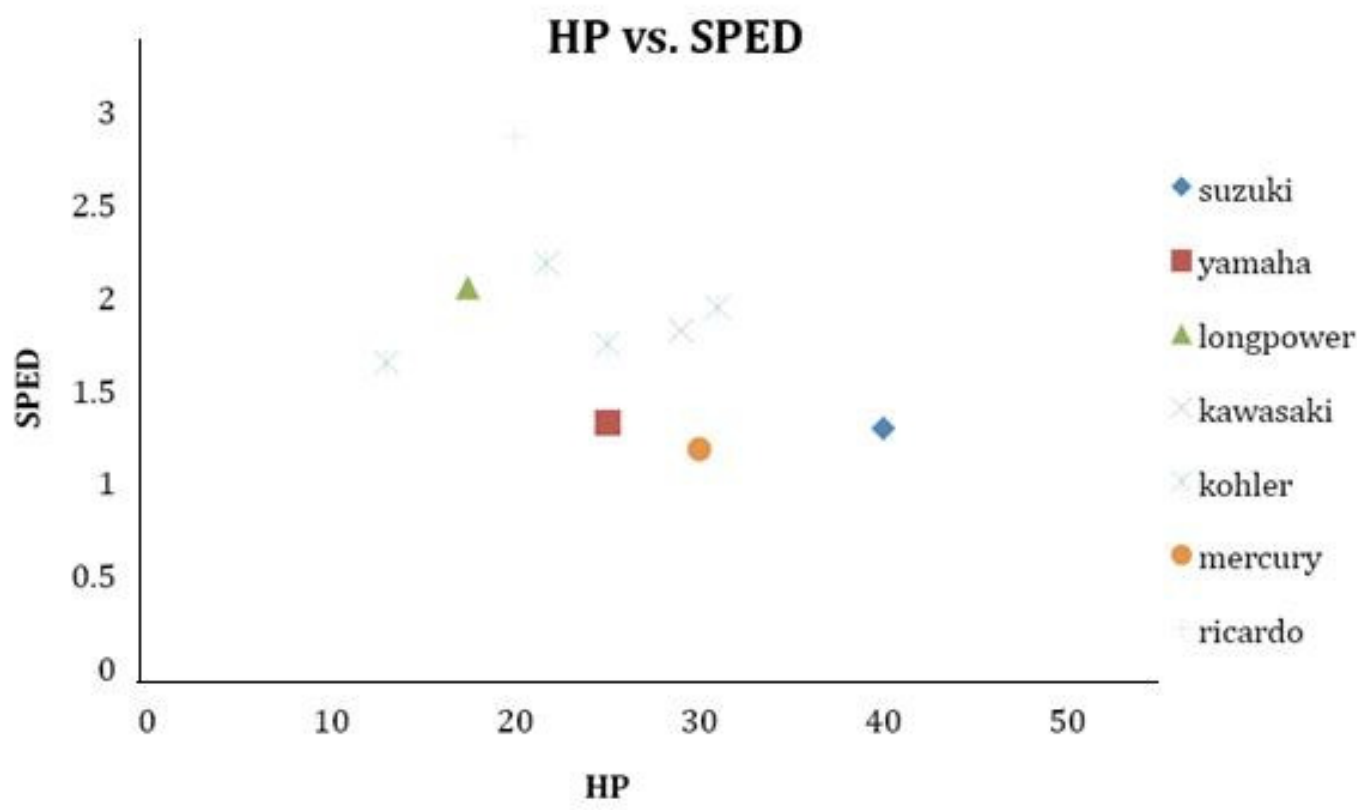

Figure 3.2.2.5 Plot of HP vs. SPED

\subsubsection{Wankel engines (TRL9)}

The Wankel engine is another type of IC engine which uses a rotary design to do work in a rotary fashion instead of reciprocating motion. It has four strokes which takes place inside the oval shaped housing. Instead of a piston, the Wankel engine uses a rotor to complete the four cycles. The rotor is very similar to the reuleaux triangle in shape. With its three peaks in contact with the housing at all times, the rotor creates 3 separate air pockets that go through intake, compression, combustion, exhaust stages in that same chamber as the rotor rotates. 


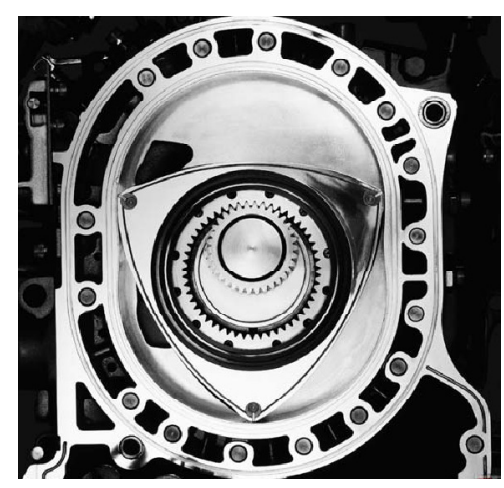

Figure 3.2.3.1 Wankel engine

The three-edged rotor inside is turning thereby around the eccentric cam with ball or roller-bearings, cogwheel-transmission. In the form of the external housing the rotor describes now the typical course. Consider: While the runner makes one revolution, the eccentric cam turns three times. The rotor and the housing form three spaces, whose volume changes periodically. The engine shown beside is designed as a four-stroke engine: Through the right opening the air/fuel mixture is sucked in by the rotor. Then the mixture is compressed and ignited when it reaches maximum compression by the spark plug.

This developed pressure pushes the rotor now. When the eccentric cam is on the right, the mixture has expanded on the left maximally and in the following clock the exhaust is ejected through the left ejection pipe. This mode of operation has many advantages: The piston does not swing, additionally no valves are needed. Typically, it is more difficult to make a rotary engine that meets the emission standards. The manufacturing costs are higher, due to the fact that the number of engines produced is less as compared to the piston engines. They typically consume more fuel than a piston engine because the thermodynamic efficiency of the engine is reduced by the long combustion-chamber shape and low compression ratio. 
One major advantage is the elimination of parts like piston, valves, connecting rod, camshafts with the usage of a rotor. Rotaries have high horsepower per displacement compared to other internal combustion engines. Because of the design, rotaries have a low risk of seizing and therefore normally run in the high rpm range. If a rotary does seize, it does not produce quite the disastrous outcome like in piston engines. The lubrication system is similar to that of the 2- stroke engine, and thus it does not need a separate system like the 4 -stroke engine.

Because rotary engines have to be manufactured with such precision to ensure good seals, they are expensive and difficult to maintain as the housing is wore down by the rotor. Since oil is mixed with fuel, part of it is burned resulting in high pollution. Unfortunately, the rotary engine does not produce a lot of torque. Yet, Wankel engines are simpler, lighter and contain less number of moving parts than other IC engines of equivalent power output. This gives Wankel a higher reliability, a smooth flow of power, and a high power to weight ratio. They are very quick in response to the throttle movement. The main advantage of using a Wankel engine in an aircraft is that they have a small frontal area than a piston engine of equivalent power, making the design of nose easy.

Due to a longer (almost 50\%) stroke duration than the four cycle engine, there is more time for a complete combustion of the mixture. This makes them more apt for direct injection. Wankel and rotary engines have been widely used in aircrafts for a long time, their usages in UAVs are increasing nowadays, and US Army uses the Wankel engine in Shadow 200. 
Plots of HP vs. Weight, Efficiency, P/W ration and SPED are made. They are prepared from the data obtained through the survey.

- Very few Wankel engines are used in UAVs or small aircraft, with very less information to comment on

- The weight of Wankel engines are very low compared to a 4-stroke engine of the same power

- In terms of efficiency, they are in the same range as 2-strokes

- Power to weight ratio is less compared to 2-stroke engines. The distribution is pretty horizontal around the horse power range

- SPED of Wankel engines aren't much higher compared to 2-stroke or 4-stroke engines. It's scattered around $0.5-1$

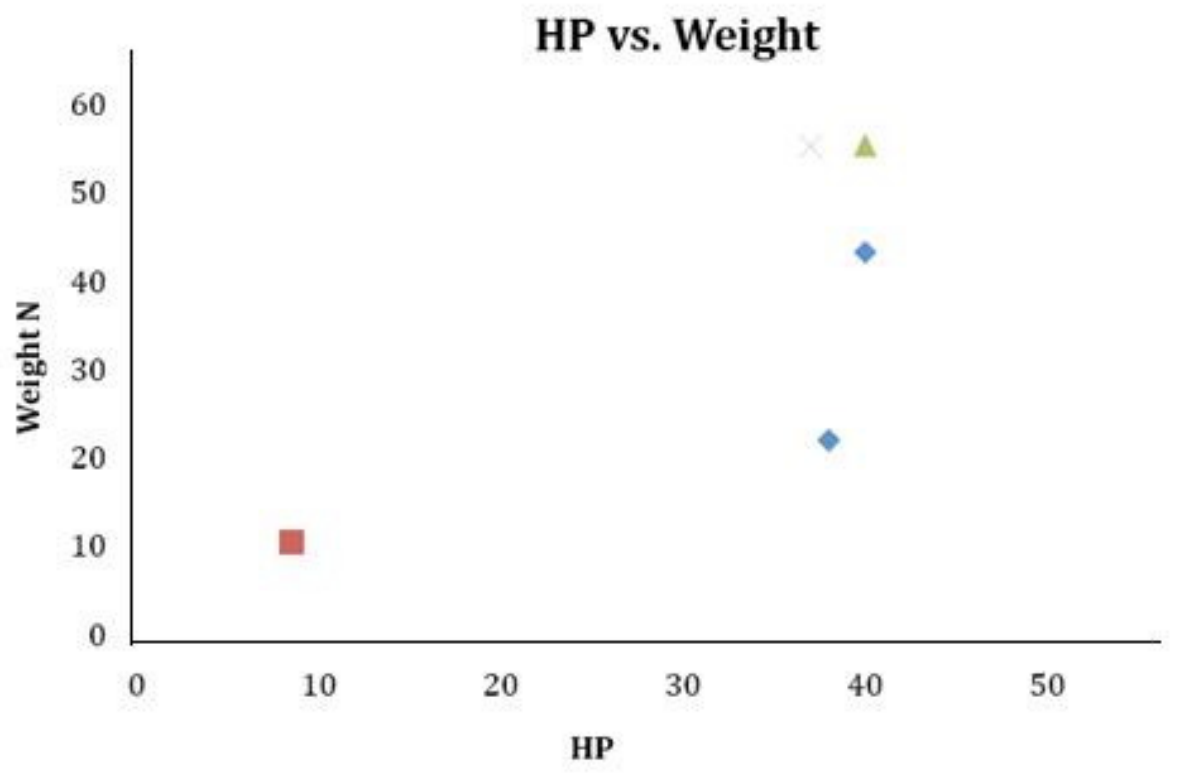

UAV Engines

cubewano

A global

wankel

Figure 3.2.3.2 Plot of HP vs. Weight 


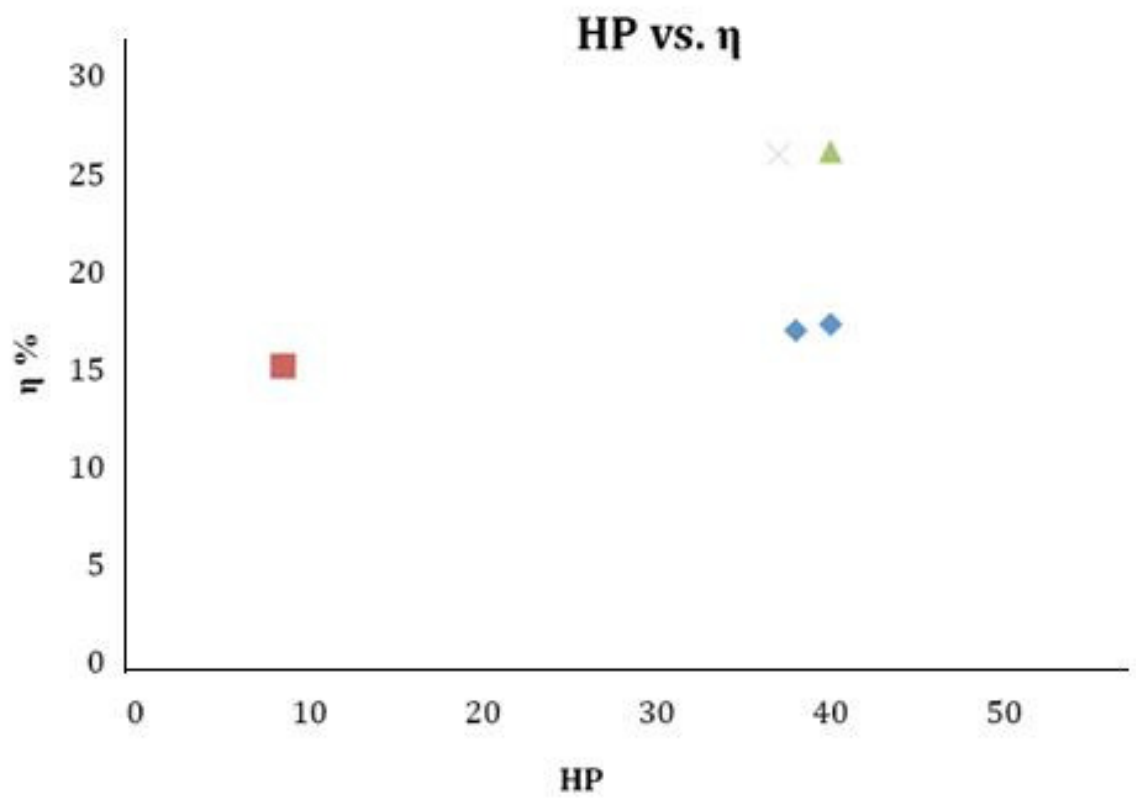

- UAV Engines

Ecubewano

$\triangle$ global

wankel

Figure 3.2.3.3 Plot of HP vs. Efficiency

\section{HP vs. $\mathrm{P} / \mathrm{W}$ ratio}

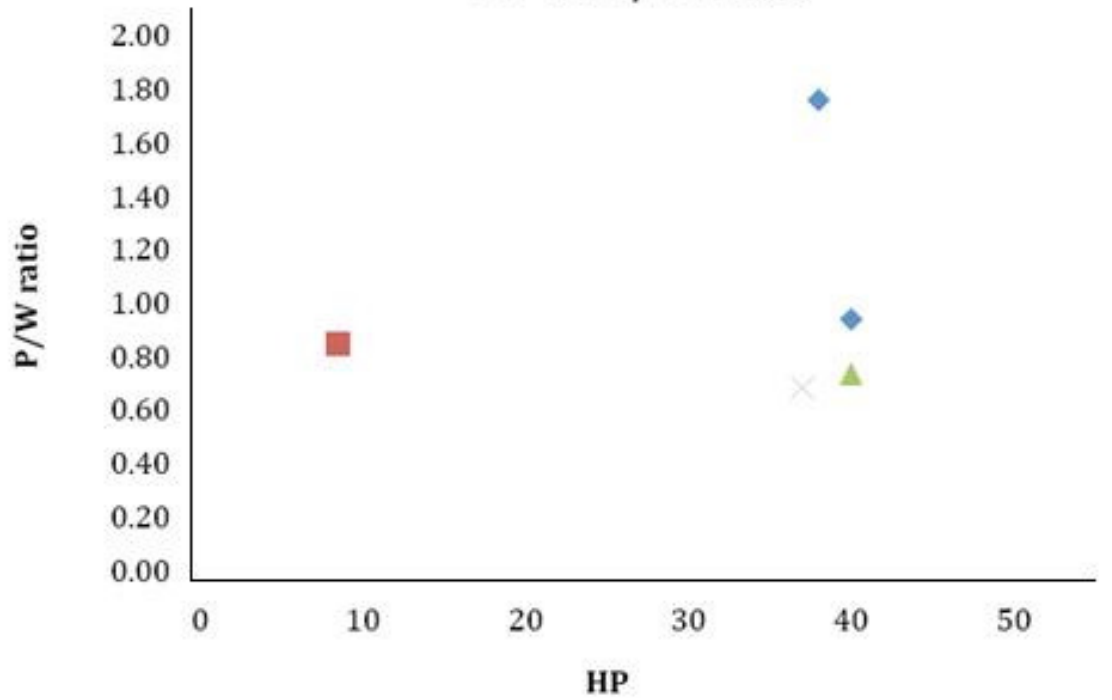

- UAV Engines

cubewano

$\triangle$ global

wankel

Figure 3.2.3.4 Plot of HP vs. P/W ratio 


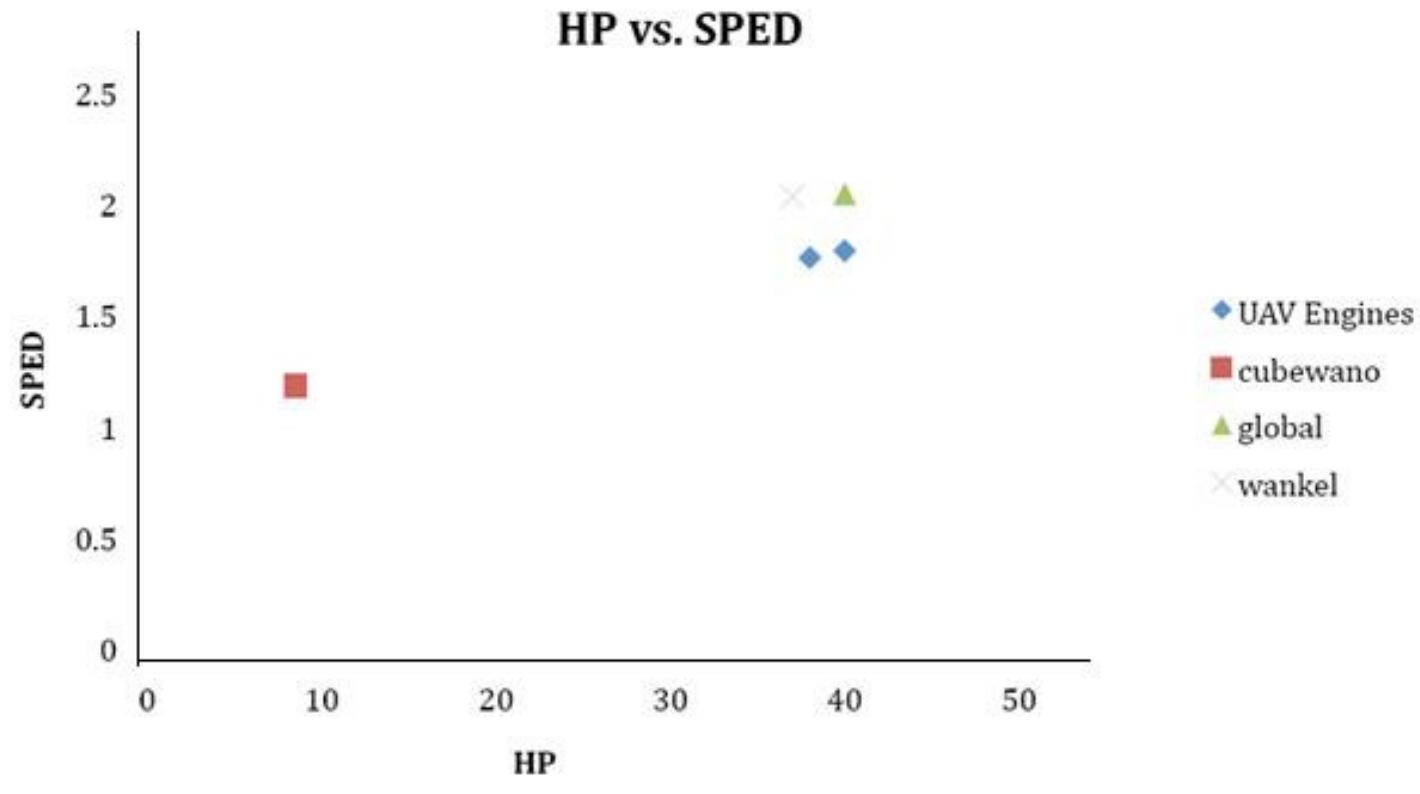

Figure 3.2.3.5 Plot of HP vs. SPED

\subsubsection{Turbines (TRL9)}

A Turbo shaft engine is a form of gas turbine which is optimized to produce shaft power, rather than jet thrust. In principle, a turbo shaft engine is similar to a turbojet, except the former features additional turbine expansion to extract heat energy from the exhaust and convert it into output shaft power. Ideally, there should be little residual thrust energy in the exhaust and the power turbine should be free to run at whatever speed the load demands. The general layout of a turbo shaft is similar to that of a turboprop, the main difference being the latter produces some residual propulsion thrust to supplement that produced by the shaft driven propeller. 


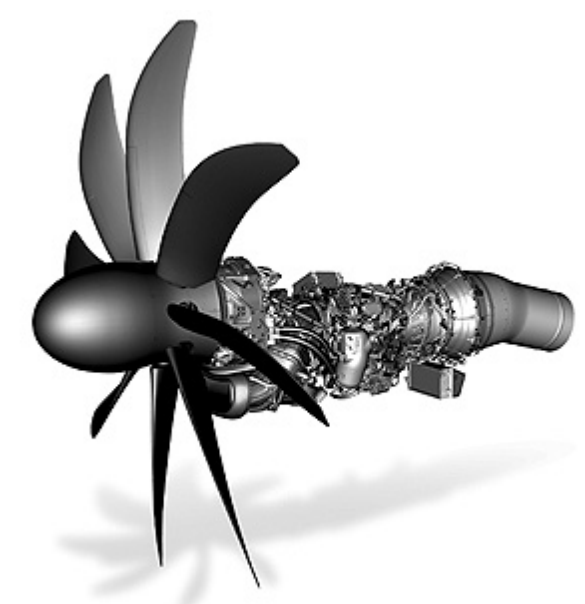

Figure 3.2.4.1 Turbine

Another difference is that with a turbo shaft the main gearbox is part of the vehicle (e.g. helicopter rotor reduction gearbox), not the engine.

Virtually all turbo shafts have a "free" power turbine, although this is also generally true for modern turboprop engines. The name turbo shaft is most commonly applied to engines driving ships, helicopters, tanks, locomotives and hovercraft or those used as stationary power sources. The first true turbo shaft engine was built by the French engine firm Turbomeca, led by the founder, Joseph Szydlowski. In 1948 they built the first French-designed turbine engine, the 100shp 782. In 1950 this work was used to develop the larger 280shp Artouste, which was widely used on the Aérospatiale Alouette II and other helicopters.

Today almost all engines are built so that power-take-off is independent of engine speed, using the free turbine stage. This has two advantages: It allows a helicopter rotor or propeller to spin at any speed instead of being geared directly to the turbine. It allows the engine to be split into two sections, the "hot section" containing the majority of the 
engine, and the separate power-take-off, allowing the hot-section to be removed for easier maintenance.

The engine is separated into two sections. The front has the intake, compressor and combustion chamber sections as well as a small turbine. This turbine drives the compressor. The hot gases then enter a separate section where a turbine powers the propeller. Nowadays turboprop engines are most commonly used on small commuter aircraft. They do not have speed necessary for most modern large capacity or high performance aero planes but are reliable and have the efficiency required for these shorter flights.

UAS Usage - Predator B-Air Force, JUCAS-Air Force \& Navy, Eagle Eye Coast Guard

Plots of HP vs. Weight, Efficiency, P/W ratio and SPED are made. They are prepared from the data obtained through the survey.

- Very few turboprop/turbo-shaft engines are made in such small scales

- The weight of turboprop engines is very low compared to a 4-stroke or Wankel engine of the same power

- In terms of efficiency, they are very low. It's scattered around 5-8\%

- Power to weight ratio is very high. This is due to the fact that they are made super light

- SPED is very low, around0.2-0.6. It shows that the real efficiency of the engine and allows making a proper comparison against other engine technologies 


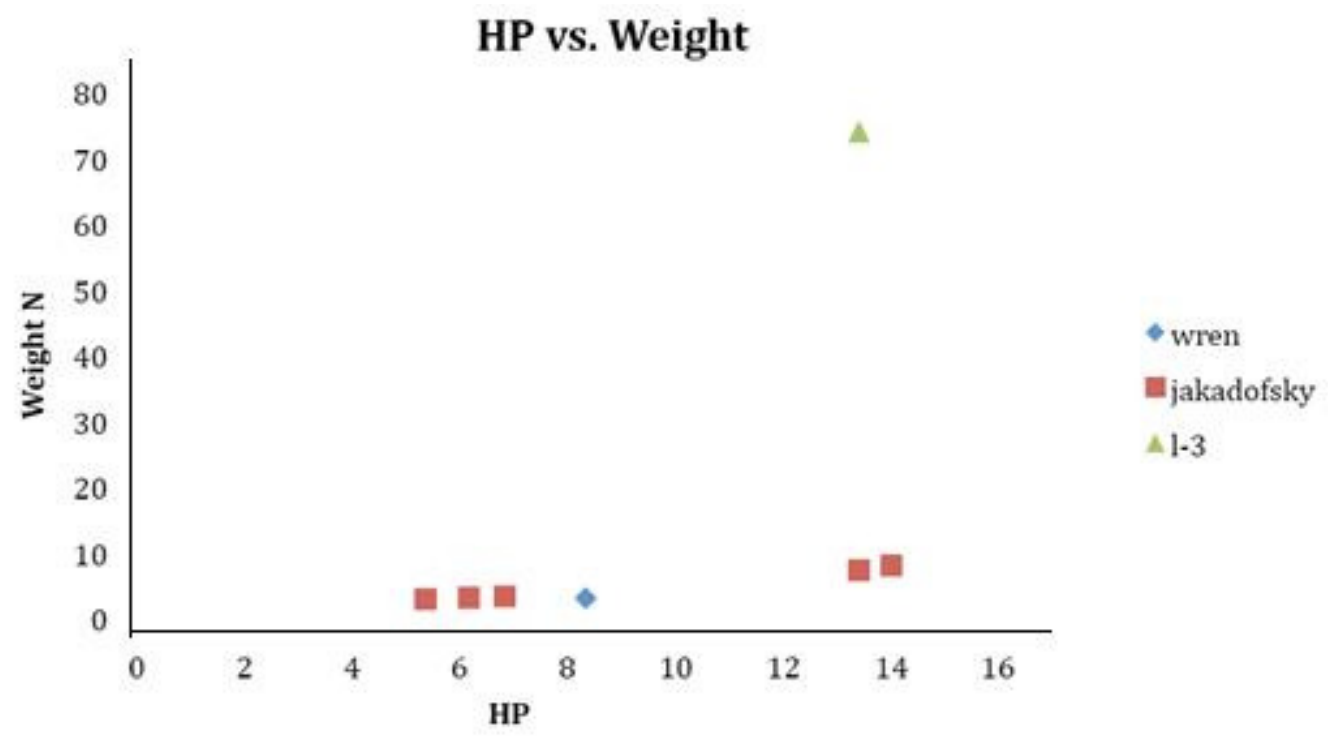

Figure 3.2.4.2 Plot of HP vs. Weight

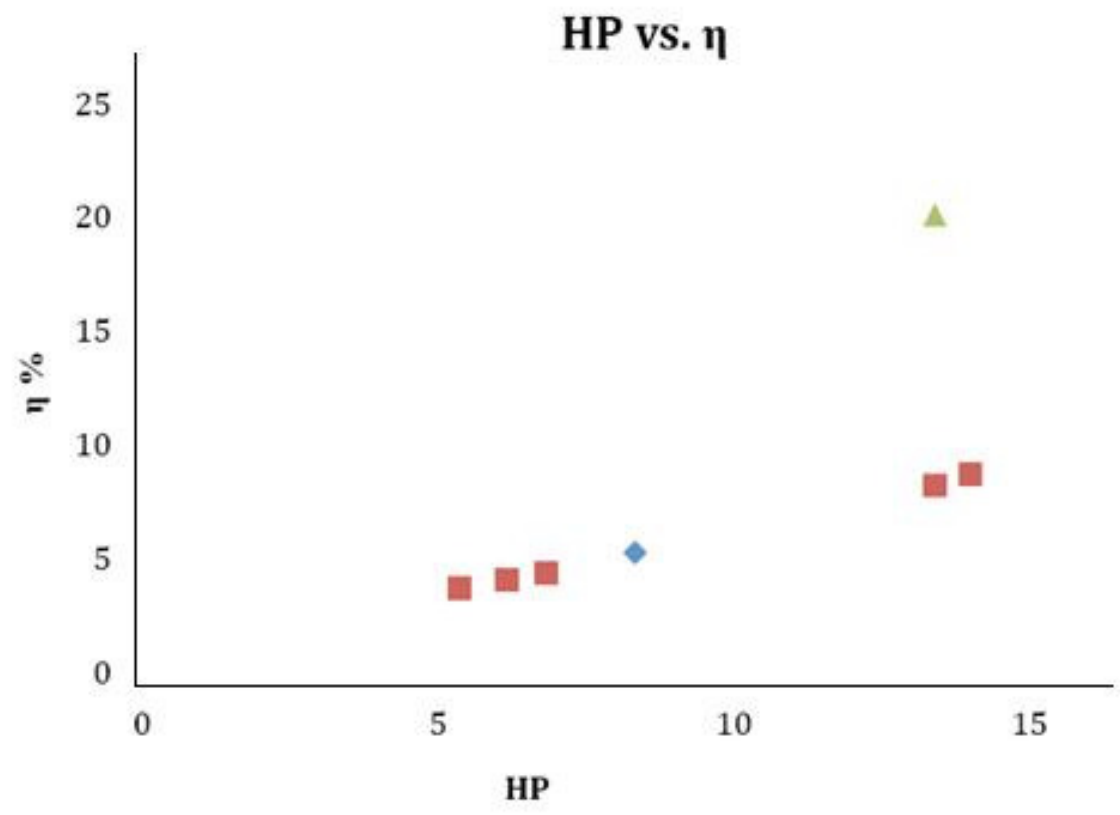

* wren

- jakadofsky A 1-3

Figure 3.2.4.3 Plot of HP vs. Efficiency 


\section{HP vs. $\mathrm{P} / \mathrm{W}$ ratio}

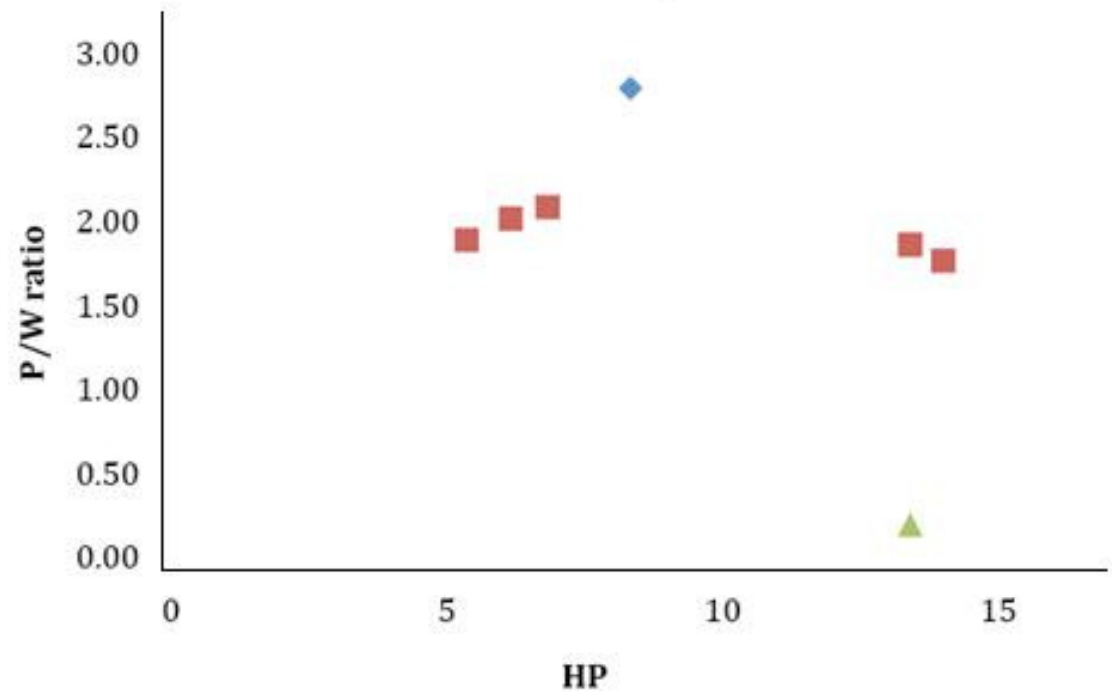

wren

injakadofsky

A $1-3$

Figure 3.2.4.4 Plot of HP vs. P/W ratio

HP vs. SPED

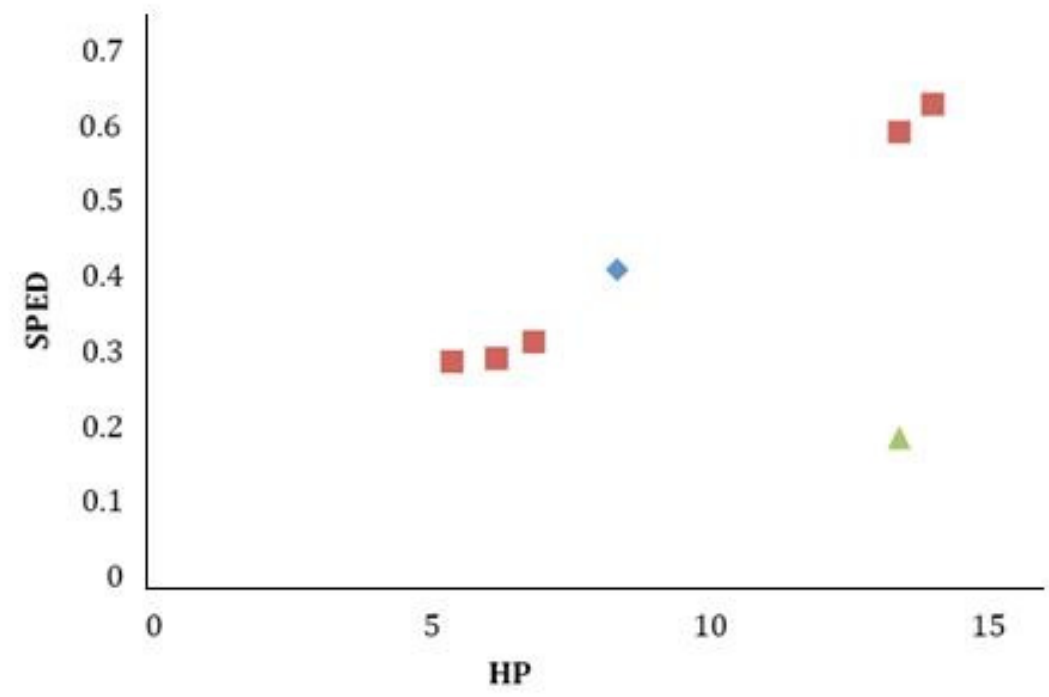

wren

피akadofsky

A $1-3$

Figure 3.2.4.5 Plot of HP vs. SPED 


\subsubsection{Electric motors (TRL9)}

These engines are light weight and are able to produce torque proportional to the power supplied. They contain few to almost no moving parts, which enable them to run at higher rpm. This makes electric motors more efficient and less pollutant than your average initial combustion engines. However, they need a constant power supply to operate and there is always the possibility of power disruption. This makes electric motors somewhat unreliable and potentially heavy depending on how much power must be carried. UAV usage - Dragon eye-marine corps, pointer-SOCOM/AF, RavenARMY/SOCOM/AF

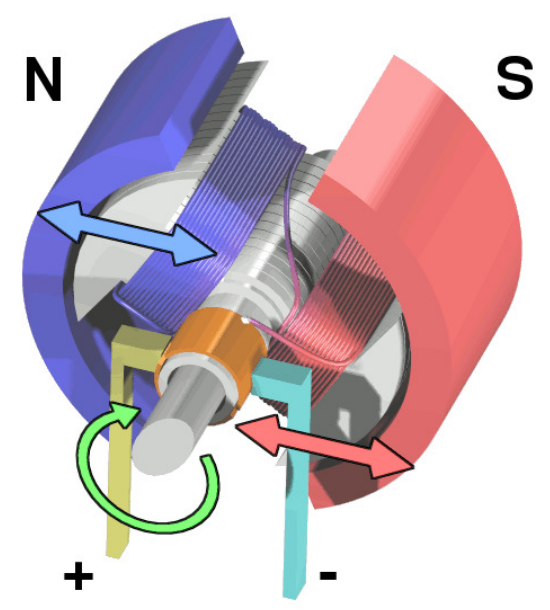

Figure 3.2.5.1 Electric motor

The following are generalized performance plots for an electric motor. They give an idea about the variation of Weight, Efficiency, Power/Weight ratio and SPED of several electric motors of varying horse power. 


\section{HP vs. Weight}

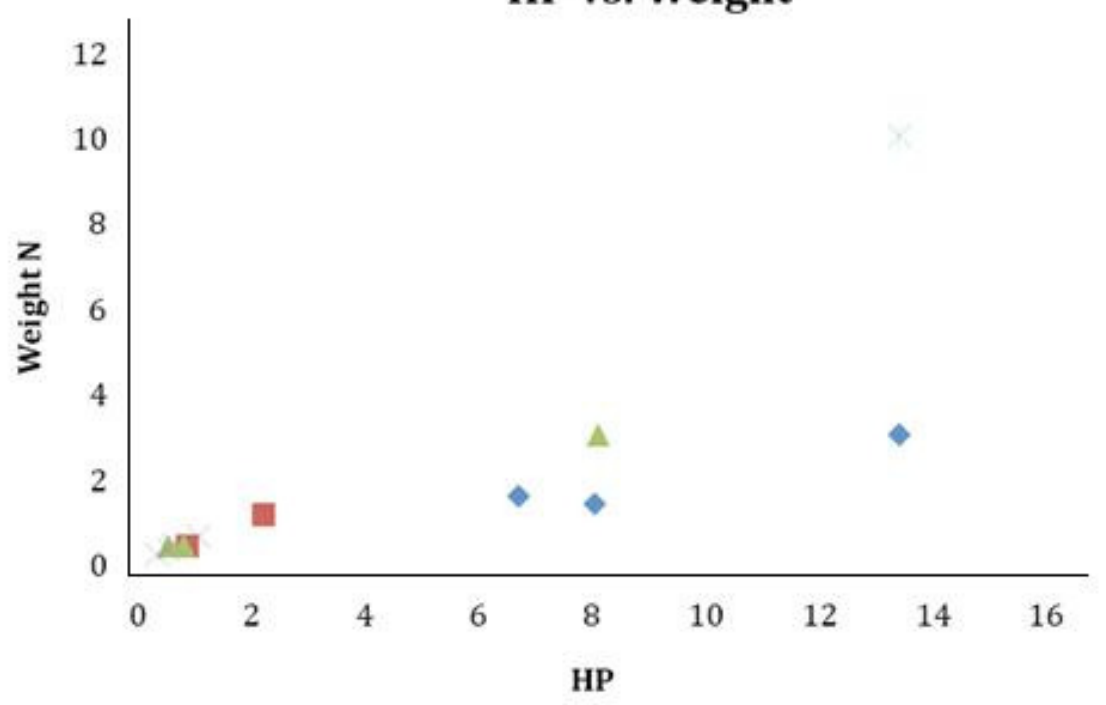

- neumotor

믈 hacker

$\Delta$ astro

himax

yuneec

Figure 3.2.5.2 Plot of HP vs. Weight

HP vs. $\eta$

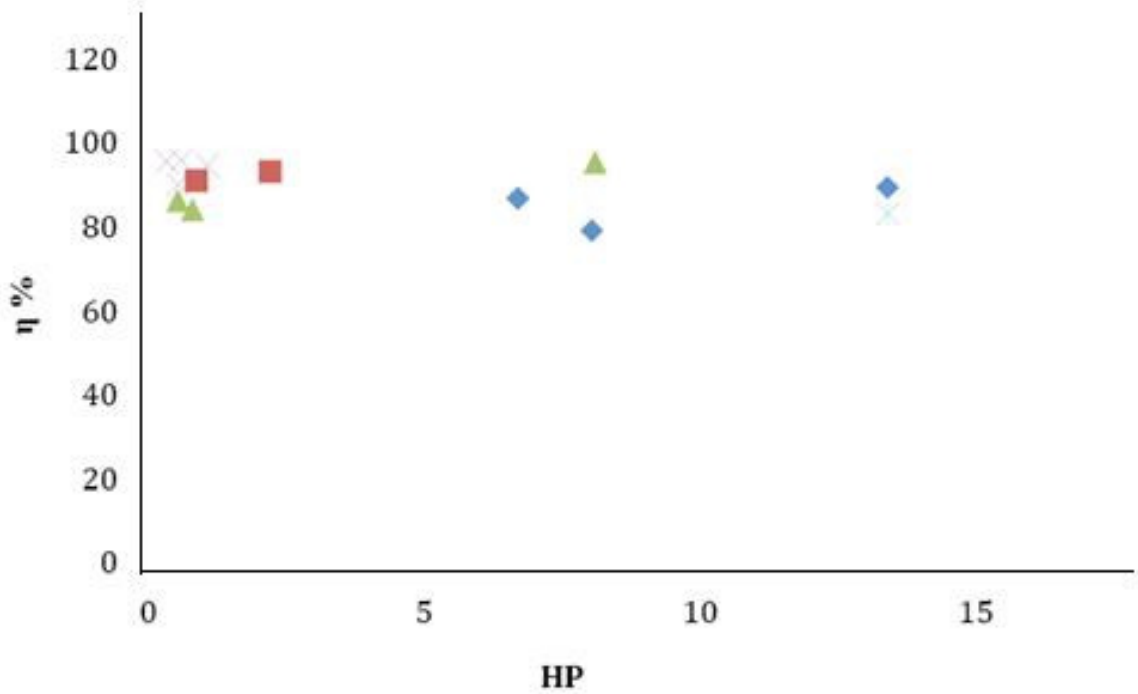

- neumotor

ㄴ. hacker

$\triangle$ astro

himax

yuneec

Figure 3.2.5.3 Plot of HP vs. Efficiency 


\section{HP vs. $\mathrm{P} / \mathrm{W}$ ratio}

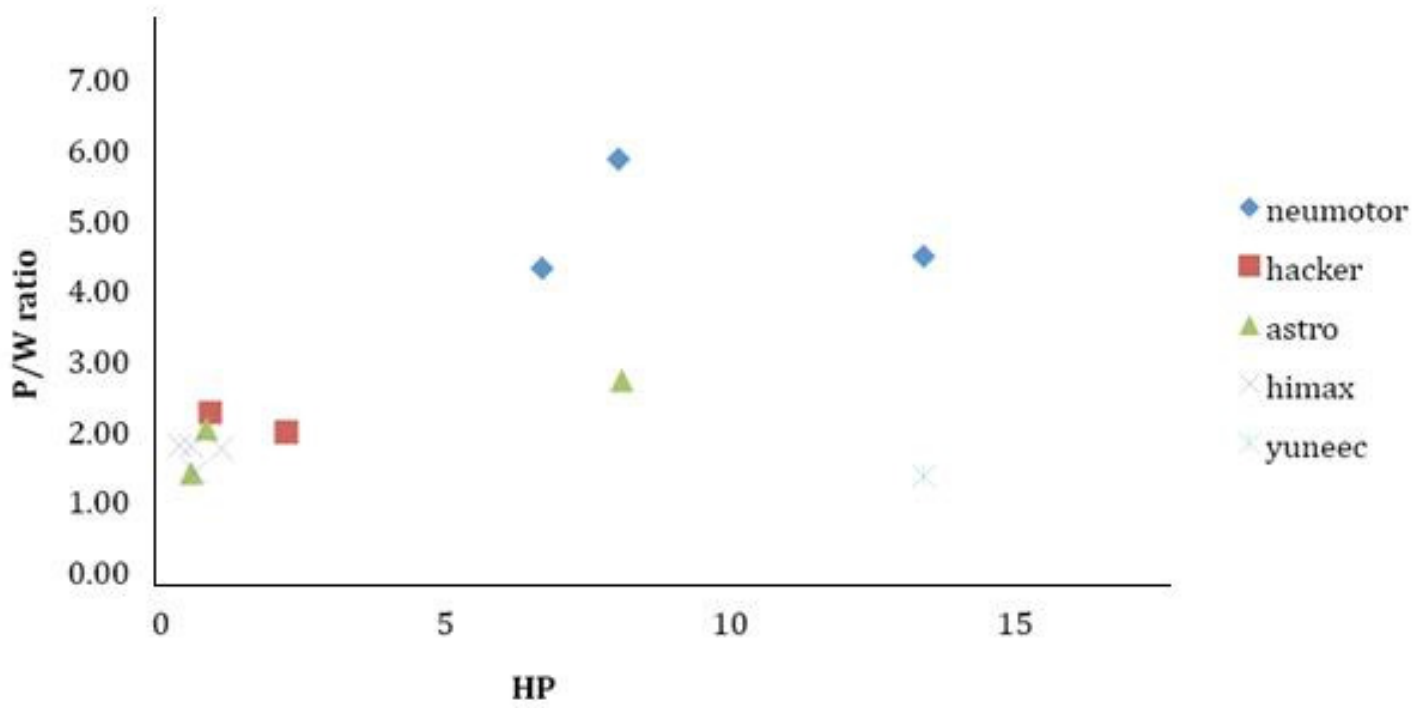

Figure 3.2.5.4 Plot of HP vs. P/W ratio

\section{HP vs. SPED}

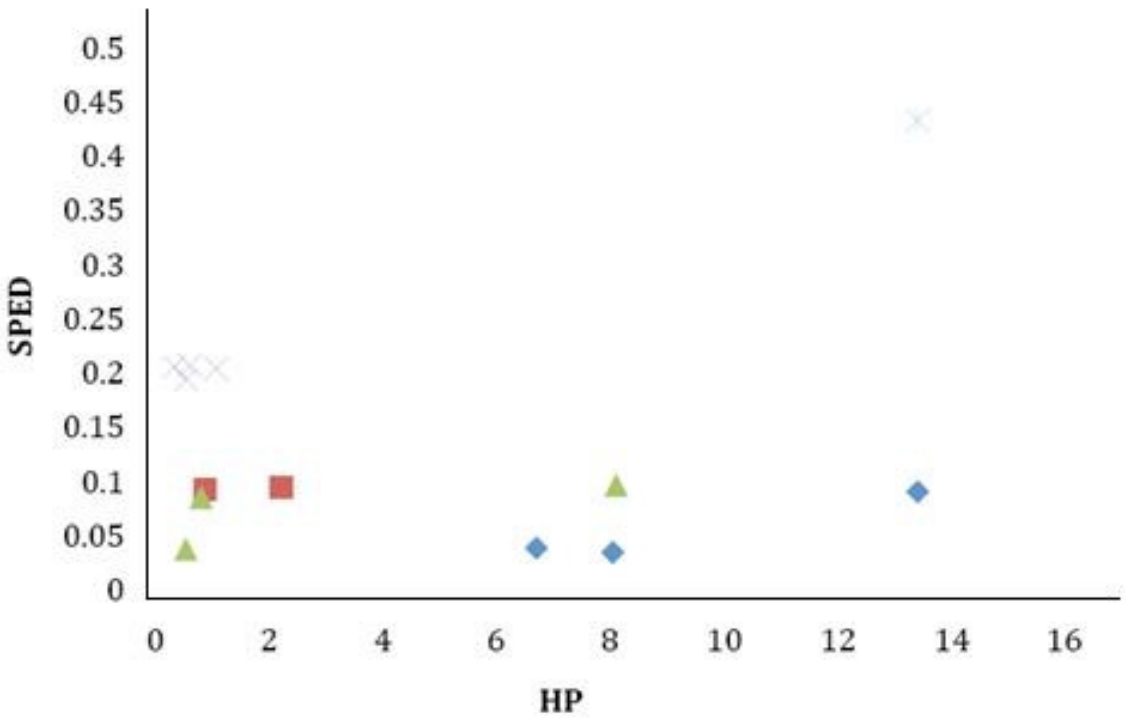

- neumotor

anacker

$\triangle$ astro

himax

yuneec

Figure 3.2.5.5 Plot of HP vs. SPED 


\subsubsection{NiMH (TRL 9)}

A NiMH- Nickel metal hydride cell, is similar to NiCad but uses hydrogenabsorbing alloy for the negative electrode instead of cadmium. They have an energy density value of $32 \mathrm{WH} / \mathrm{lb}$, which is comparatively higher than NiCad (25 WH/lb). Commercially available NiMH batteries have nominal charge capacities (c) ranging from $1100 \mathrm{mAh}$ to $2900 \mathrm{mAh}$ at $1.2 \mathrm{~V}$. They have charge/discharge efficiency of $66 \%$. A fully charged NiMH battery has a starting discharge voltage of $1.4 \mathrm{~V}$, and falls down to $1.25 \mathrm{~V}$ at $10 \%$ Depth of Discharge (DOD) and remains at this voltage until the cell is over $80 \%$ discharged. These batteries have a self-discharge rate of $30 \% /$ month and is affected by temperature difference.

When the battery is over charged at low rates the oxygen that is produced at the positive electrode is able to recombine at the negative electrode resulting in the battery dissipating the overcharge energy harmlessly as heat. The chemical reactions that occur in NiMH are as follows.

The negative electrode reactions is given below

$$
\mathrm{H}_{2} \mathrm{O}+\mathrm{M}+\mathrm{e}^{-} \leftrightharpoons \mathrm{OH}^{-}+\mathrm{MH} \text {. }
$$

The electrode is charged in the right direction of this equation and discharged in the left direction. On the positive electrode, nickel oxyhydroxide (NiOOH) is formed.

$$
\mathrm{Ni}(\mathrm{OH})_{2}+\mathrm{OH}^{-} \leftrightharpoons \mathrm{NiO}(\mathrm{OH})+\mathrm{H}_{2} \mathrm{O}+\mathrm{e}^{-}
$$

The metal $\mathrm{M}$ in NiMH batteries can actually be several different types of intermetallic compounds with the most common being $\mathrm{AB}_{5}$ with $\mathrm{A}$ representing a mixture of Lanthanum, Cerium, Neodymium, Praseodymium, and B is Nickel, Cobalt, Manganese or Aluminum. Some other compounds are available that deliver slightly higher energy 
densities, but are not commonly found in commercial batteries because that extra energy comes at the expense of longevity.

\subsubsection{Lithium Ion/Polymer (TRL9)}

LiPo or Lithium Ion/Polymer batteries have an energy density of $75 \mathrm{WH} / \mathrm{lb}$; almost double the capacity of NiMH. They have really good charge/discharge efficiency of $99.8 \%$. There is no need for metal casing, which reduces the weight of the battery and facilitates shaping of the battery pack to fit the device it will power. Because of this denser packing ability and elimination of metal casing, increases the energy density of Lipoly batteries by $20 \%$ compared to Li-ion batteries. The voltage of Li-poly battery varies from about $2.7 \mathrm{~V}$ (when discharged) to about $4.23 \mathrm{~V}$ ( fully charged), and Li-poly batteries have to be protected from overcharge by limiting the applied voltage to no more that $4.235 \mathrm{~V}$ per cell used in a series combination. Lithium batteries have higher internal resistances than equivalent sized NiCad or NiMH batteries. However most battery packs in current generation small aircraft require many cells in parallel to provide sufficient flight times, and this resulting decrease in effective resistance makes the battery type more suitable for higher power applications. Cathode and anode reactions in a LithiumIon/Polymer are as follows:

$$
\begin{gathered}
\mathrm{LiCoO}_{2} \leftrightarrow \mathrm{CoO}_{2}+x \mathrm{Li}^{+}+x e^{-} \\
\text {Cathode reaction } \\
x \mathrm{Li}^{+}+x e^{-}+6 \mathrm{C} \leftrightarrow \mathrm{Li}_{x} C_{6}
\end{gathered}
$$

Anode reaction 
In general, Lithium-Ion/Polymer batteries offer very low profile, flexible form factor, and light weight with improved safety.

\subsubsection{Lithium sulfur (TRL 9)}

These are galvanic type cells with very high energy density values (180 WH/lb). Lithium is dissolved from the anode surface during discharge and reverse lithium plating to the nominal anode while charging. Polysulfide is reduced on the anode surface in sequence while the cell is discharging:

$$
\mathrm{S}_{8} \rightarrow \mathrm{Li}_{2} \mathrm{~S}_{8} \rightarrow \mathrm{Li}_{2} \mathrm{~S}_{6} \rightarrow \mathrm{Li}_{2} \mathrm{~S}_{4} \rightarrow \mathrm{Li}_{2} \mathrm{~S}_{3}
$$

Across a porous diffusion separator, sulfur polymers form at the nominal at cathode as the cell charges:

$$
\mathrm{Li}_{2} \mathrm{~S} \rightarrow \mathrm{Li}_{2} \mathrm{~S}_{2} \rightarrow \mathrm{Li}_{2} \mathrm{~S}_{3} \rightarrow \mathrm{Li}_{2} \mathrm{~S}_{4} \rightarrow \mathrm{Li}_{2} \mathrm{~S}_{8} \rightarrow \mathrm{Li}_{2} \mathrm{~S}_{8} \rightarrow \mathrm{S}_{8}
$$

The nominal cell voltage raises in the range 2.5-1.7 $\mathrm{V}$ non-linearly during discharge; though they are packed for $3 \mathrm{~V}$. The increase in efficiency is a simple result of the higher energy components used. In 2007, a British company QinetiQ test flew their Zephyr Solar airplane to a new world unmanned duration record of 54 hours. The aircraft was made to use high efficiency solar cells that charged lithium sulfur battery packs in the wings during the day, and used that energy to fly through the night.

The two stage reaction during their discharge increases their capacity, but requires the use of dedicated microcontrollers to control the load and output of the battery at different operating points. The variable system voltage also complicates propulsion system design for small aircraft, as the early voltage peaks assists takeoff, but means the optimal cruise conditions must be a compromise as the voltage varies $10 \%$ between the initial and secondary plateau. 


\subsubsection{Hydrogen Fuel cells (TRL 9)}

A fuel cell is an electrochemical cell that produces electricity from a fuel tank. Fuel cells are different from conventional electrochemical cell, as they consume reactant from an external source, which must be replenished. By contrast, batteries store electrical energy chemically and hence represent a thermodynamically closed system. A hydrogen type fuel cell uses hydrogen as its fuel and oxygen as its oxidant.

The most common type of fuel cell designed to power UAV's is the proton exchange membrane fuel cell (PEM). This type of fuel cell was used in Oklahoma State's Pterosaur aircraft to power an unmanned aircraft distance world record. The PEM fuel cell that was used in Pterosaur UAV had an efficiency of $41 \%$, combined with hydrogen to provide an energy density of $7402 \mathrm{WH} / \mathrm{lb}$ if it were not for the excessively heavy storage of hydrogen gas. Pressurizing hydrogen reduced the energy density to $395 \mathrm{WH} / \mathrm{lb}$ which is still impressive.

\subsection{Near and long term technologies}

The previous section discussed the current propulsion technology. In order to completely understand the extent of these technologies in the near and long term future with respect to UAS, a thorough understanding of each technology is a must, this includes any interesting history related to the engine, its design features, individual performance plots and plots comparing technologies against each other, level of widespread use in present UAVs, advantages and disadvantages.

Secondly, knowledge of what is being developed and how beneficial would that be compared to the existing technology and how long would it take to replace the existing system is necessary. 


\section{ESSP \\ (Efficient Small Scale Propulsion)}

\section{The Plan}
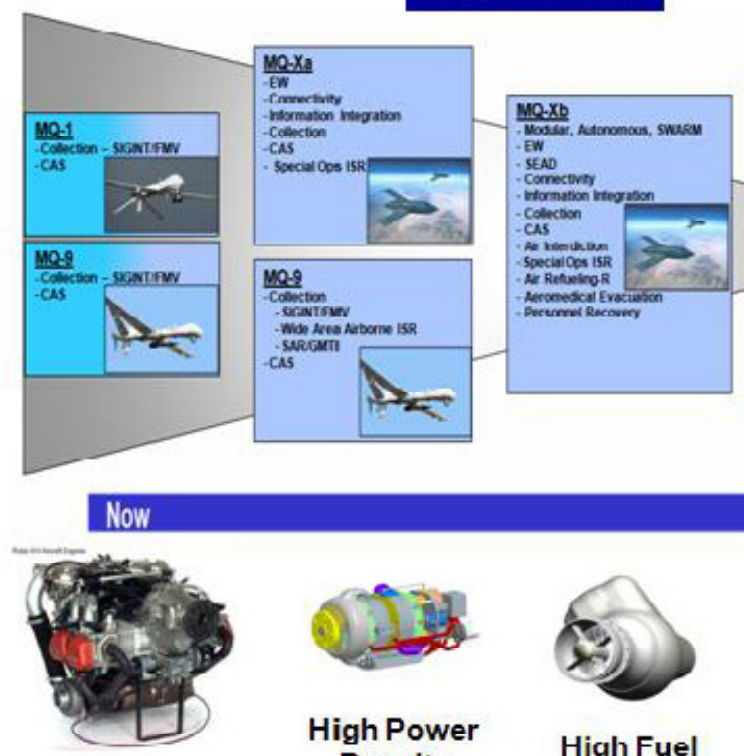

Rotax 914 (MQ-1)

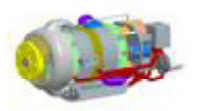

High Power Density Nutating Engine

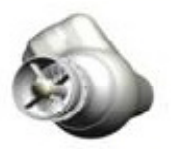

High Fuel

Efficiency

Excentric

Engine
Eficient Small Scale Propulsion (ESSP)

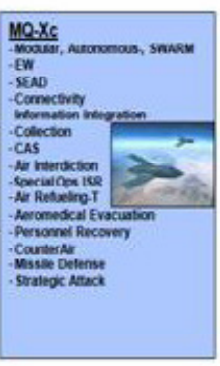

Small Turbine Engines

Internal Combustion

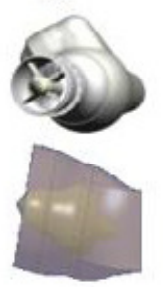
Engines
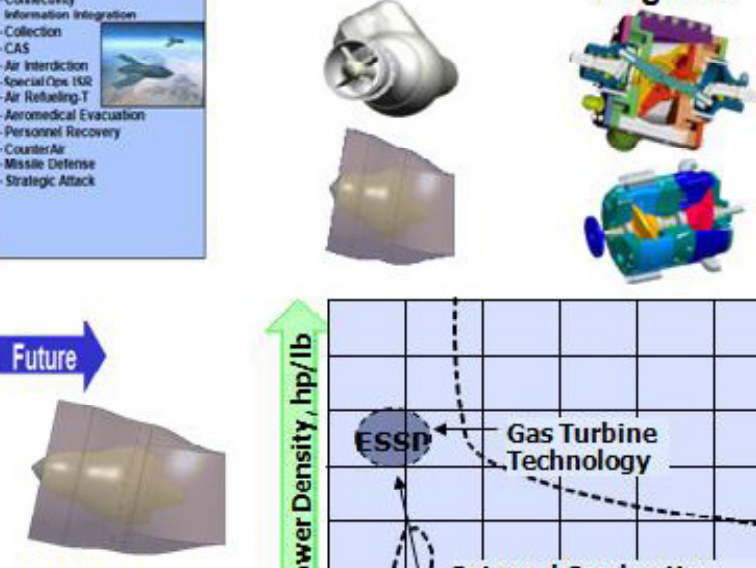

High Bypass Geared Ducted Turbofan

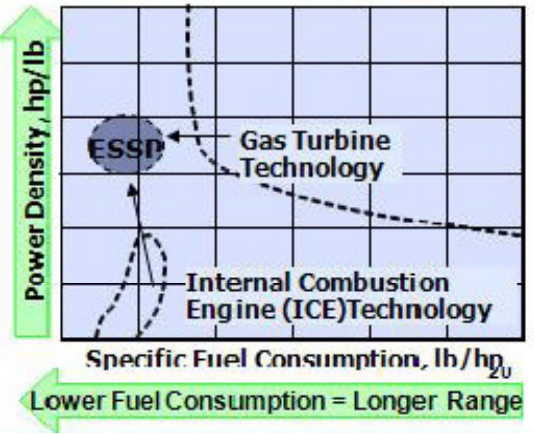

Figure 3.3.1 Expected growth of small scale propulsion system

The figure above is an example showing the existing propulsion system and the expected one in the left corner and expected long term propulsion system with respect to specific fuel consumption in $\mathrm{lb} / \mathrm{hp}$ and power density in $\mathrm{hp} / \mathrm{lb}$ for USAF (United States Air Force) in the small scale propulsion sector in the right corner.

Other near and long term technologies include hybrid engines, turbo and super chargers. Hybrid engines give the best from both worlds (gasoline and electric). They provide better efficiency, improved power and fuel economy. The electric motor provides additional power to assist the engine whenever there is a need for acceleration, high 
torque application etc. One major disadvantage of hybrid engines is the increase in weight due to the need to carry batteries as well as fuel.

All that a turbocharger does is it increases the output hp, without much increase in engine weight. Typical turbocharger setup provides $30-40 \%$ improvements in power. This is achieved with the help of a turbine that spins the exhaust gases from the engine; in turn spinning the air pump. This gives a boost of around 6-8psig. This is a $30-40 \%$ increase as atmospheric pressure is $14 \mathrm{psig}$.

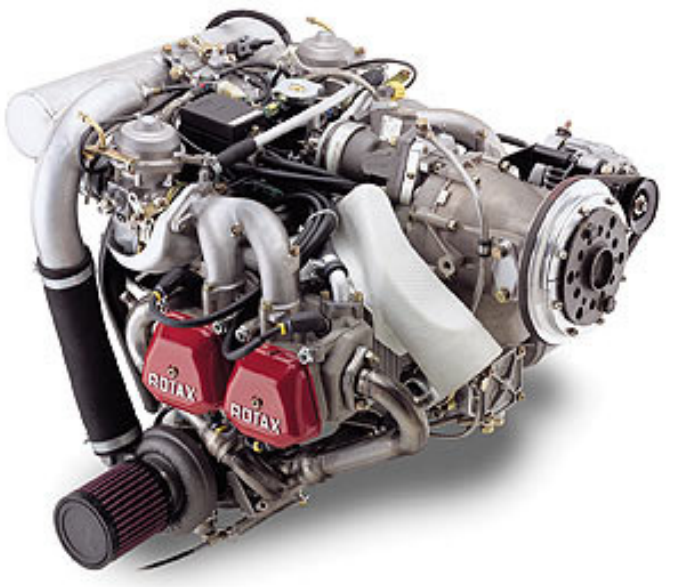

Figure 3.3.2 Turbocharger engine

A super charger is simply an air compressor pushing more air in on the IC engine. This increases the amount of fuel burned per cycle, increasing the output produced by the engine. Power to the supercharger is provided with the help of belt or gear driven by the crankshaft. Superchargers are widely used in aircraft engines to boost up performance at higher altitudes. Since, the density of air reduces as altitude is gained; more mass flow rate increases the amount of oxygen content in the chamber enabling a more complete combustion of the mixture. 


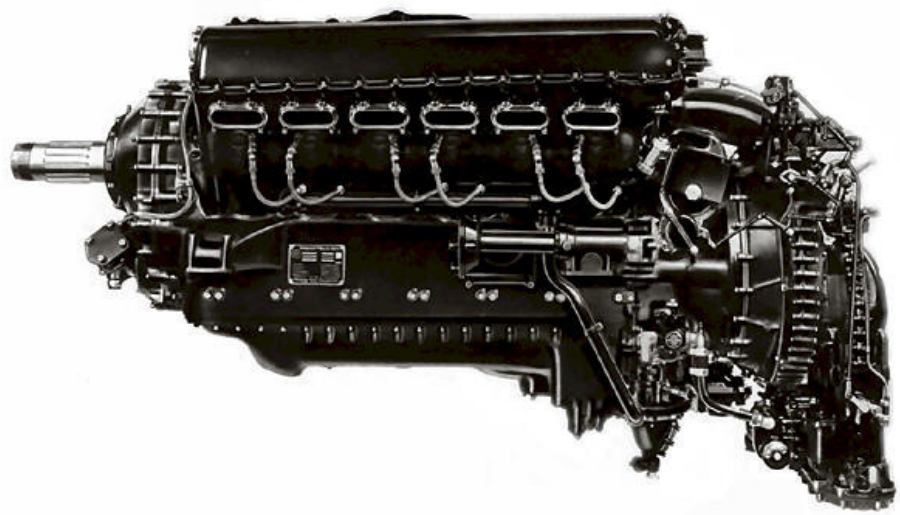

Figure 3.3.3 Super charger engine

\subsection{Comparison of current propulsion technologies}

Here, all the current propulsion technologies are compared to each other. This includes two and four stroke carburetor; two and four stroke EFI, Wankel, and electric and turbine propulsion systems. These specs were obtained during the course of the survey, and are tabulated as provided by the manufacturers.

It can be observed that in terms of efficiency, electric motors have the upper hand followed by 4 -stroke engines. Electric motors are better even when compared in terms of weight,

P/W ratio, but it's clouded by that fact that it has the lowest energy density. That is, for a given amount of fuel or power supplied, the energy output produced is very low. This makes it necessary to carry large number of batteries to provide power, affecting the weight of the aircraft. For a specific output HP, two stroke engines have less weight and better SPED values than other propulsion systems. Their low weight, gives them higher 
$\mathrm{P} / \mathrm{W}$ ratio. Lower SPED value denotes that less amount of fuel is necessary to perform a given mission compared to others.

Four stroke engines have better efficiency compared to others, but are affected by P/W ratio. The deciding factor for selecting a particular propulsion system apart from mission characteristics would be their P/W ratio, SPED and ratio of SFC to power density. Considering these three prime factors, two stroke and turbines are the best performers. But in terms of efficiency, two stroke carburetor variant doesn't perform up to the level expected. Their EFI/TBI variants have improved performance traits making them a better performer.

The turbo shaft/turboprop engine excels in most of the parameters compared above; especially they have a very high $\mathrm{P} / \mathrm{W}$ ratio. Their performance gets affected as the engines are scaled down to smaller size. This is largely due to the inability to achieve better compression and poor sealing characteristics at a reduced scale.

\subsection{Summary of advantages and disadvantages of each technology}

\section{Two-stroke:}

\section{Advantages:}

- Two stroke engines are widely used in UAVs due to their less weight

- They have higher $\mathrm{P} / \mathrm{W}$ ratio

- Better SPED values

\section{Disadvantages:}

- Noise level is high compared to 4-stroke and Wankel engines 


\section{Four-stroke:}

\section{Advantages:}

- Better fuel economy than Wankel and turbine engines

\section{Disadvantages:}

- They are not used extensively due to heavy weight.

- $\mathrm{P} / \mathrm{W}$ ration is very low compared to 2 -stroke

- Considerable amount of noise persists

\section{Wankel:}

\section{Advantages:}

- Lighter in weight compared to 2 and 4-strokes

\section{Disadvantages:}

- Due to less power generated, Wankel engines are not used extensively.

- Low $\mathrm{P} / \mathrm{W}$ ratio

- Poor fuel economy

\section{Turbine:}

\section{Advantages:}

- Have higher P/W ration than any other type

- Very low weight compared to others

\section{Disadvantages:}

- Very low fuel economy

- Have not been used in small UAVs yet, due to bad fuel economy at lower scales

\section{Electric:}

\section{Advantages:}


- More efficient than other types of technology

- Less weight

- Better P/W ratio

\section{Disadvantages:}

- Lower SPED values

- Not suitable for long range missions due to the low energy density values of battery used.

Plots comparing HP to weight, efficiency, SPED, P/W ratio, as well as SFC to Power density is made in the range of $0-50 \mathrm{HP}$. These plots enable us to look for trends, as well as compare all the different technologies as the output horse power increases. The information in these plots is from the survey and is obtained from the manufactures.

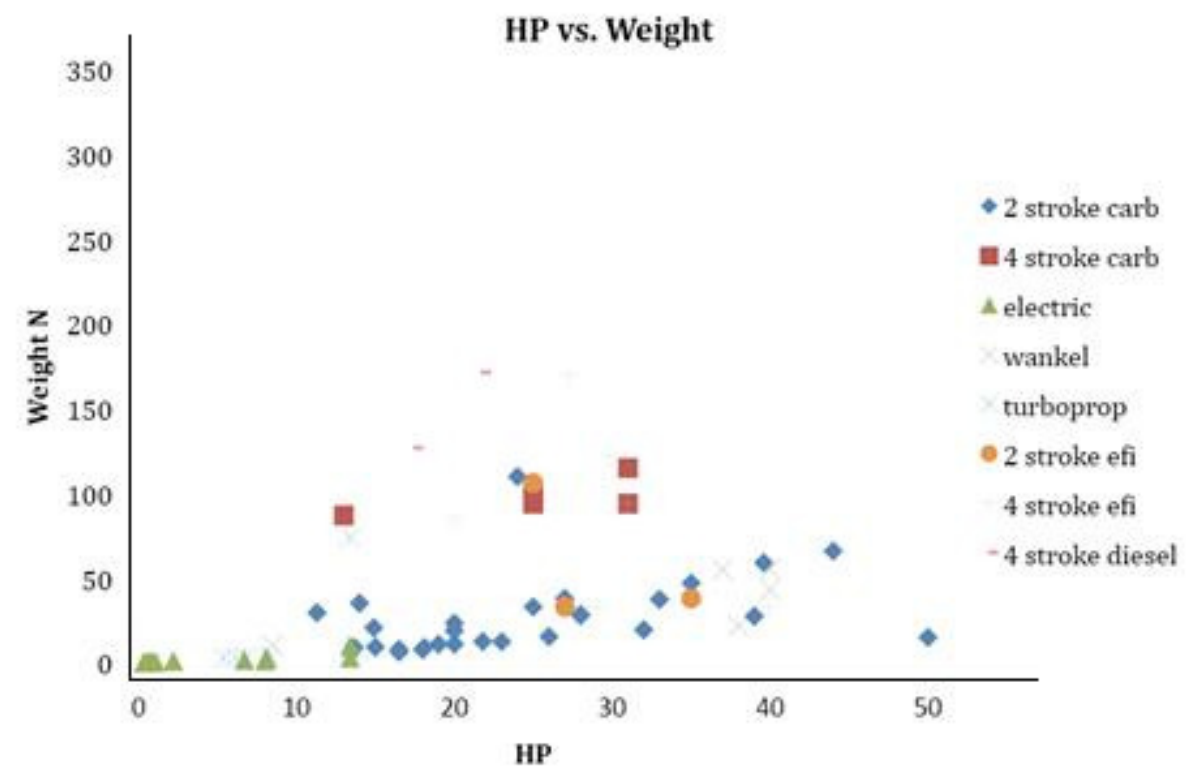

Figure 3.5.1 Plot of HP vs. Weight 


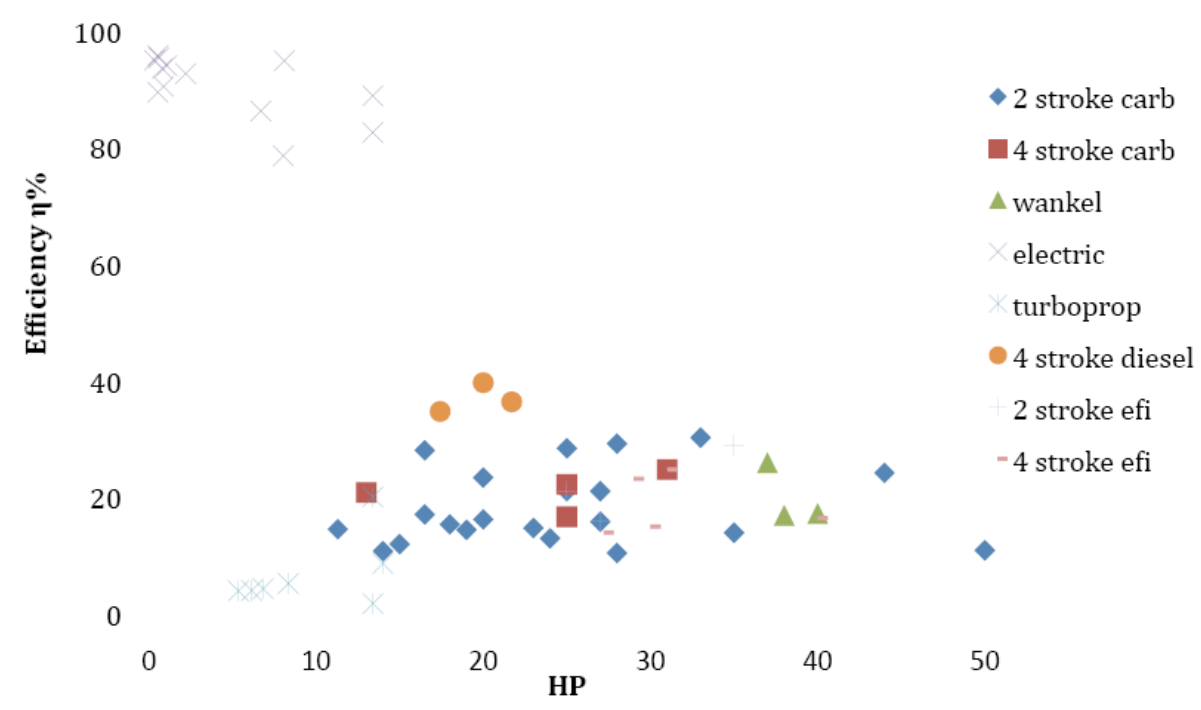

Figure 3.5.2 Plot of HP vs. Efficiency

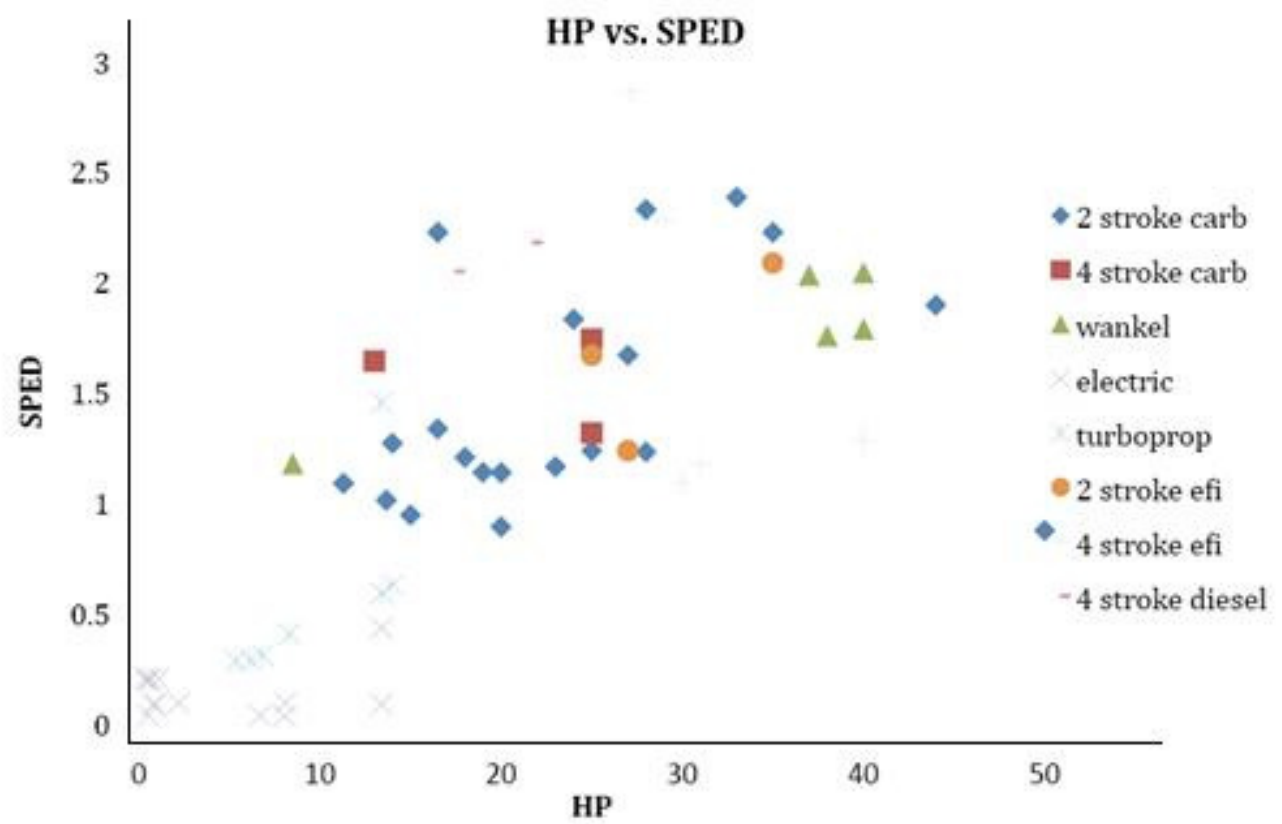

Figure 3.5.3 Plot of HP vs. SPED 


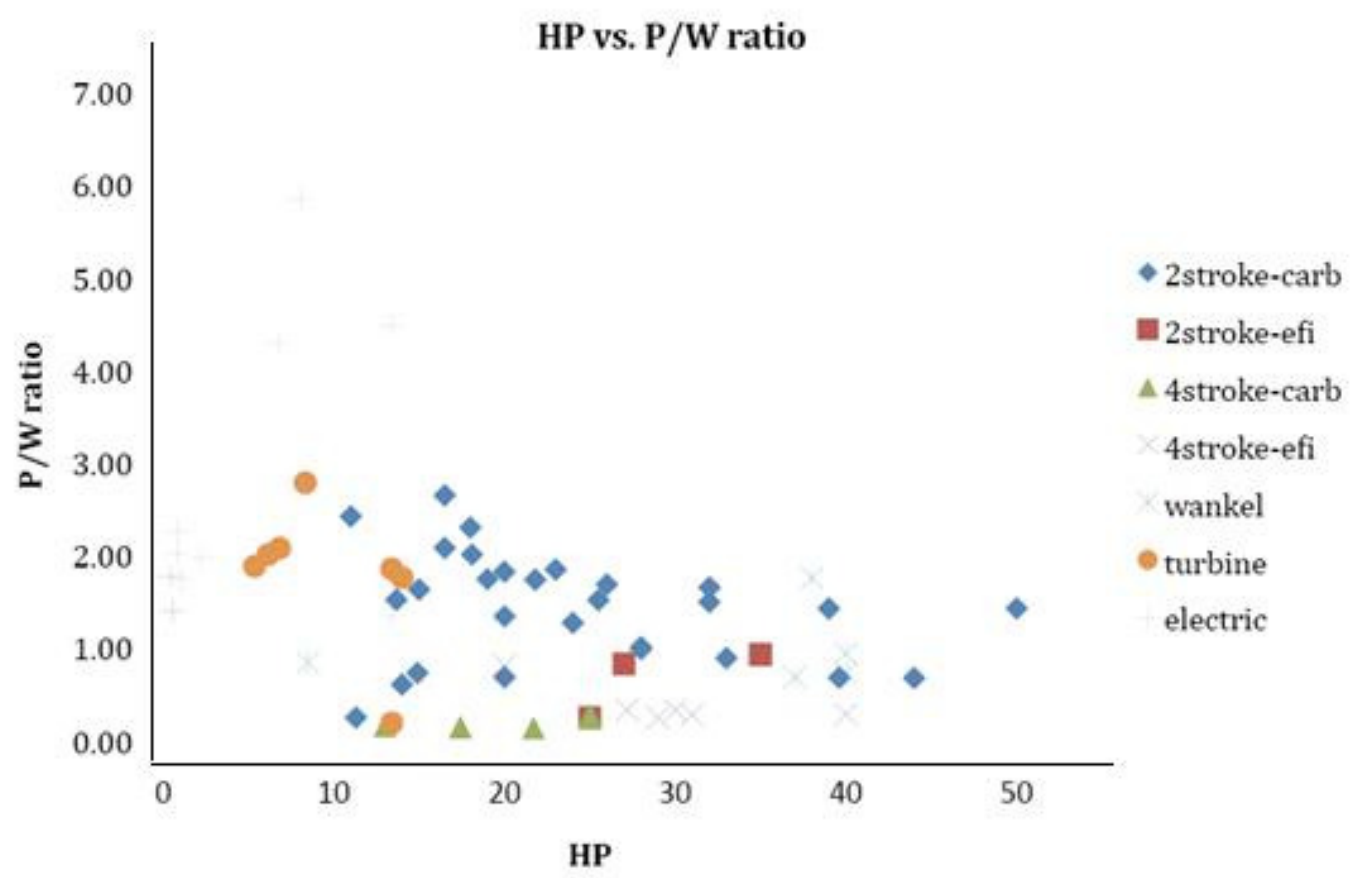

Figure 3.5.4 Plot of HP vs. P/W ratio

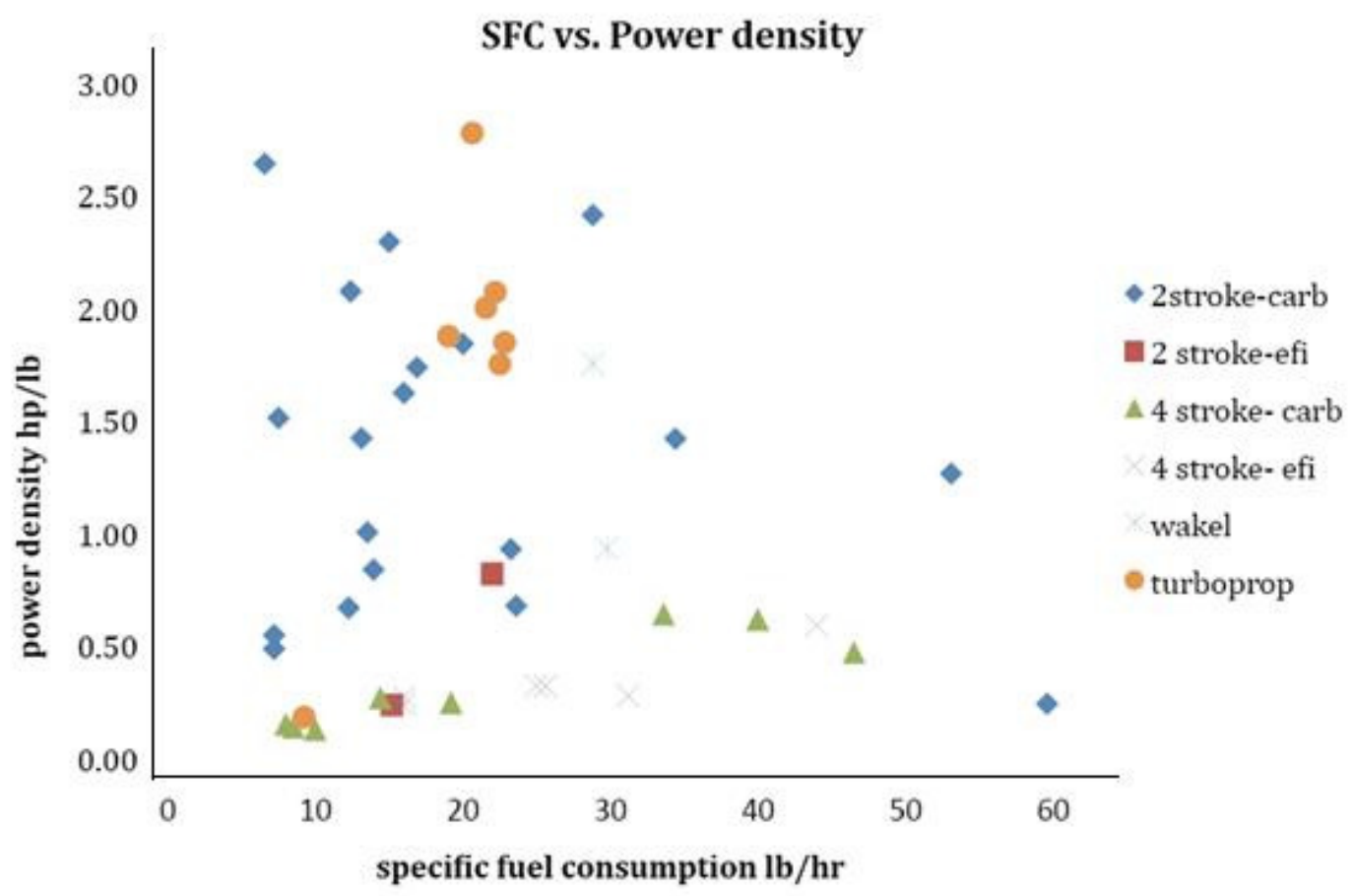

Figure 3.5.5 Plot of Specific fuel consumption vs. Power density 


\subsection{Future propulsion technologies}

The following is a summary of other propulsion systems found in the literature that are in varying stages of development and their potential advantages.

\subsubsection{Nutating engine}

This new type of internal combustion engine uses concave disks. The engine is made using two disks, one for intake and compression and the other for expansion and exhaust. The output power is transmitted through the shaft system. The disk is attached to a z-shaped drive shaft that causes it to wobble or "nutate" and in the process four cycles are completed-intake, compression, combustion and exhaust. One of the primary difficulties was the development of proper sealing, combustion pre-chamber, cooling circuits and fuel injection system.

Interestingly, the outer surfaces of the disks never come in contact with the housing inner-walls. This gives an upper hand over other IC engines since most of the inner wall surfaces are thermal barrier coated.

The smooth cycles result in lower vibrations compared to other internal combustion engines. The small engine's Z-shaped drive shaft transmits power directly to the output shaft so hardly any power is lost in transmission. This fact makes nutating engines have very high power densities up to 4 times greater than those of 4-stroke engines. The major challenge with the Nutating engine is the complex relationships between air flow, combustion pre-chamber geometry, fuel injection and spark timing are, as yet, are insufficient. This technology is relatively new so specifications are vague since it is still at the conceptual level and not fully produced, leaving nutating engines with a TRL level of 6 . 


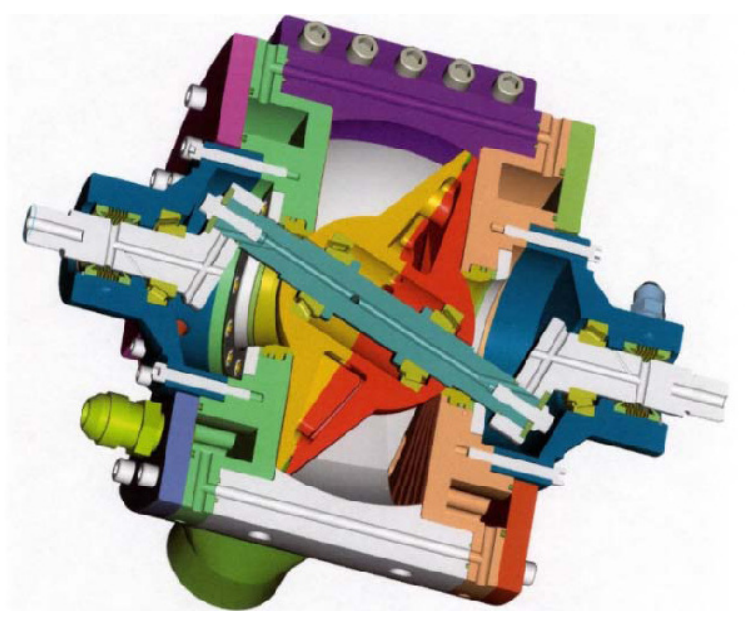

Figure 3.6.1.1 Nutating engine

\subsubsection{Six stroke engine}

Technically speaking, there are three different types of 6-stroke engines. Each has 6 stages to complete one cycle, runs on heavy fuel, and has a separate added on chamber either for combustion or to replace moving valves as is discussed in the subsequent sections below.

The first type was created in 1883 by Samuel Griffin from a town called Bath in Somerset, England. His engine operated much like a 4-stroke except it had an external heated chamber from the compression cylinder that was held around $550^{\circ} \mathrm{F}$. Compressed air would enter this chamber and when fuel was sprayed, it vaporized and then ignited by hot bulb ignition.

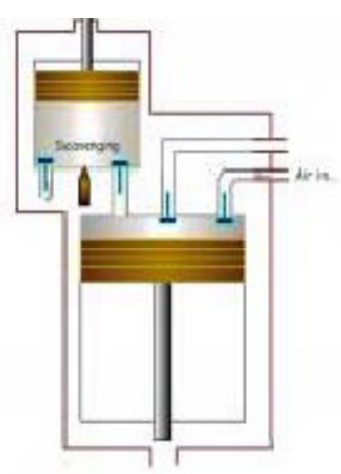

Figure 3.6.2.1 Six stroke engine 
The third type of 6-stroke takes 4-stroke engine technology and simply adds on to the Otto cycle in a resourceful manner. This was invented in the U.S. by Bruce Crower. Like Griffin engines, the combustion chamber is separate from the compression chamber. After the normal 4- stroke Otto-cycle, water is sprayed into the combustion chamber. The heat generated from the previous power cycle causes the water to expand into steam and create downward pressure on the piston, thus adding a second power stroke. This crucial step requires four valves - 1) initial air intake into the compression cylinder 2) moving the compressed air to a separate chamber 3) releasing the heated air back into the combustion chamber and 4) exhaust. Some obvious advantages of this type of 6-stroke is an increase in thermal efficiency and the reduction of weight as compared to 4-strokes since a cooling system is no longer necessary. In addition, the direct fuel injection permits optimal fuel combustion and thus reduces emissions and increases fuel efficiency. Unfortunately, 6-stroke engines have more moving parts and the added weight of the separate combustion and compression chambers cancel out the weight savings from the lack of a cooling system.

While six stroke technologies has been tested in the automotive industry, this technology has only been observed for use in UAV's, so this engine is at level 1 on the TRL scale.

\subsubsection{HCCI engine}

A HCCI (homogeneous charge compression ignition) engine combines the advantages of both diesel and gasoline engines. Like a petrol run engine, fuel and air are premixed before combustion takes place to ensure an evenly distributed mixture. Also, 
instead of igniting the fuel with a spark, it is simply compressed until its ignition point much like a diesel engine.

This diesel-run engine offers gasoline-like emissions with diesel-like efficiency. However, because the combustion takes place due to compression, there is no direct initiator of the process and is therefore challenging to control. Very responsive pressure sensors allow the engine to make quick adjustments which is the key since these engines are extremely sensitive to operating conditions.

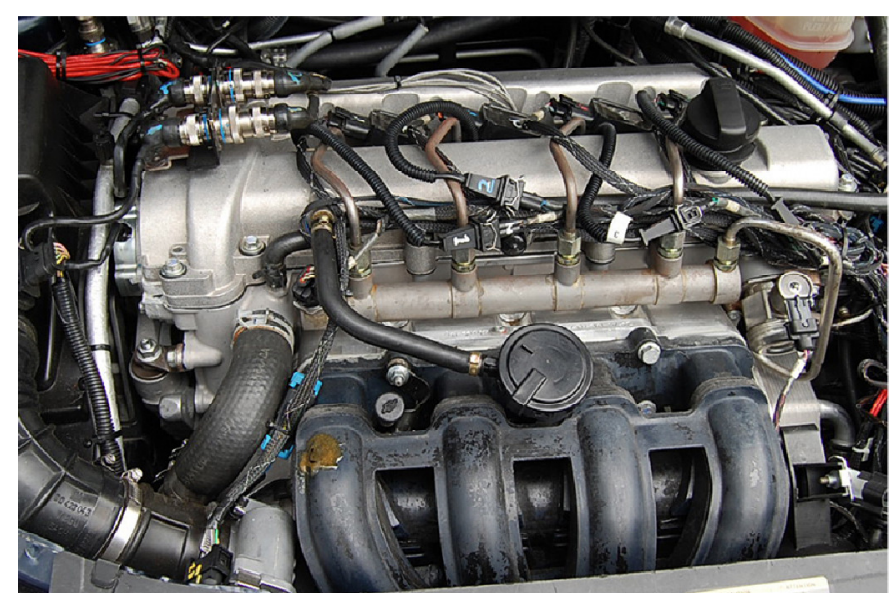

Figure 3.6.3.1 HCCI engine

HCCI engines are also able to run in idle and low-load situations. These favorable factors are stimulating research into this merged technology leaving these engines with at level 3 of the TRL scale.

\subsubsection{Dual fuel engine-Natural gas and Diesel}

A dual fuel diesel engine operates much like a regular diesel engine with one advantage - it can run on either a mixture of natural gas and diesel or diesel alone. Patented fuel injectors are electronically controlled and release the correct amount of each fuel into the chamber depending on the power required. These injectors are controlled by pulse width modulated signals based on readings on manifold pressure, gas 
temperature, gas pressure, air temperature, and fuel mapping. These signals are sent from the electronic control unit which interprets the gathered information and produces the best combination of fuels to acquire maximum efficiency and emissions.

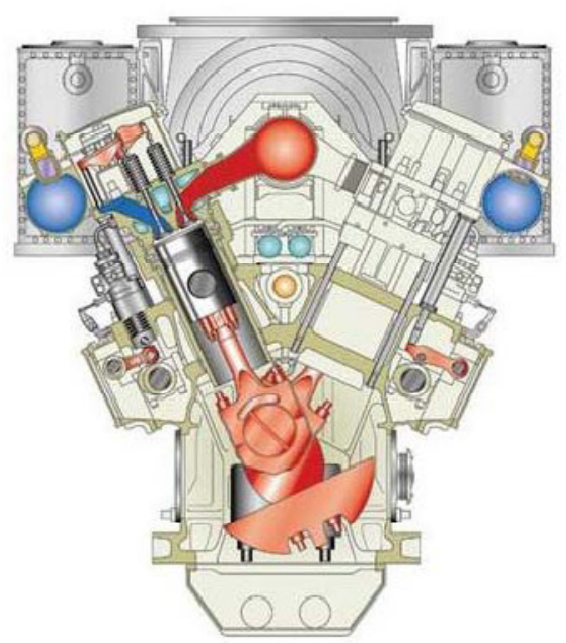

Figure 3.6.4.1 Dual fuel engine-Natural gas \& Diesel

The fuel mixture can be as much as $90 \%$ natural gas and still maintain engine efficiency and full horsepower potential. With this addition, these engines reduce the nitrogen oxide emissions by as much as $66 \%$. Regrettably, the mechanism to shut off the natural gas flow when necessary is problematic and requires lubrication. Furthermore, duel fuel engines are relatively expensive at the moment and contain more moving parts then a normal diesel engine.

Today, dual fuel engine technology is more developed in the automotive business, but today heavy fuel engines are being more closely studied giving this engine a TRL level of 1.

\subsubsection{Electric-Diesel hybrid}

A hybrid contains two engines - one small diesel or gasoline engine that runs at a constant rpm, thus maximizing fuel efficiency, and an electric engine that provides extra 
power boosts when necessary like take-off for an aircraft or driving uphill for an automobile. The diesel or gasoline engine runs off its respected fuel, and the electric motor is powered by batteries.

There are two ways to arrange these two types of engines called parallel and series arrangements.

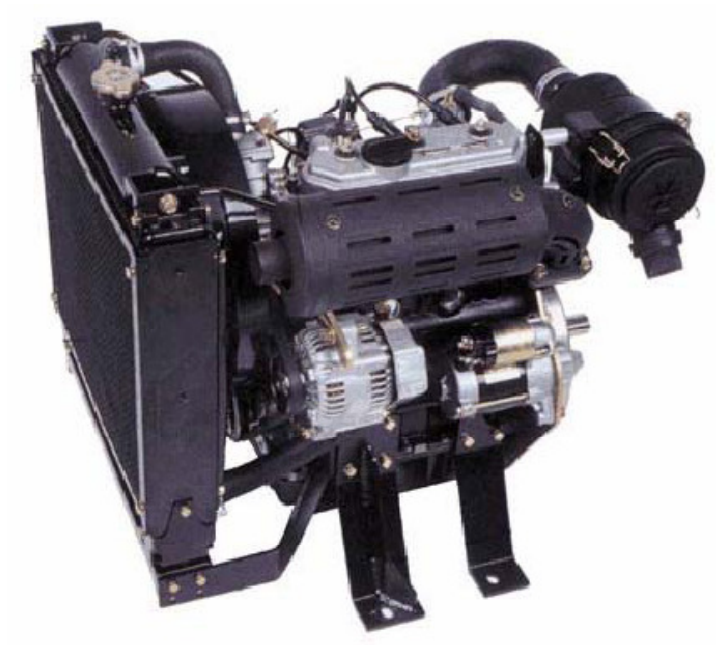

Figure 3.6.5.1 Electric Diesel Hybrid

In a parallel arrangement, both the electric and IC engine turn the transmission at the same time. They are both independently connected to the transmission to provide propulsion. In a series arrangement, the IC engine never directly drives the transmission. It turns a generator which can either power the electric motor or charge the battery pack. The electric motor actually drives the transmission.

Hybrids can reduce fuel consumption by as much as $20 \%$ compared to a vehicle with only an IC engine. In a hybrid, the IC engine can afford to be considerably smaller than if it was the sole source of power for the vehicle since it has assistance from an electric motor. Unfortunately, the added weight of the battery and electric motor can sometimes outweigh the reduced mass from the use of a smaller IC engine. 
The hybrid model has been successful on larger vehicles like watercraft, land vehicles, and aircraft such as the hybrid electric rotary wing platform from Flax Air. The military is looking at a potential UVA model created by British engineer Geoff Hatton that combines the design basics of a hovercraft with that of a helicopter. This gives hybrids a TRL value of 4 . 


\section{CHAPTER IV}

\section{DYNAMOMETER}

A dynamometer is simply a device used to measure force or power of an engine, simultaneously measuring torque and rotational speed. It provides accurate information and helps validate engine performance. As of date, there has been very few dynamometers built to test engines in this power range and are summarized below.

\subsection{Thomas dynamometer}

This dynamometer was built to test small scale engines and quantify their performance and compare the effects of engine modification. The dynamometer was designed to test energy density of various small scale engines and measures torque, RPM and fuel flow. A point load cell is coupled to a known length of moment arm on the engine side to measure torque. Moment arm is mounted on the engine side to ensure that torque contamination is minimized. RPM is measured with an optical transducer that outputs a high logic level each time it senses the reflective tape on the engine shaft pass by. Fuel flow is averaged over time by continually acquiring samples from a sensitive digital balance, and then applying a linear curve fit to the resulting mass and time data. This dynamometer can be used to test any engine with at-least 200 Watts of output power. This dynamometer uses an electric motor for the purposes of simulating a hybrid 
type system and also used for engine starting. Lab view is used to record all the data that are obtained and this reduces the uncertainty in the data.

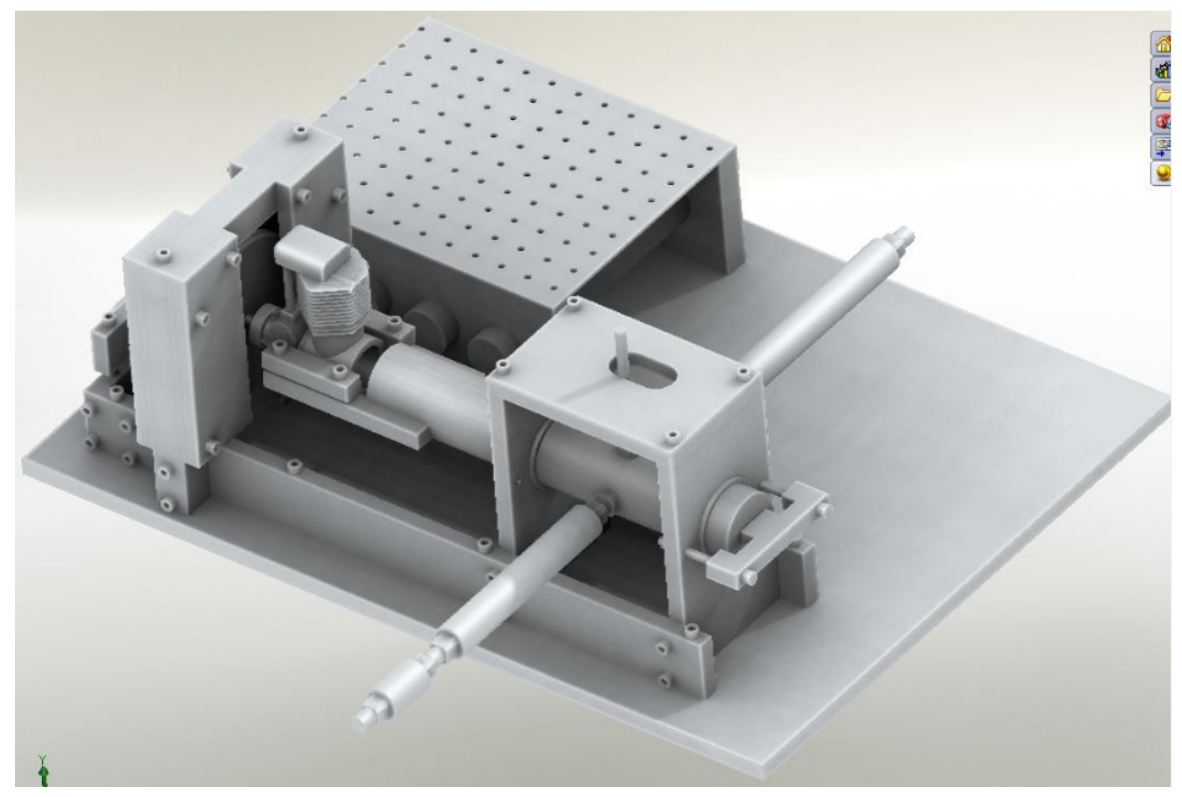

Figure 4.1.1 Thomas dynamometer

\subsection{Menon dynamometer}

This is another dynamometer used to quantify small scale engines. It is a hysteresis brake type dynamometer and measures horsepower, torque and fuel flow data. The Menon dynamometer goes a little bit farther and detects airflow into the engine using a TSI 4021 mass flow meter which allows for scavenging measurements, and data presentation based on fuel to air ratio. Torque is passed on to the $5 \mathrm{lb}$ load cell using a reaction torque cradle. Because the load cell is rigidly mounted, the cradle is locked down each time the engine passes the resonant frequency of the rotating system or else the load cell will be destroyed. Overall torque and power measurements are found to be accurate to $+-8.5 \%$ and the torque uncertainty is around $+-2.5 \%$. Overall, US Army research 
office found Menon dynamometer to be capable of delivering many types of high quality data with its highly accurate sensors.

This dynamometer is also used in another publication regarding micro engines by Sookdeo. In this paper the moment arm based torque measurement system is replaced by correlating the output of a connected generator to true output horsepower. This method is inaccurate but necessary because of the large uncertainty of the load cell based system.

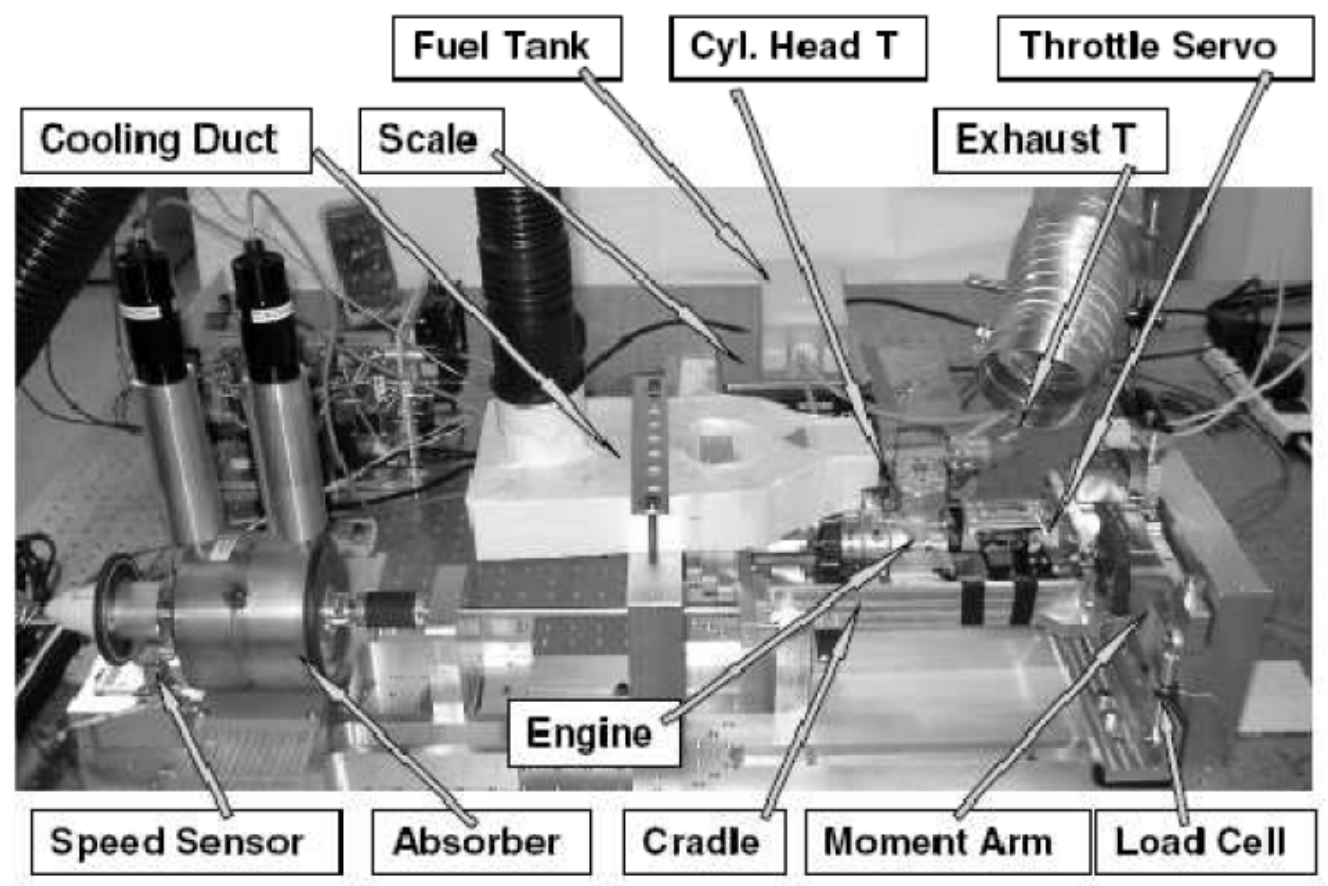

Figure 4.2.1 Menon dynamometer

\subsection{Korean Aerospace research institute dynamometer}

This dynamometer makes use of the land and sea dynamometer system and is an eddy current brake dynamometer. Much of the system is similar to Menon dynamometer, the torque is passed on to the load cell directly. Most of the work was done by Shin Et. Al. It revolves around comparing engine test results with those predicted by a program 
developed at the Sloan automotive engine laboratory at MIT over many years. The software package predicted horsepower output as a function of RPM very well, but was considerably off when trying to compute BSFC. This dynamometer would have similar problems with cradle resonance destroying load cells.

Additionally, the land and sea dynamometer has an entry cost of 13,500 dollars, which does not include the engine starter, computer, auxiliary sensors, and other accessories.
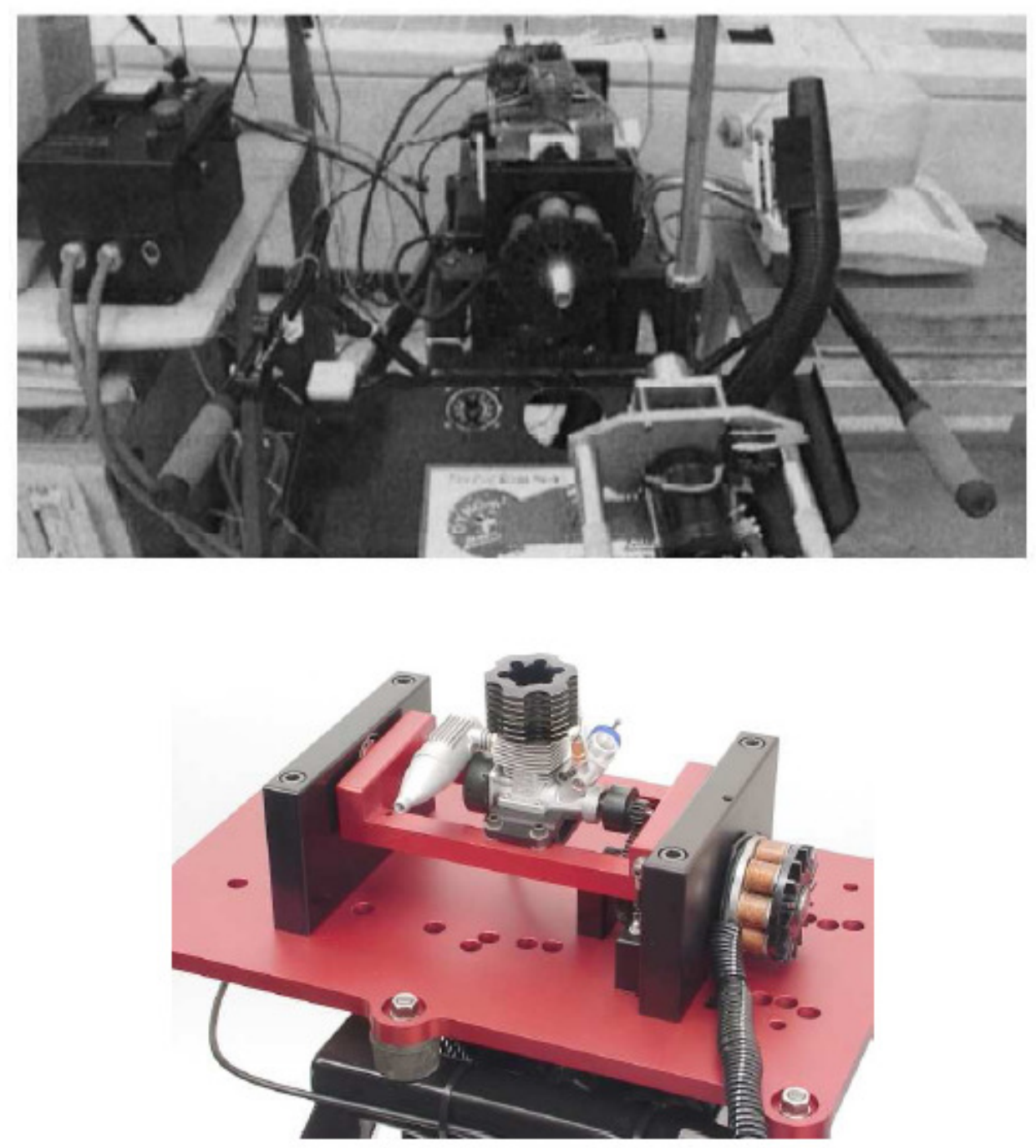

Figure 4.3.1 Korean Aerospace research institute dynamometer 


\subsection{Fuel Injection system}

Fuel injection systems are widely used to improve one or more performance characteristics. In any UAS or aircraft P/W ration and fuel economy are major deciding factors on the selection of propulsion system. 2-stroke engines best fit this requirement as they are super light and relatively fuel efficient. The catch is that most aircraft engines are tuned for best performance at sea level. As altitude is gained, the density of air drops and leaves the engine to run with a very rich fuel air mixture. With EFI in place; the control module senses the pressure in the intake air vent and controls the amount of fuel squirted in accordingly.

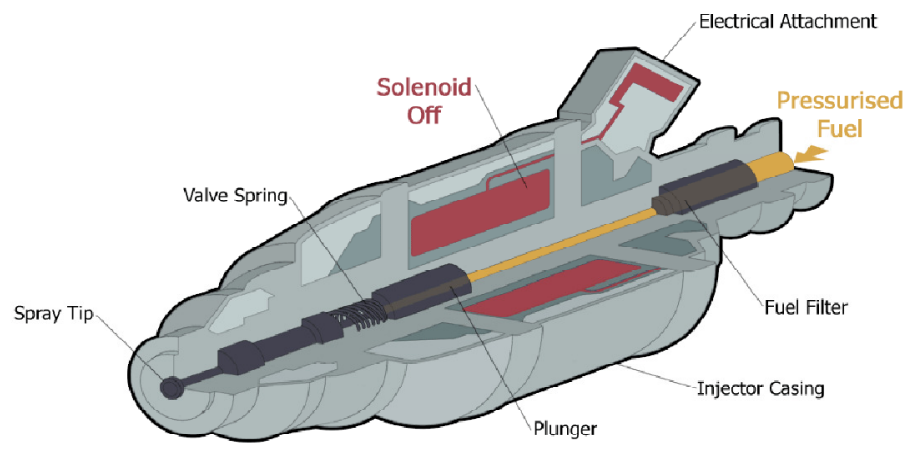

Figure 4.4.1 Fuel injection system

There are several benefits that come along with fuel injection system. The decision taken during the design phase determines the parameter for which the system will be optimized for. A few examples are listed below,

- Power output

- Fuel efficiency

- Emissions performance 
- Ability to accommodate alternative fuels

- Maintenance cost

- Reliability

- Smooth operations

Some of the benefits listed above conflict each other; they cannot be incorporated on the same engine control system.

\subsubsection{Types of fuel injection system}

There are several types of fuel injection system to choose from depending on the application and performance characteristics. They are,

- Throttle body injection

- Continuous injection

- Central port injection

- Multi-port injection

- Direct injection

Throttle Body Injection (TBI) also known as Central Fuel Injection (CFI) or single point injection is simply a high pressure carburetor. It was introduced in 1940 for large aircraft engines. The main difference between the TBI and the carburetor is that TBI is pressurized system and requires a pump to create high pressure. This system injects the fuel at the throttle body, same as the carburetor. The major advantage of this system is the low cost of manufacture and less weight, very few moving parts made maintenance relatively cheaper. TBI was extensively used on passenger cars and trucks in the 1980 to 1995 timeframe. 
Continuous Injection also known as Continuous Injection System (CIS) was introduced in 1974. In this method, fuel in continuously sprayed from the injectors rather than being pulsed like Throttle Body Injection. Gasoline is pumped from the fuel tank to the fuel distributor, which separates the single pipe line into smaller pipes, one for each injector. The amount of fuel supplied to the injectors depends on the angle of the air vent, which is determined by the flow rate of air past the vent, and control pressure. The pressure is regulated for altitude, full load, or cold engine. This is the most common type of injector in piston aircraft engines, because it requires no electricity to operate.

Central Port Injection (CPI) or Central Port Fuel Injection (CPFI) was first incorporated by General Motors. Instead of spraying fuel directly into the manifold like a throttle-body injector, the injector routes fuel into the fuel lines that have poppet-style spray nozzles on the end. When the pressure inside the lines reaches the opening pressure of the poppet valves, fuel sprays out of the nozzles into the engine's intake ports. In the first generation CPI system, all the nozzles spray simultaneously when the injector opens. In the second generation CSFI (Central Sequential Fuel Injection) system, the injectors are controlled individually and fire only once every other revolution of the crankshaft. This allows the system to provide sequential fuel injection for better emissions, performance and fuel economy.

Multi-point Fuel Injection (MPFI) injects fuel into the intake port, rather than at a central point within an intake manifold, referred to as SPFI. MPFI can be sequential like CSFI, in which $\backslash$ injection is timed to coincide with ach cylinder's intake stroke or batched without precise synchronization to any particular cylinder's intake stroke or simultaneous, in which fuel is injected at the same time to all the cylinders. 
Unlike other methods, this system operates at much higher pressure as the fuel is injected just after the compression stroke. Direct injected engines are much cleaner and more efficient than indirect injected engines. Due to better dispersion of the fuel, higher compression ratios are permitted, for enhancing output. Fuel economy is increased to a great extent. Few direct injection engines use piezo electric injectors for fast response time. 


\section{CHAPTER V}

\section{PROPULSION SYSTEM SURVEY}

Understanding current propulsion system technologies in the accepted horsepower range is the key factor for this research and a study was done to support this and it gathers information on propulsion system used in various UAVs. The prime focus was on the 20$30 \mathrm{Hp}$ range, although propulsion technologies in the range of 5-100 $\mathrm{Hp}$ were included to provide a broad vision. A wider horse power range was chosen to identify possible trends in Efficiency or Horse Power or Specific Propulsive Energy Density (SPED).

The study shows promising directions to proceed in selecting a better engine, by comparing several parameters such as power to weight ration, SPED, efficiency etc based on objective. SPED is the energy density of the fuel used for that engine (e.g. Watt-hr/lb, or $\mathrm{MJ} / \mathrm{kg}$, etc.) * propulsive efficiency. This gives us the total energy available. It is essentially the same thing as 1/BSFC. For example, a propulsion system with a SPED of $10 \mathrm{HP}-\mathrm{hr} / \mathrm{lb}$ could produce $10 \mathrm{HP}$ for 1 hour using $1 \mathrm{lb}$ of fuel. The study provides good grounds to compare different manufacturers to one another based on various parameters. It provides an idea of what type of technology is currently available and what is on the horizon or what could be expected in the near future. It eliminates uncertainty and guess 
work regarding the performance of the propulsion system by providing quantifiable data provided by the manufacturer to be used as a ground reference. The study includes information such as name of the engine/manufacturer, engine picture, engine class, application, fuel used, injection system, peak $\mathrm{hp}$, fuel consumption at peak $\mathrm{hp}$, engine weight, efficiency, SPED and Power to Weight ratio (P/W). Engine class is again classified into 2-stroke, 4-stroke, Wankel, Turbine and Electric. Application is classified as ground or aircraft based on where they are used. Fuel used is Hvy for Heavy fuel, Gas for gasoline and the battery used for electric. Injection system is C for carburetor and DFI for throttle body injection or Digital/Electric fuel injection. These details are gathered from the respective manufacturers through phone or website and efficiency, SPED and $\mathrm{P} / \mathrm{W}$ ratio are calculated.

This study covers a comprehensive list of engines in the 5-100 hp range with important attributes like HP, efficiency, fuel consumption, weight, power, etc. Results are provided in appendix. 


\section{CHAPTER VI}

\section{EXPERIMENTAL SETUP}

This section discusses the rationale for building the dynamometer followed by the experimental setup and operating procedure. The primary reason for building this engine dynamometer was to enable engine performance to be quantified, and comparison of the effects of engine modification. A dynamometer is simply a device for measuring the torque and speed of an engine. It can be made to measure other parameters based on the requirements. In general, dynamometers are broadly classified into absorption and transmission type. The former absorbs power produced by the engine while the latter transmits power through to other power consuming machinery. The most common type of dynamometer is the transmission type, which is primarily used where the engine is to be tested under natural working conditions like an airplane or in an automobile.

\subsection{Rationale for dynamometer}

All the data for the study are obtained through the manufacturer. Mostly, different manufacturers use different techniques or instruments to obtain these data, creating differences in the value measure is one reason, or the person providing the specification from the manufacturers end is a non technical operator and due to technical 
misunderstanding false data could be provided. For e.g. instead of obtaining fuel consumption at peak hp, fuel consumption at partial throttle or at cruising power could be provided. This puts the efficiency calculation way off. Sometimes, they collect the engine data at optimum conditions and report that for marketing benefits or to gain an edge over competitors. Obviously, this is not conducive to our study since these specifications are false under normal operating conditions.

A means of quantifying these data, or in other words, testing the engine at normal conditions and obtaining the data for ourselves is necessary. One way to quantify is to measure all the required quantities with the help of a dynamometer.

The dynamometer built for this study, measures torque, fuel flow, and engine speed (RPM), temperature at cylinder head and exhaust. This enables us to calculate efficiency, HP, Break Specific Fuel Consumption (BSFC) and SPED. Efficiency, HP can be calculated as explained previously. For a reciprocating engine, BSFC is just a measure of the fuel efficiency. It is the rate of fuel consumption over the power produced by the engine or any propulsion system. It facilitates easy comparison of different engines.

$$
\begin{gathered}
B S F C=\frac{\text { Fuelrate }}{\text { Power }} \\
\text { SPED }=\frac{1}{B S F C}
\end{gathered}
$$

The data acquired are made accurate by accounting for uncertainty in the calculations. The dynamometer is built to facilitate testing of engines with a maximum output of 50HP. One of the main features of its design is how heavy duty and rigid it was built. It is built out of 3in. square tubing with $0.25 \mathrm{in}$. wall thickness. This makes sure that our data is not influenced by structural integrity failure. The stiction factor is pretty low 
and is strong enough to handle the thrust the engine provides. The engine and exhaust components are all mounted to the centre rotating shaft, preventing contamination of the torque as the shaft rotates.

Keeping safety in mind, a heavy duty wind shield was installed to prevent airflow from the exhaust reaching the display devices and viewing area. Also, there is a kill switch hard wired into the circuit to prevent unexpected starts and to kill the engine power whenever necessary.

\subsection{Measurements and instrumentation}

The dynamometer was primarily designed to test output HP and efficiency. In order to calculate these parameters torque, RPM and fuel flow have to be measured. Throttle and fuel air mixture can be controlled remotely through a servo. A kill switch is provided to cut the power to the spark head, whenever an emergency stop is required.

\subsubsection{Torque}

Torque is a form of force, which tends to rotate an object about an axis. In order to measure the torque dissipated from the engine, an $\mathrm{S}$ type tension load cell with a maximum capacity of $250 \mathrm{lb}$ is used. The load cell is positioned at exactly 1 foot from the centre of the moment arm. This converts the output from the load cell into torque as torque is simply the force applied times the length of the moment arm. The load cell is hooked up to XK315A indicator, which displays the output torque produced by the engine.

\subsubsection{RPM}

The RPM is measured using a Remote Optical Modulated Sensor (ROMS) sold by monarch instruments. The ROMS is capable of detecting a reflected pulse from a 
target l consisting of T-5 reflective tape at a distance of 1-24 inches from the propeller. The sensor is hooked up to the side of the dynamometer close enough to get a reflected pulse from the propeller. The ROMS sends out a positive pulse voltage of 0 to $+5 \mathrm{~V}$ every time it picks up a pulse. The sensor has a operating range of 1-20000 RPM and requires 5.0-24 Vdc @ 50mA power supply.

The pulse output from the ROMS is picked up by the ACT-3 panel meters. It has several modes of operation, like RPM, frequency, rate of change, etc. In the RPM mode, the unit behaves like a tachometer displaying RPM from an input of 1 pulse per revolution. The instrument effectively multiplies the input frequency (pulse per second) by sixty to derive RPM. The unit is powered by $12 \mathrm{Vdc}$.

\subsubsection{Flow meter}

The fuel flow is measured using a rotameter. The one used in this application is a variable area meter; measures the flow rate of liquid through a closed tube. It doesn't require external power, just used the properties of a fluid together with gravity to measure fuel flow. The fuel line from the storage tank is connected to the lower end of the rotameter and the other end is connected to the fuel line of the engine. The rotameter should always be vertically oriented to get an accurate flow measurement. When there is fuel in the line, the float is pushed up by the pressure of the fluid and the gravity pulls the float down.

The float is usually made in sphere or ellipsoid shape. They rotate axially as the fluid pass. The float comes to a rest at the point where the pressure in the tube is compensated by the float's gravitational pull. The graduations on the tube allow us to make measurements. The rotameter used for our application is FL-113, has a capacity to 
measure flow rates of $3-300 \mathrm{cc} / \mathrm{min}$ of water and can handle pressure up to $75 \mathrm{psi}$. The unit is made out of borosilicate glass with a polycarbonate shield to for use in pressurized systems. The float is made up of stainless steel for a better flow range and has a $\pm 2 \%$ reading accuracy. This rotameter is used for a carburetor engine.

In order to test fuel injected engines a Pelton turbine wheel type flow meter was used. This is primarily due to the high pressure in the fuel line. This high pressure (around 45psig; achieved through a fuel pump) in the line causes rotameter tube to expand and affect the calibrations.

Within the flow meter, the fluid engages a rotor, causing it to rotate at an angular velocity proportional to the flow rate. This creates an AC voltage in the magnetic pickup mounted on the outside of the unit. As each turbine blade passes the base of the pickup coil, the total magnetic flux density is changed, thus inducing a single voltage pulse. The pulse rate generated becomes a very accurate measurement of flow rate.

The flow meter is hooked up to a rate meter/totalizer. The totalizer consumes $115 \mathrm{Vac}$ power and is compatible with TTL, magnetic pick up, CMOS type flow measuring devices for input. Both the flow meters are calibrated for discharge. In the case of rotameter a known amount of fuel is allowed to pass through the flow meter and the corresponding graduation on the tube is noted down. With this we can calculate the discharge and its corresponding graduation on the scale. Since the relation between discharge and the graduations on the scale are linear, few data points and their corresponding discharge, the flow meter could be calibrated. The same procedure is followed to calibrate the Pelton turbine wheel type flow meter. The calibration charts for the flow meter are included in the appendix. 


\subsubsection{Thermocouple}

Temperature at the cylinder head and exhaust are observed using the kapton insulated thermocouples. A 24 AWG gage K-type thermocouple is used and has a maximum service temperature of $600^{\circ} \mathrm{F}$. The end of the thermocouple is kept in contact wherever a measure of temperature is necessary, in our case at the cylinder head and exhaust and held in place with the help of bailing wires. The other end of the probe is connected to the back of the DP470 measurement indicator. It has a resolution of $0.1 / 1^{\circ}$. Six different temperature measurements can be observed simultaneously. The unit is powered by 115 Vac supply.

\subsubsection{Propeller}

The load for the engines is the propeller. A wide range of props are used to obtain different load settings. This enables us to get data points on the high and low ends of the power curve. The propellers used are, 24X10, 26X10, 28X12, 30X10, 30X12, 32X10 and $33 \times 10$.

\subsubsection{Control module}

Two different servos are used for throttle and fuel/air mixture control. Astro servo tester is used to control the servo remotely to adjust the throttle and mixture control. A Futaba S3002 servo is used to provide throttle control and a HS-785HB high torque winch servo provides mixture control. Since the servo for mixture control is in the same plane as the engine on the mounting plate, a $90^{\circ}$ turn of the control rods was necessary to actuate the mixture screw. A flexible screw driver is used to achieve this control. High torque servo is required to turn the linkage inside the screw driver. 
The servos and their controllers are powered by $12 \mathrm{Vdc}$ supply. A Black \& Decker Electro-mate 400 is used for this purpose. It provides AC/DC power when charged.

The power to the spark plugs on the engine is provided with the help of 6Vac $1800 \mathrm{~mA}$ adapter. A emergency stop switch is hardwired to the line to kill the power supply to the spark plugs in case an immediate shut down was necessary, improving the safety to the operator. A Micro Squirt Engine Control Unit (ECU) is used to sense different parameters and control fuel injection on the engine. It senses the intake manifold pressure, temperature RPM, spark timing and accordingly triggers the fuel injection. TBI is implemented here. The amount of fuel injected in to the throttle body can be controlled manually by looking at the volumetric efficiency map. A Mega tune software interface is used to pass commands on to the micro squirt. The Micro Squirt is powered by $12 \mathrm{Vdc}$ power supply and interfaces with the computer using s serial RS-232 cable.

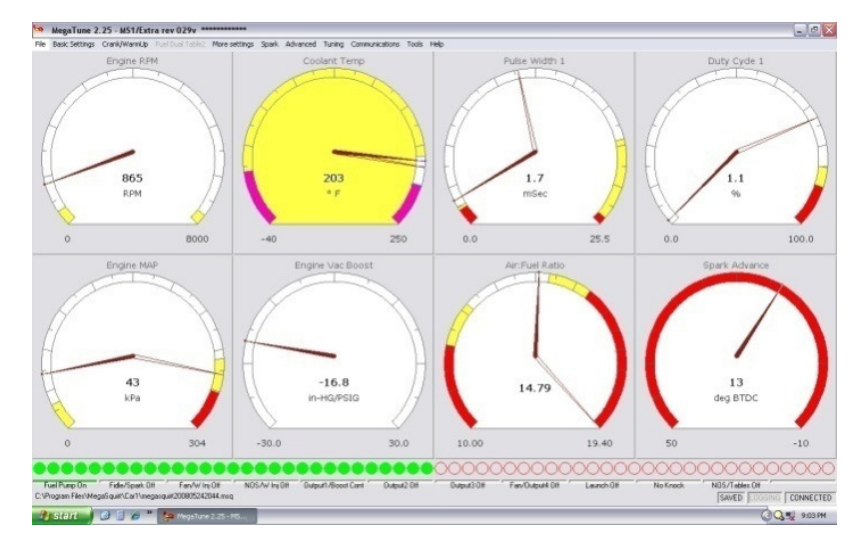

Figure 6.2.6.1 Control module of EFI system

\subsection{Construction}

The dynamometer test rig was made with the intention of being sturdy and portable. The frame is made out of 3.25in. square steel tubing. The steel tubes are purchased from Stillwater steels. A CAD model was prepared initially, followed by 
manufacture/assembly. Cross braces are added for extra supports and to prevent structural flexing due to load.

The central core of the dynamometer was built with cylindrical steel tubing of 5.725 in inner diameter. A low stiction deep groove bearing of 5.625 in outer diameter was used and press fitted on the cylindrical steel tubing, with a shaft running through the entire length of it. This shaft freely rotates about the axis of the cylindrical tube. The engine mounting plate is connected to one end and the moment arm to the other end of the shaft. The low stiction and smooth rotation of the shaft enables complete transfer of the torque created by the engine to the moment arm. Load cell is connected to the moment arm at a foot's distance from the centre of rotation to measure the toque generated by the engine.

Engine mount is made out of quarter inch thick steel plate and center bonded engine mounts are used to dampen out any vibration from the engine to reach the shaft. The detachable engine mount makes testing of various engines easy.

For safety purposes, Plexiglas is provided in-between the engine and the control board side. It also prevents the deposit of exhaust gases on to the control board. Metal slots are welded at the bottom of the frame; enables transportation of the dynamometer using forklifts, in case an outdoor experimentation is necessary. The figure shows the completed dynamometer with all the measurement probes and data acquisition in place. 


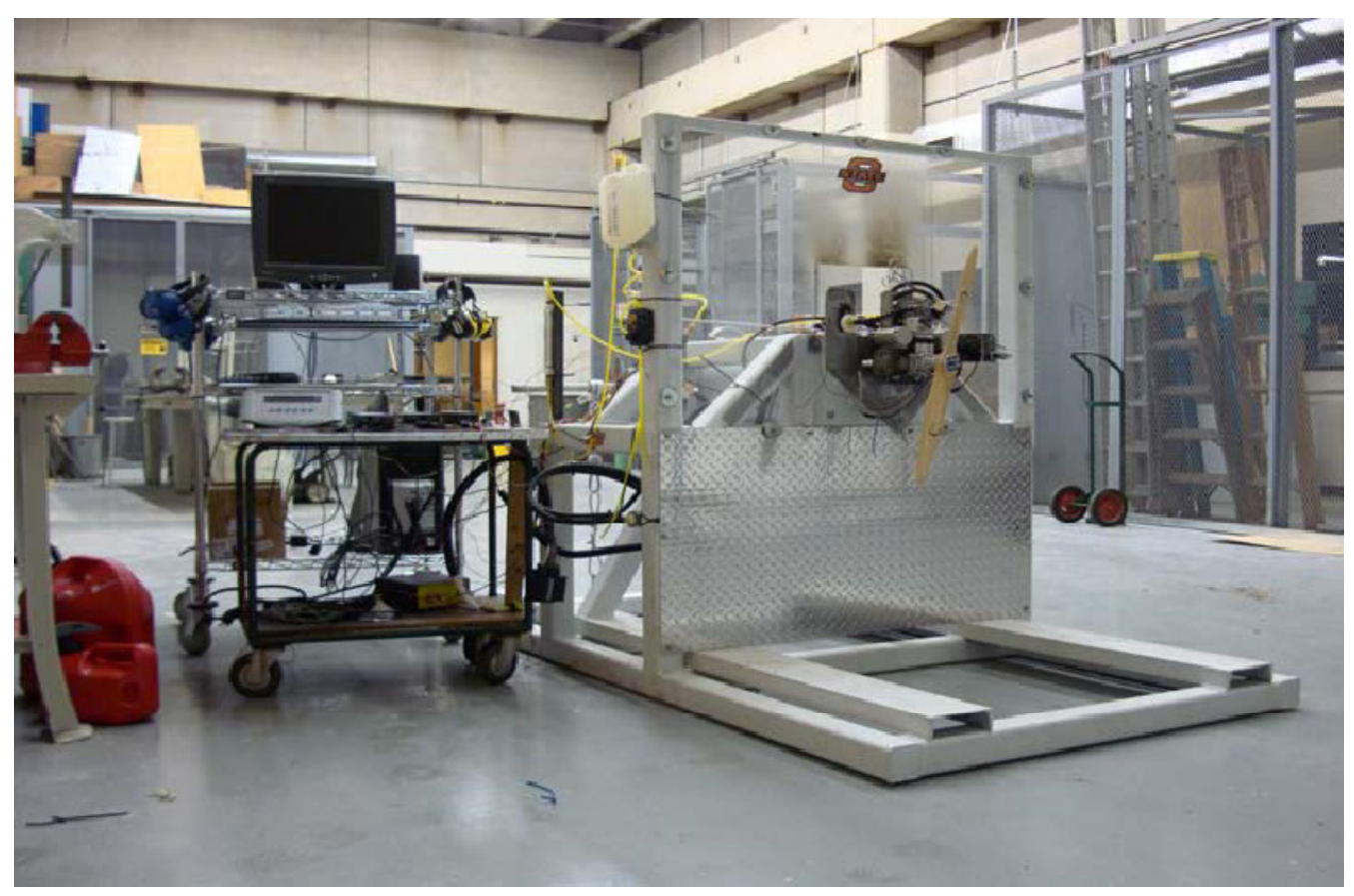

Figure 6.3.1 Dynamometer

\subsection{Dynamometer specification}

The dynamometer can be made to test any IC engine in the range of 5-30HP. The specifications of the measurement devices are listed below.

- Torque: $0-250 \mathrm{lb} / \mathrm{ft}$

- RPM: 1- 20000 Revolutions per minute

- Flow meter:

Rotameter: 3-300 CC/min.

Pelton turbine wheel type flow meter: $50-500 \mathrm{ml} / \mathrm{min}$.

- Temperature: 6 channel thermocouple with a service range of $0-600^{\circ} \mathrm{F}$.

- Power supply: $115 \mathrm{Vac}$ and $12 \mathrm{Vdc}$ supply.

\subsection{Operating procedure}

Before starting the engine, a routine check of all the wiring is done to make sure all the devices are powered and to eliminate any loose connections. It is made sure that 
there are no air bubbles in the fuel line and the line to both the flow meters. Any air bubble that is in the system has to be pumped out before starting the engine for two reasons; they provide inaccurate measurement of the fuel flow and secondly they reduce the performance of the engine. The propeller is turned manually, until the engine kicks in and starts. It could be started electronically, given the time and money restrictions, it was chosen to be done manually. Once the engine is running, fuel flow can be monitored from whichever flow meter that is hooked to the system and the RPM and torque can be read from the respective instruments. The engine performance is monitored by varying the flow level and throttle. It is achieved with the help of throttle and mixture control servos. At every different position, the engine is allowed to stabilize for a while before and readings are made.

\subsection{Two-Stroke FI system construction}

There were several challenges in making this 2-stroke engine work on EFI. To start with, making the housing for the fuel injector was difficult. It has to fit in-between the carburetor and throttle body. Making this part was tricky due to the relatively small size of parts and restriction of space on the engine. It was required that, both carburetor and fuel injector be assembled together, so that it could be easy to alternate between the two and obtain data.

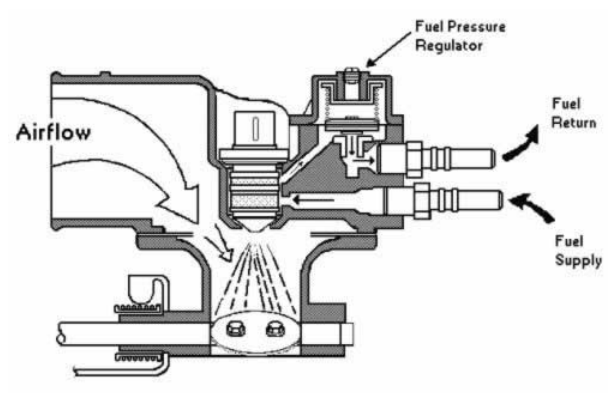

Figure 6.6.1 working procedure of 2-stroke FI system 
The figure 6.6.1 shows a TBI system. Also, getting accurate data from the sensors were tough. They were to be calibrated and accounted for uncertainty. Also, the sensor has to get ignition timing right and squirt the fuel into the throttle body accordingly. Input from the Hall Effect sensor of the ignition is fed into the ECU to get timing of the cycle.

For this study, Throttle body injection was incorporated on a 2-stroke engine and improvements were observed. The engine chosen for this operation was $116.3 \mathrm{cc} 2$ cylinder 2 stroke engine from BME. The engine displaces 12.0 HP and weighs 4.56lb. Two different data sets were collected, engine specs like HP, efficiency, fuel consumption before and after TBI. This facilitates easy comparison of both the data sets. The test data and conclusions are discussed in later sections.

TBI is a very versatile, and easy to maintain form of electronic controlled mechanical fuel injection. TBI has high speed response characteristics to constantly changing conditions and allows the engine to run with the leanest possible air/fuel mixture ratio, greatly reducing exhaust gas emissions. Because its air/fuel mixture is so precise, based upon much more than simple engine vacuum and other mechanical metering means, TBI naturally enjoys an increase in fuel economy over a simple mechanical form of fuel introduction such as an outdated carburetor. The TBI form of EFI is achieved with the help of Engine Control Unit (ECU) also known as Engine Command Module (ECM). In our application the ECM is the Micro Squirt (MS). It controls the TBI through all stages of operation according to data received regarding the current state of engine performance, speed and load. The main component of this assembly is the throttle body injector mounted on top of the intake manifold, much like a 
carburetor. The throttle body injector is composed of two different components, the throttle body, and the injector.

The throttle body is a large throttle valve, with a pair of linked butterfly hinged flapper valves, which are controlled by a simple mechanical linkage to the throttle controlled by the throttle servo. Depressing the servo controller will force the throttle valve to butterfly open further and further, increasing the flow of air through the throttle valve and instructing the ECM to add more fuel, thus producing more power, faster speed, and acceleration.

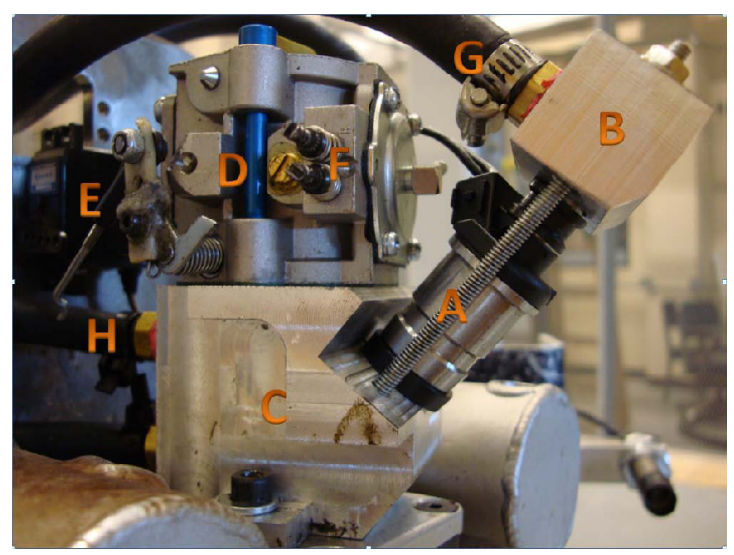

Figure 6.6.2 section of EFI made for BME 116

The picture shows the TBI assembly. It can be seen that the assembly is simply a spacer held between the carburetor and the throttle body. Different parts are identified from A through $\mathrm{H}$. they are,
A- Fuel injector
F- Mixture control
B- Injector bolt
G- Fuel line
C- Metal spacer
H- Pressure sensor
D- Carburetor
E- Throttle control 
A high pressure, fuel pump is used with the TBI system. This pump is located near the fuel tank. Fuel from the tank is vacuumed by the pump and sent through a Fuel Pressure Regulator (FPR) which dampens the pulsation and turbulence generated from the pump and gives out smooth flow of fuel with a pressure of $45 \mathrm{psi}$.

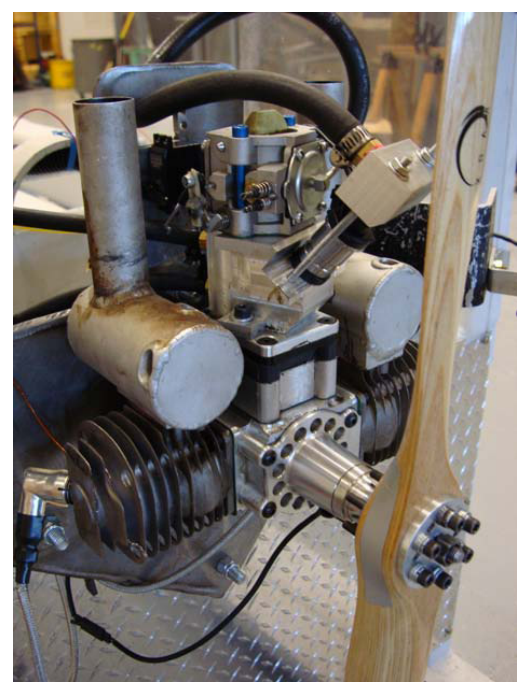

Figure 6.6.3 BME 116 with EFI

A safety relay in the system shuts the pump off after two seconds, to keep the fuel from flooding the engine. Figure shows the complete assembly of the TBI on the BME 116 engine. Proper care should be taken when working with EFI system. The fuel system is pressurized. If you remove a fuel line, you could/will get yourself drenched in fuel! The fuel pump used on the EFI system is much more powerful than that found on a carburetor installation. For this very reason, the second problem is that you cannot use the EFI fuel pump to feed a carburetor, and you cannot use a normal carburetor mechanical style fuel pump (low pressure) to feed the EFI system. In order to work on any part of the EFI system, you must first depressurize your fuel system! 


\section{CHAPTER VII}

\section{UNCERTAINTY ANALYSIS}

The sensors used to obtain data have different levels of accuracy, which corresponds to rise in uncertainty. There is a thin hairline difference between uncertainty and error. Error is the difference between the true value and measured value and is a fixed number and cannot be a statistical variable as uncertainty is, on the other hand uncertainty is the value that error might take on in a given measurement. While estimating uncertainty we usually deal with two types of uncertainty, precision uncertainty and bias uncertainty. The value and method behind calculating precision and bias uncertainty depends on the nature of experiment, for example a single sample experiment and repeat sample experiment. A sample here refers to an individual measurement of a specific quantity. Precision and bias uncertainty combined, gives the total uncertainty in our result for $\mathrm{x}$. If the bias uncertainty is $\mathrm{B}_{\mathrm{x}}$ and precision uncertainty is $\mathrm{P}_{\mathrm{x}}$, then the two may be combined in a root-mean-square sense as

$$
U_{x}=\sqrt{B_{x}^{2}+P_{x}^{2}}
$$

Care was taken during the design of the system to ensure that uncertainty remained a bare minimum while not being extravagant on expensive sensors in areas where they are not essential. Uncertainty rises from a single value to values that are 
formed by many measured values, and based on many calibrations which each have their own uncertainty, understanding how they build up is the key to designing hardware wisely and obtaining minimal uncertainty in all calculated parameters.

Suppose, we have an equation of the form,

$$
y=A \frac{x_{1}^{m} x_{2}^{n}}{x_{3}^{k}}
$$

and the uncertainties in $\mathrm{x}_{1}, \mathrm{x}_{2}$, and $\mathrm{x}_{3}$ are known with odds of $\mathrm{n}: 1$, then the uncertainty in $\mathrm{y}$ is given by

$$
\frac{u_{x}}{y}=\sqrt{\left(m \frac{u_{1}}{x_{1}}\right)^{2}+\left(n \frac{u_{2}}{x_{2}}\right)^{2}+\left(k \frac{u_{3}}{x_{3}}\right)^{2}}
$$

The following is a table of uncertainty values for load cell, RPM, rotameter and digital flow meter followed by calculations for uncertainty in HP, Efficiency ( $\eta$ ) and SPED.

\begin{tabular}{lll}
\hline Measuring device & $\begin{array}{l}\text { Bias uncertainty in \% } \\
\mathbf{B}_{\mathbf{X}} \mathbf{X}(95 \%)\end{array}$ & $\begin{array}{l}\text { Standard deviation in \% } \\
\sigma_{\mathrm{X}} \mathbf{X} \times\end{array}$ \\
\hline Load cell & 3.04 & 0.1 \\
RPM & 0 & 0.005 \\
Rotameter & 0.05 & 2 \\
Digital flow meter & 0.001 & 0.1 \\
\hline
\end{tabular}


The uncertainty from load cell, RPM, Rotameter and Digital flow meter propagates in to uncertainty in HP, Efficiency and SPED and the calculations for that are as follows.

Uncertainty in HP:

$$
P_{[H P]}=\frac{\operatorname{Torque}_{[L b-f t] \times R P M}}{5252}
$$

Similar to the very first equation shown in this section above, the HP equation can be segmented in terms of torque and RPM as we can see that they are the critical parameters governing HP. The uncertainty in HP can be split into uncertainty due to bias $\left(\mathrm{B}_{\mathrm{HP}}\right)$ and precision $\left(\mathrm{P}_{\mathrm{HP}}\right)$. Precision uncertainty in a single sample experiment is calculated by treating precision errors like bias error and estimating standard deviation based on the knowledge of the experiment. The uncertainty (at 19:1 odds) is twice the standard deviation of the test condition. To be precise, $\pm 1.96 \sigma \approx 2 \sigma$ will cover $95 \%$ of the readings made.

$$
\begin{gathered}
\frac{B_{H P}}{H P}=\left[\left(\frac{B_{\text {torque }}}{T}\right)^{2}+\left(\frac{B_{R P M}}{R P M}\right)^{2}\right]^{1 / 2}=3.04 \% \\
\frac{\sigma_{H P}}{H P}=\left[\left(\frac{\sigma_{\text {torque }}}{T}\right)^{2}+\left(\frac{\sigma_{R P M}}{R P M}\right)^{2}\right]^{1 / 2}=0.10 \% \\
\frac{P_{H P}}{H P}=\frac{1.96 \sigma_{H P}}{H P}=0.19 \% \\
\frac{u_{H P}}{H P}=\left[\left(\frac{B_{H P}}{H P}\right)^{2}+\left(\frac{P_{H P}}{H P}\right)^{2}\right]^{1 / 2}=3.04 \%
\end{gathered}
$$


The total uncertainty in HP given by precision and bias is around 3.04\%. In a similar fashion propagation of uncertainty in Efficiency and SPED are found by breaking down their fundamental equation as shown in the equation before and found to be $4.96 \%$. Inspection reveals that Torque has the greatest contribution to uncertainty. Improving the range of the load cell will greatly reduce the uncertainties in measurement. Also we can say that most of the uncertainty in load cell arises from bias uncertainty, which could be fixed by installing a load cell with its full scale reading closer to the operating range. 


\section{CHAPTER VIII}

\section{RESULTS \& DISCUSSION}

A comprehensive database of all the commercially off the shelf propulsion systems in the market that are available today were collected and recorded. Manufacturers were contacted personally and information like output HP at peak rpm, fuel consumption, engine class, fuel grade etc was put-together. The main target range of power was 5-30HP, although all propulsion system in the range of 5-100HP was recorded in order to identify trends.

The survey has information on a total of 71 different propulsion systems, 332 strokes, 15 4-strokes, 12 electric, 5 Wankel, 6 turbines respectively. From the information that was obtained, specifications like Output power, Efficiency and SPED were calculated.

In-order to verify the genuineness of the data collected, a dynamometer was built to measure torque, RPM and fuel flow. The frame of the dynamometer was built out 3in steel square rods. The central core of the dynamometer is a cylindrical shaft of 7 in diameter. The shaft is held in place with the help of a low stiction bearing. The dynamometer gives out torque, RPM, fuel flow, temperature at cylinder head and exhaust. 
Three different engines were tested on the dynamometer. A BME 1502 stroke 2 cylinder gasoline engine that has a displacement of $149 \mathrm{cc}$, a BME 116 Xtreme 2 stroke 2 cylinder gasoline engine with a displacement of $116 \mathrm{cc}$ and a modified TBI BME 116 engine. The choices of the engine were based on the following criterion, a) they fit the Tiger-Shark class UAV range in their power output and weight also, b) knowledge gained from the survey, c) BME was a part of the team that was put-together for this project.

Test results from the 3 engines are tabulated in this section. Plots of RPM vs. HP, RPM vs. SPED, RPM vs. Efficiency shows the variation in the parameters based on change in RPM. Plots of HP vs. SPED and HP vs. Efficiency gives the picture on the maximum efficiency and SPED values achieved for that HP. Plot of Fuel flow rate vs. HP shows the performance curve of the engine, gives an insight on how the performance increases to an extent as the output increases and tends to drop beyond a certain point, which is considered as the peak performance point for that particular engine. 


\subsection{Engine Data:}

\subsubsection{BME 150 LT 2-Stroke Carburetor Gasoline engine}

\section{Manufacturer's data:}

- Displacement: $149 \mathrm{cc}$

- Horse power: 16.5

- Propeller range: 2 blade 30x10, 3 blade $27 \times 12$

- Weight: $6.25 \mathrm{lb}$

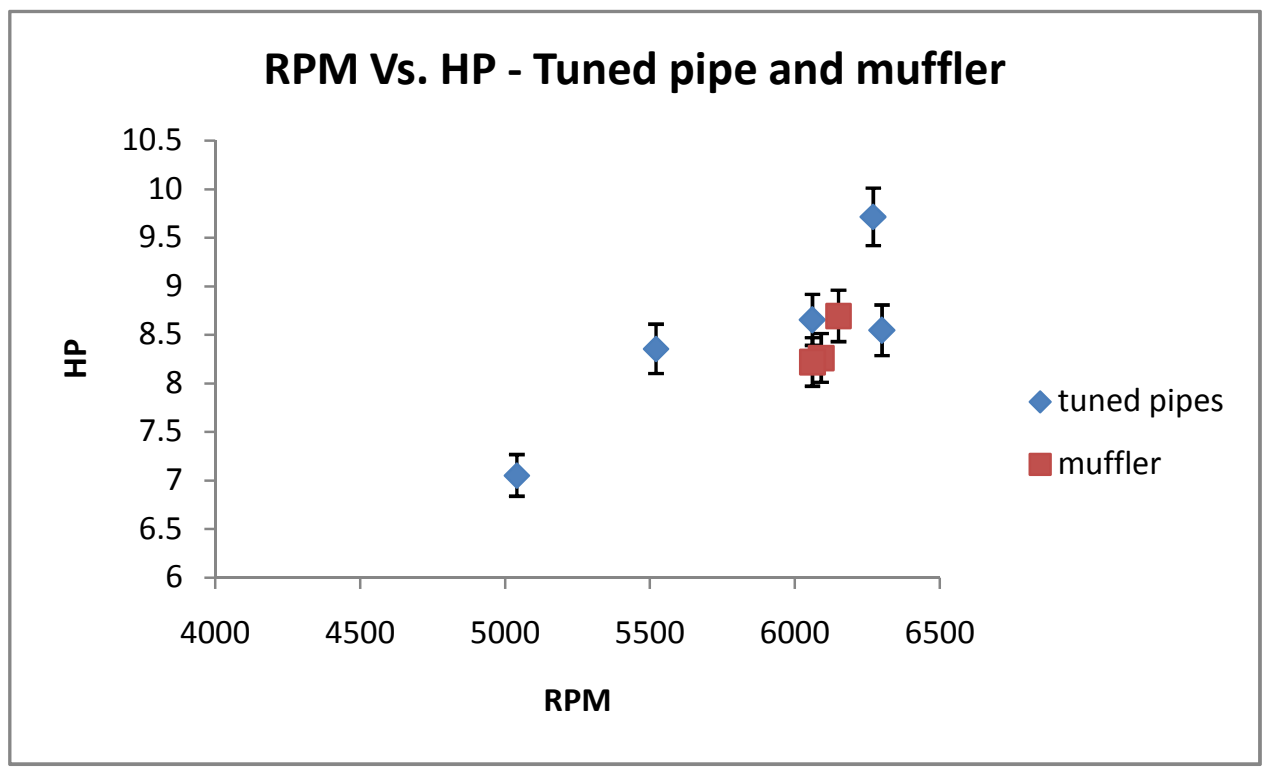

Figure 8.1.1.1 Plot of RPM vs. HP 


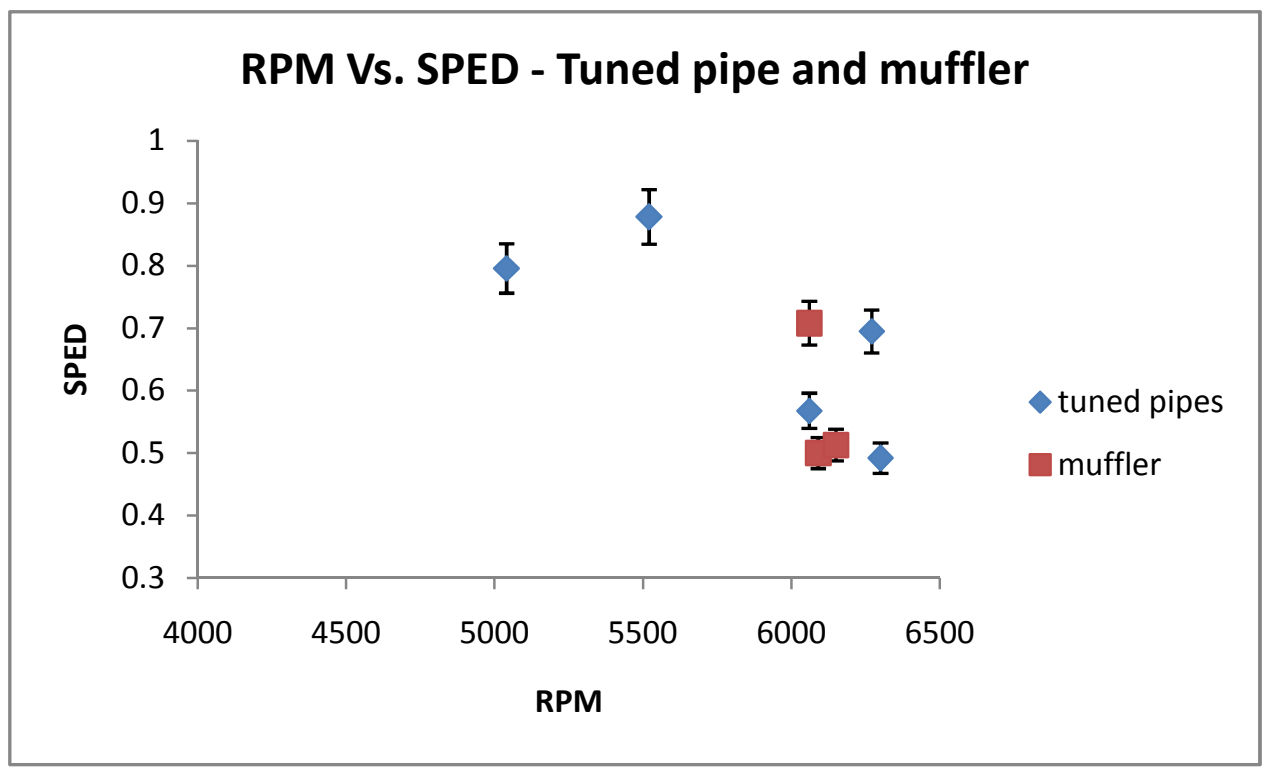

Figure 8.1.1.2 Plot of RPM vs. SPED

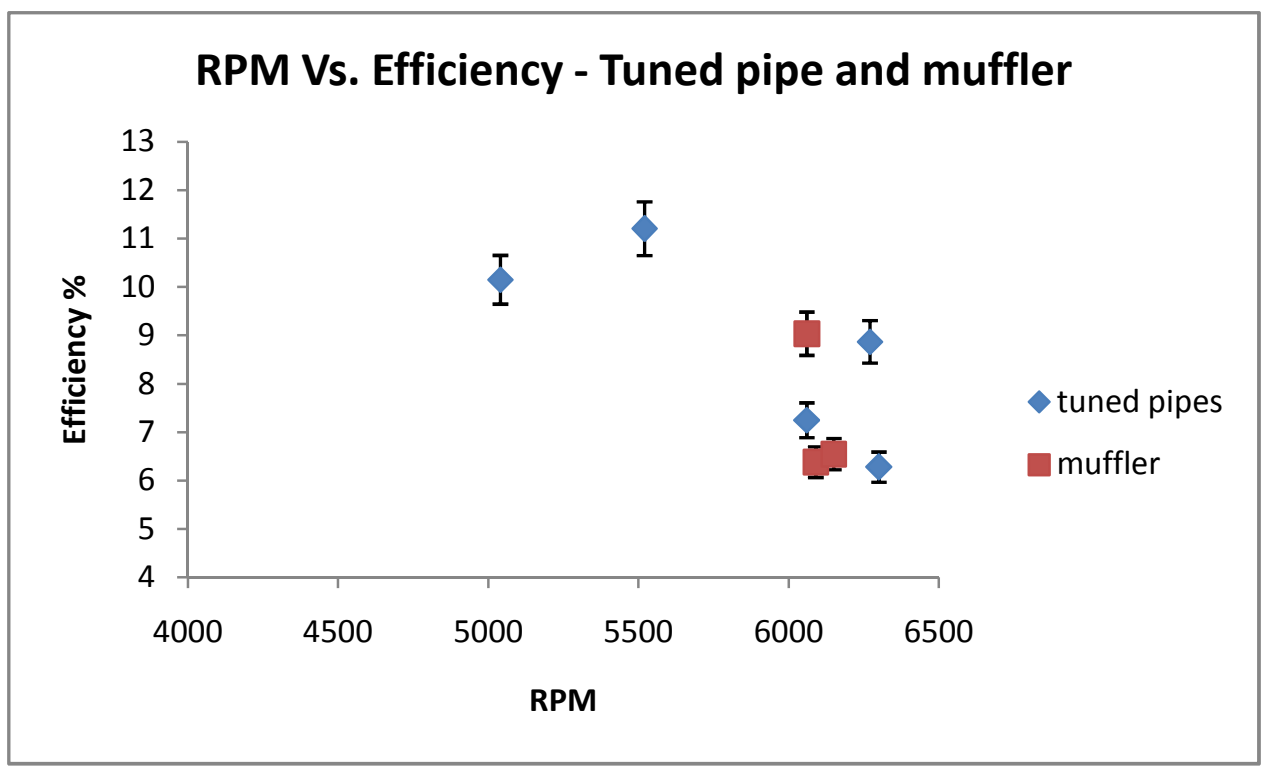

Figure 8.1.1.3 Plot of RPM vs. Efficiency 


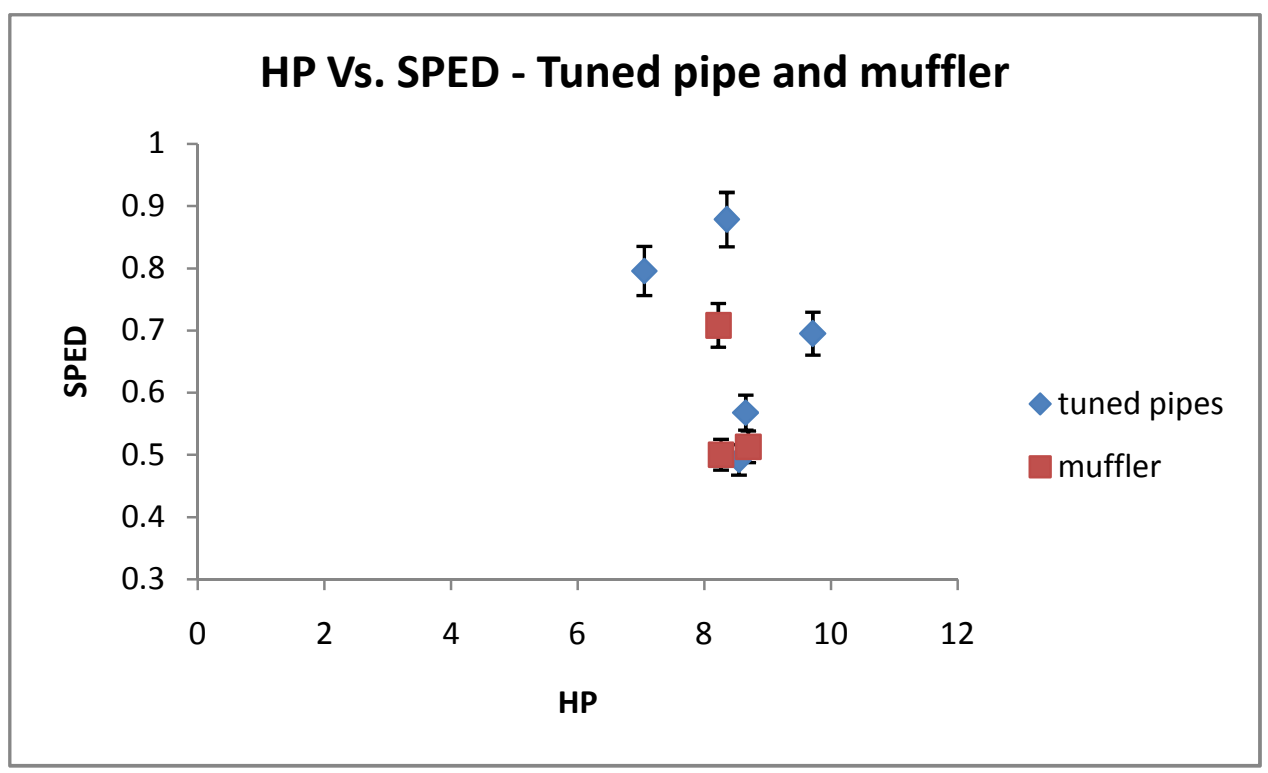

Figure 8.1.1.4 Plot of HP vs. SPED

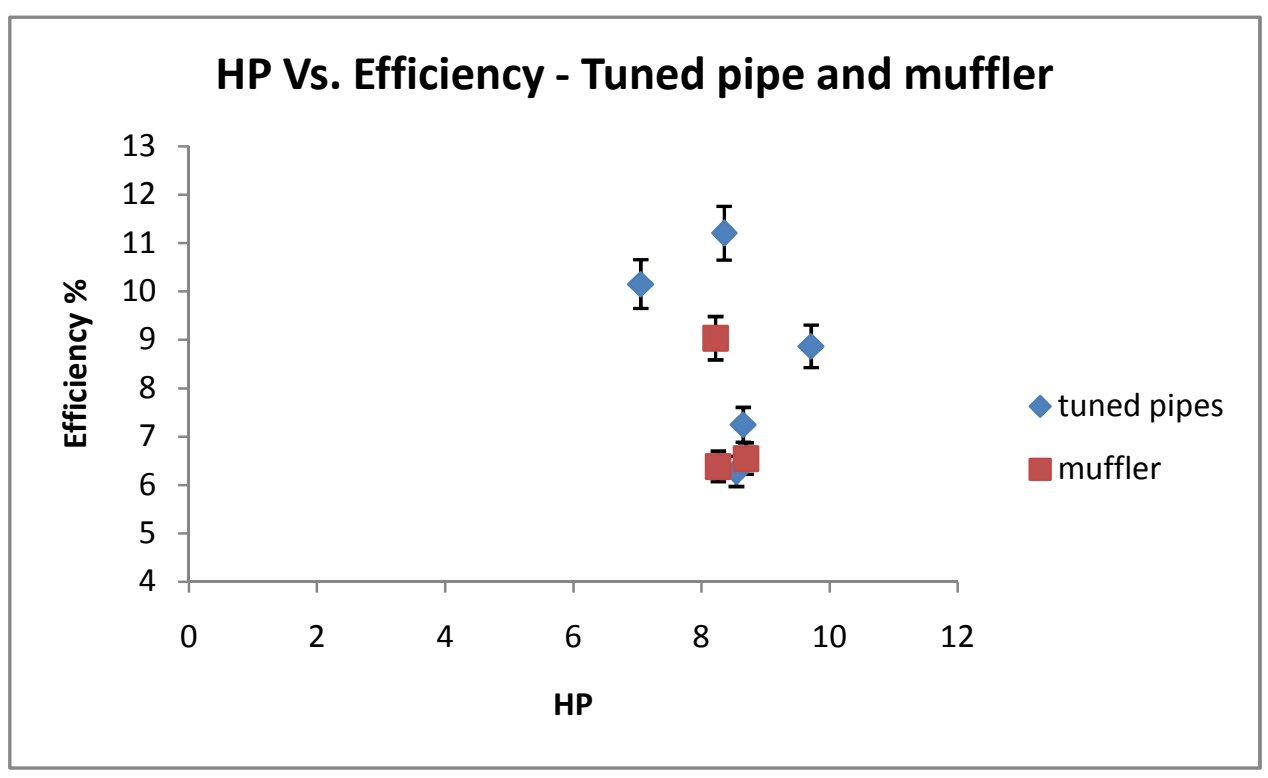

Figure 8.1.1.5 Plot of HP vs. Efficiency 


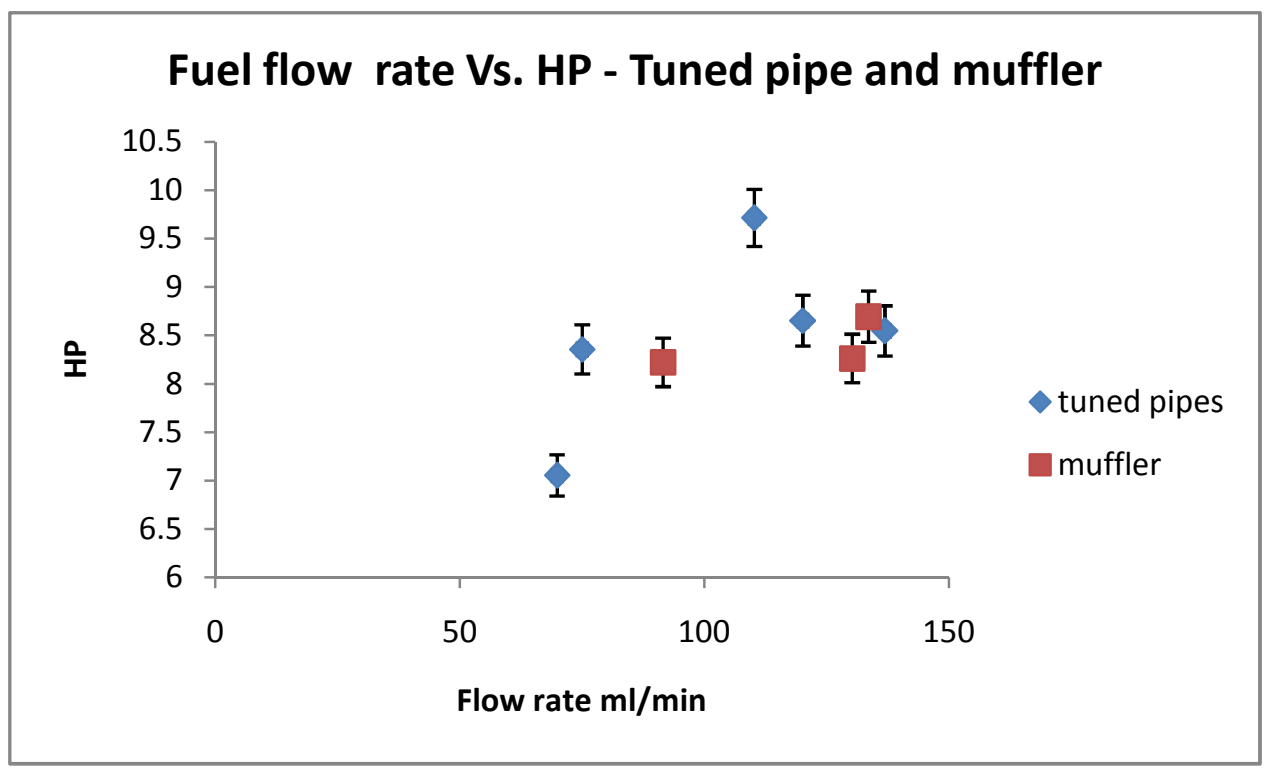

Figure 8.1.1.6 Plot of Fuel flow rate vs. HP

Inference

- Manufacturer's information suggests that at 6000RPM, an output power of $16.5 \mathrm{HP}$ can be observed with an efficiency of $28 \%$.

- With uncertainty accounted for, the maximum output power observed was 9.71HP, with an efficiency of $8.86 \%$ and SPED of 0.69 .

- It is of no surprise that tuned-pipes provide better efficiency and output as they better scavenging of the engine. The reason behind this being the flow characteristics of exhaust gases from the engine.

- The maximum efficiency observed was $11.2 \%$ with an output power of $8.35 \mathrm{HP}$ with tuned-pipes.

- These data were observed for different loads, the load being the propeller. The propellers used are 28x10, 28x12, 30x10, 30x12, and 32x10. 


\subsubsection{BME 116-Xtreme 2-Stroke Carburetor Gasoline engine}

\section{Manufacturer's data:}

- Displacement: $116.3 \mathrm{cc}$

- Horse power: 12.0

- Propeller range: 2 blade $28 \times 10,28 \times 12,29 \times 10,30 \times 8$

- Weight: $4.56 \mathrm{lb}$

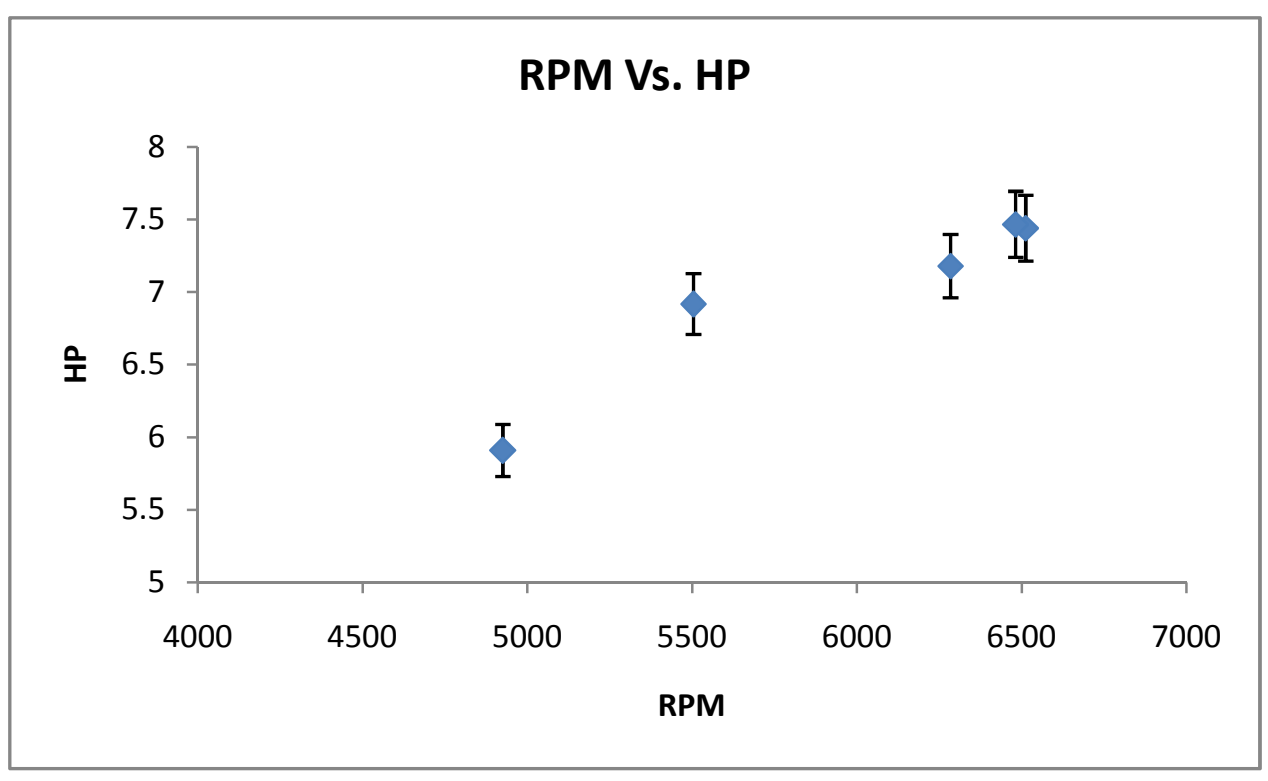

Figure 8.1.2.1 Plot of RPM vs. HP 


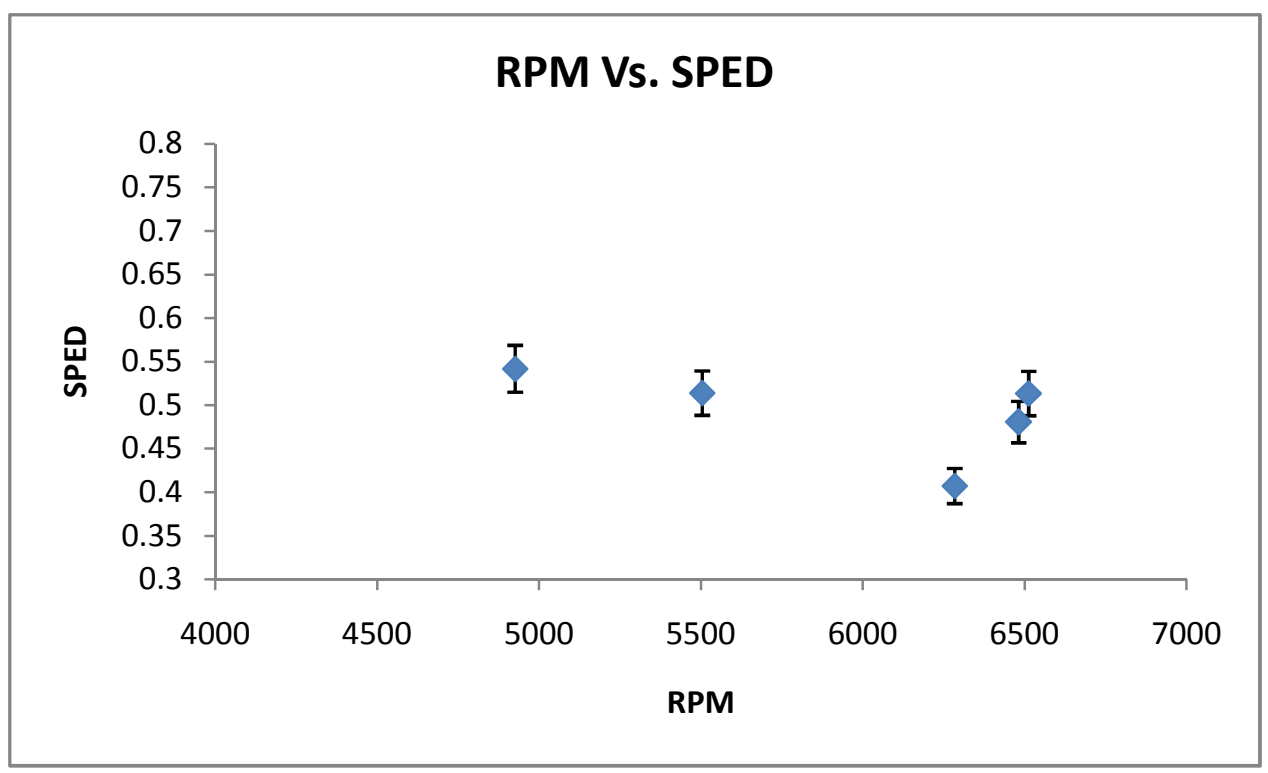

Figure 8.1.2.2 Plot of RPM vs. SPED

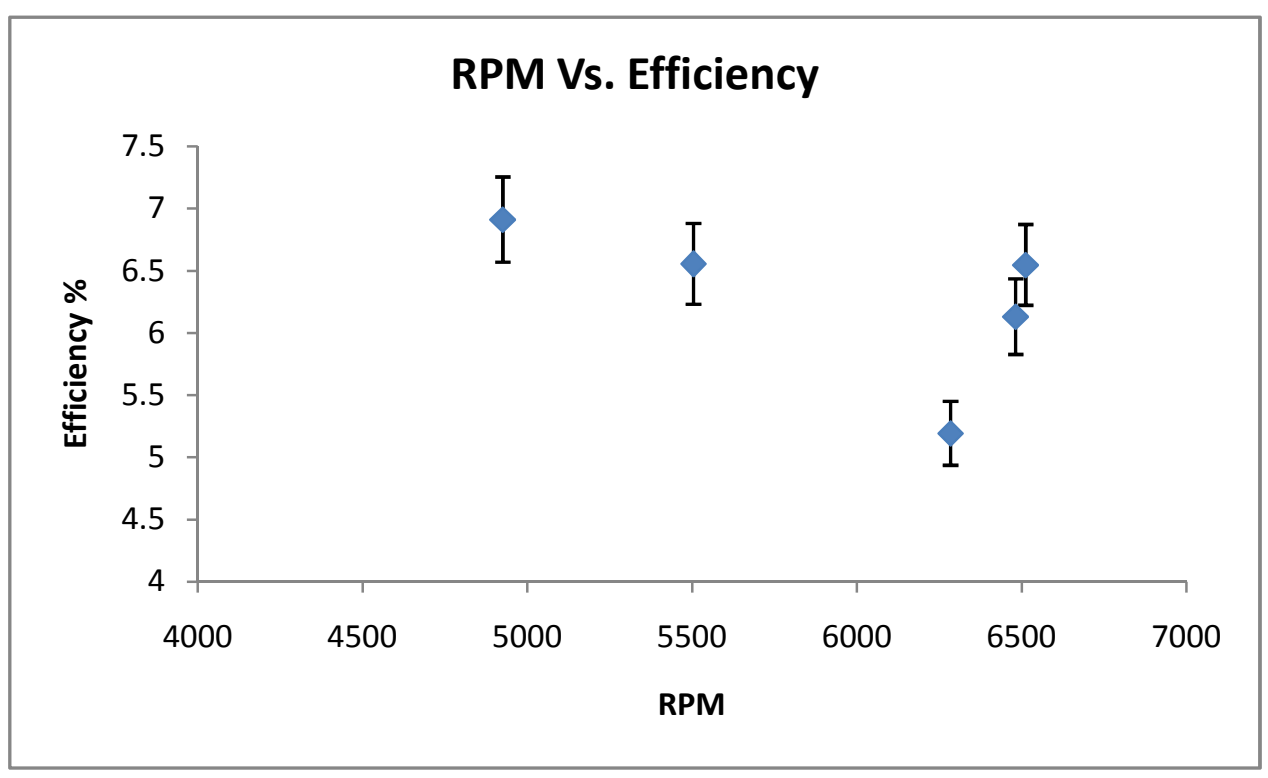

Figure 8.1.2.3 Plot of RPM vs. Efficiency 


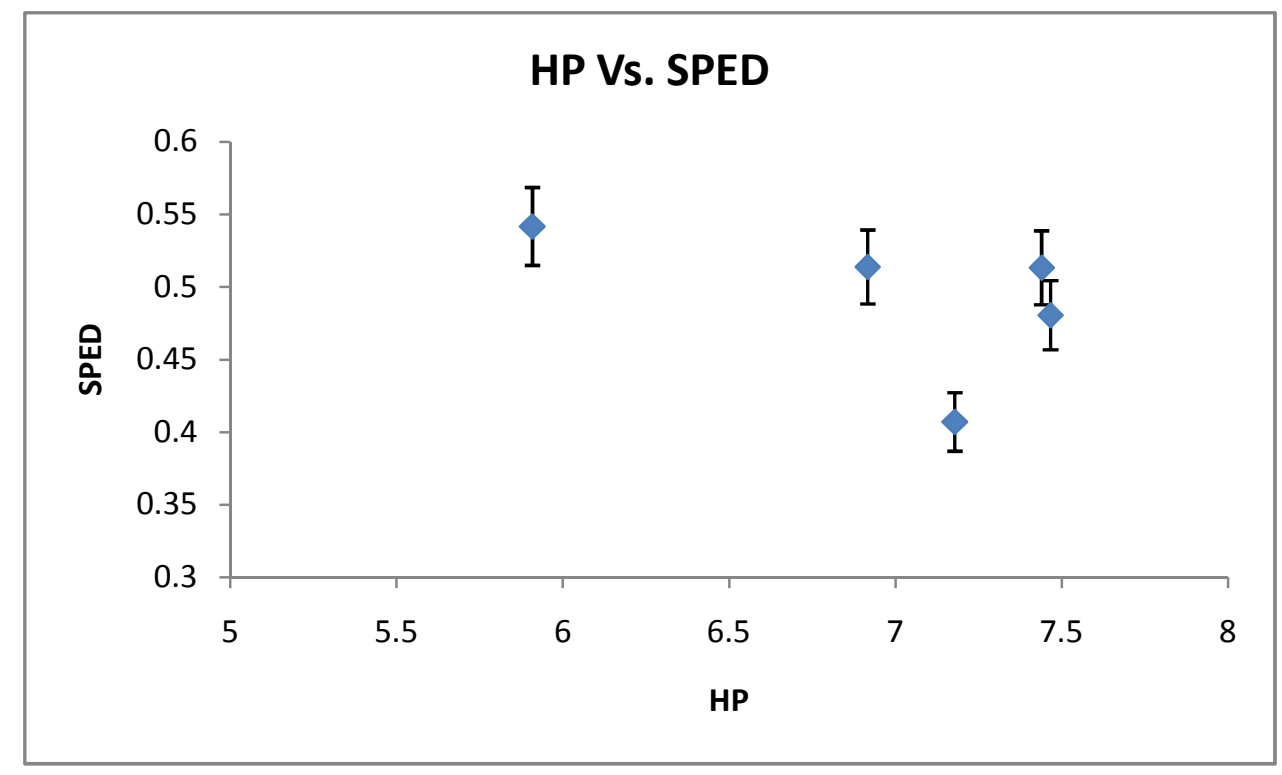

Figure 8.1.2.4 Plot of HP vs. SPED

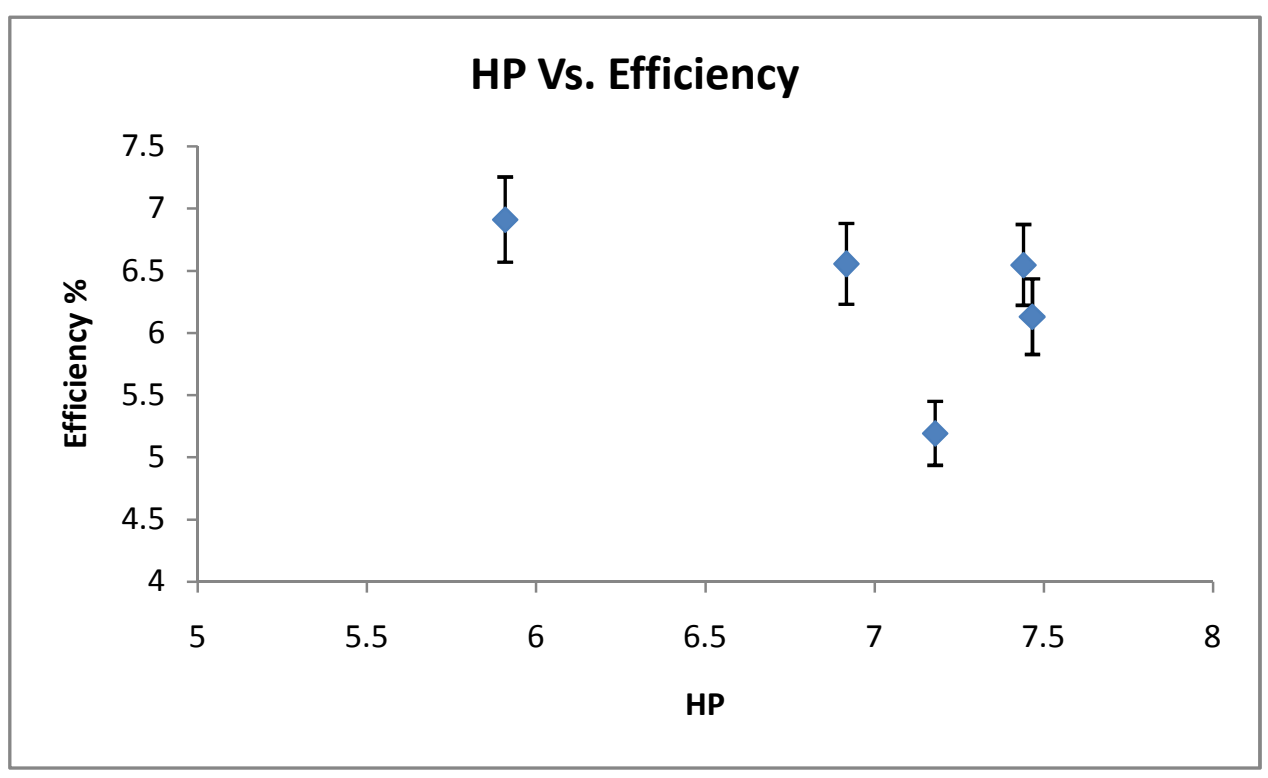

Figure 8.1.2.5 Plot of HP vs. Efficiency 


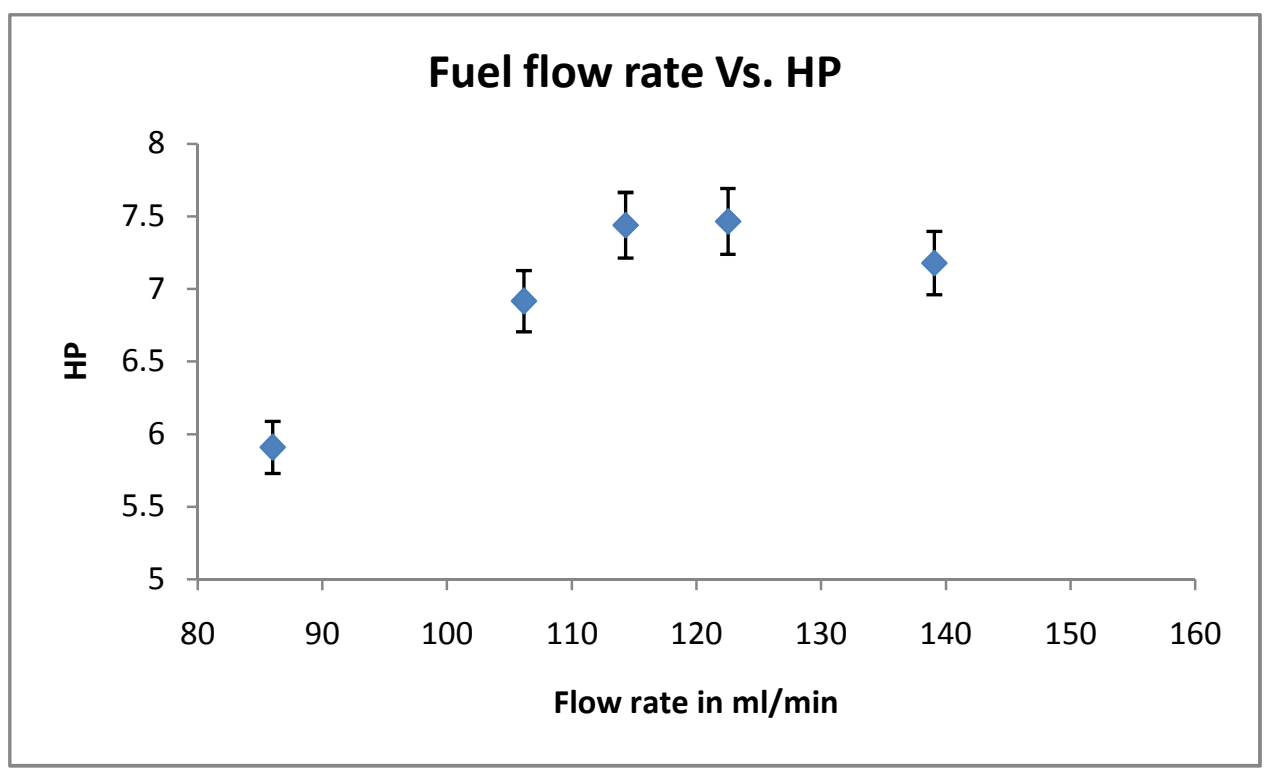

Figure 8.1.2.6 Plot of Fuel flow rate vs. HP

Inference

- According to manufacturer's data a maximum of $12 \mathrm{HP}$ with an efficiency of $21.3 \%$ can be achieved.

- With uncertainty accounted for, the maximum output power observed was $7.46 \mathrm{HP}$ with an efficiency of $6.13 \%$ and SPED of 0.48 for a $26 \times 10$ propeller

- The maximum efficiency observed was $6.91 \%$ with an output power of $5.9 \mathrm{HP} \&$ SPED of 0.54 for a $30 \times 12$ propeller.

- These data were observed for different loads, the load being the propeller. The propellers used are 26x10, 27x10, 28x10, 30x10 and 30x12. 


\subsubsection{BME 116 modified EFI gasoline engine}

The BME 116 Engine was retro-fitted with an EFI system and its performance was observed. The EFI was integrated into the engine in a way that would be easy to switch between carburetor and EFI and observe the performance characteristics. Two different data sets were collected, engine specs like HP, efficiency, fuel consumption before and after TBI. The results are tabulated below.

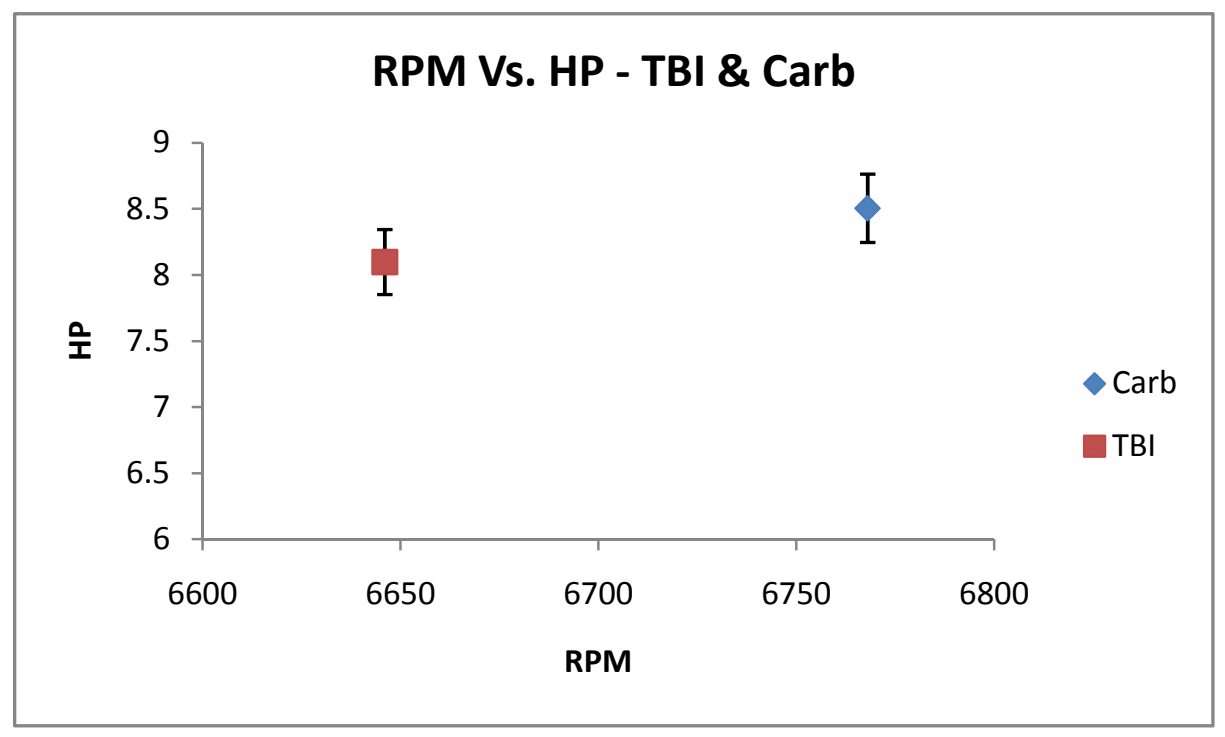

Figure 8.1.3.1 Plot of RPM vs. HP

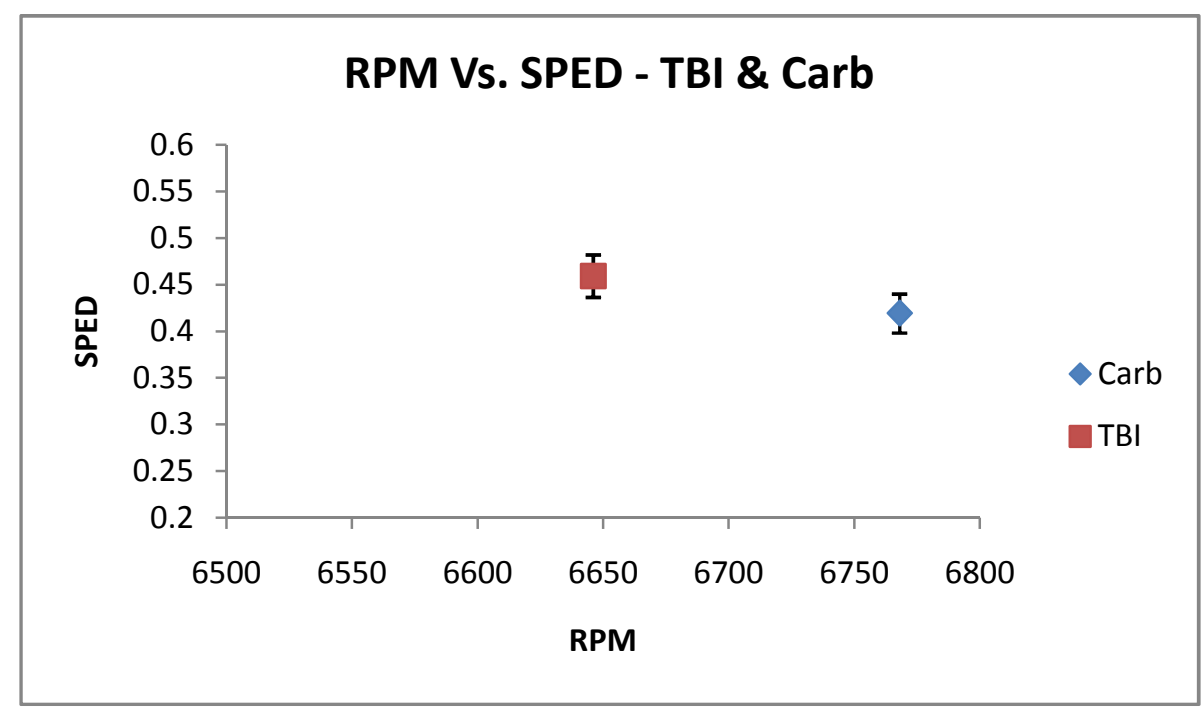

Figure 8.1.3.2 Plot of RPM vs. SPED 


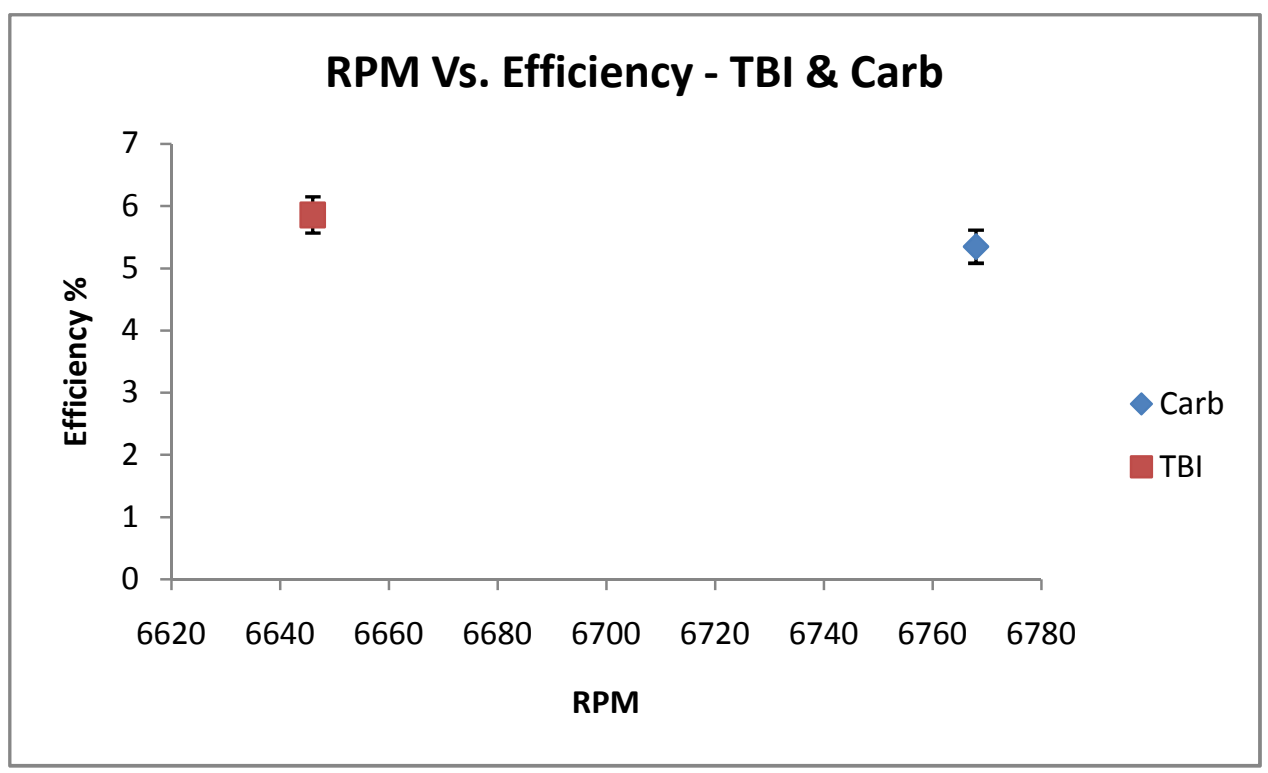

Figure 8.1.3.3 Plot of RPM vs. Efficiency

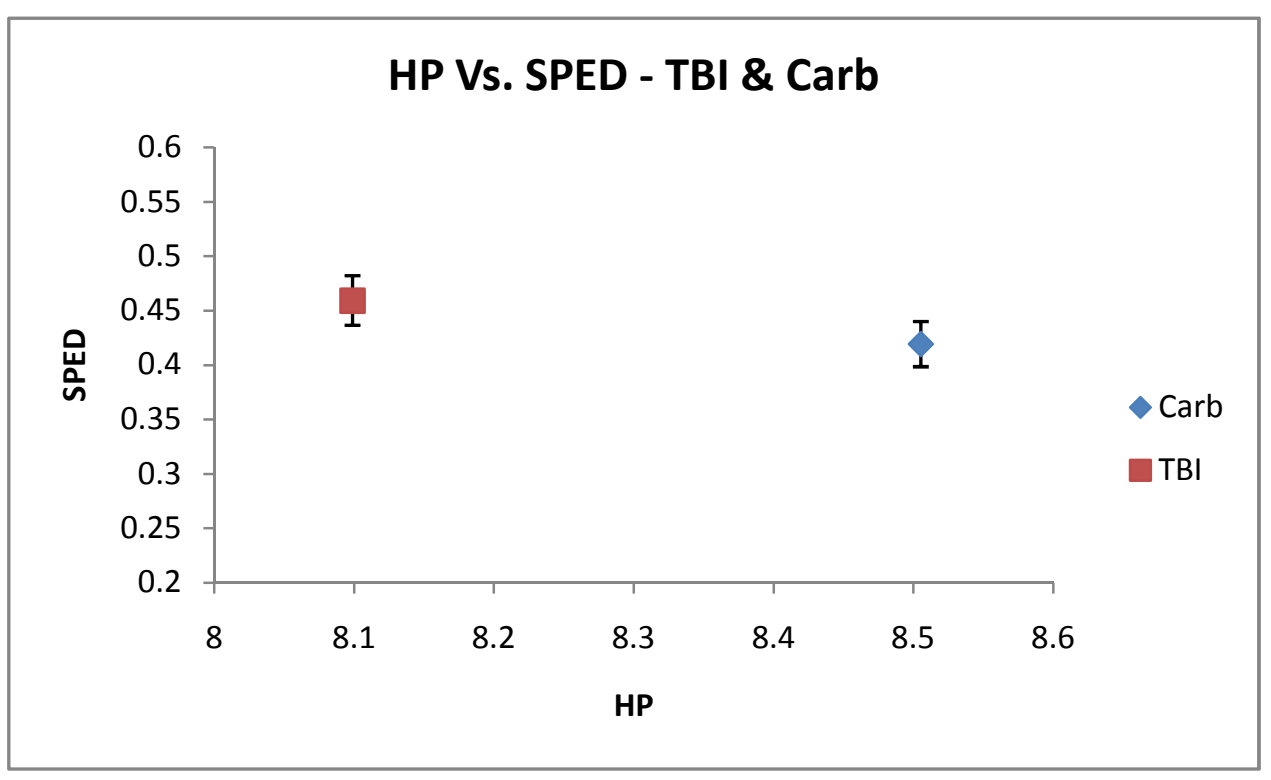

Figure 8.1.3.4 Plot of HP vs. SPED 


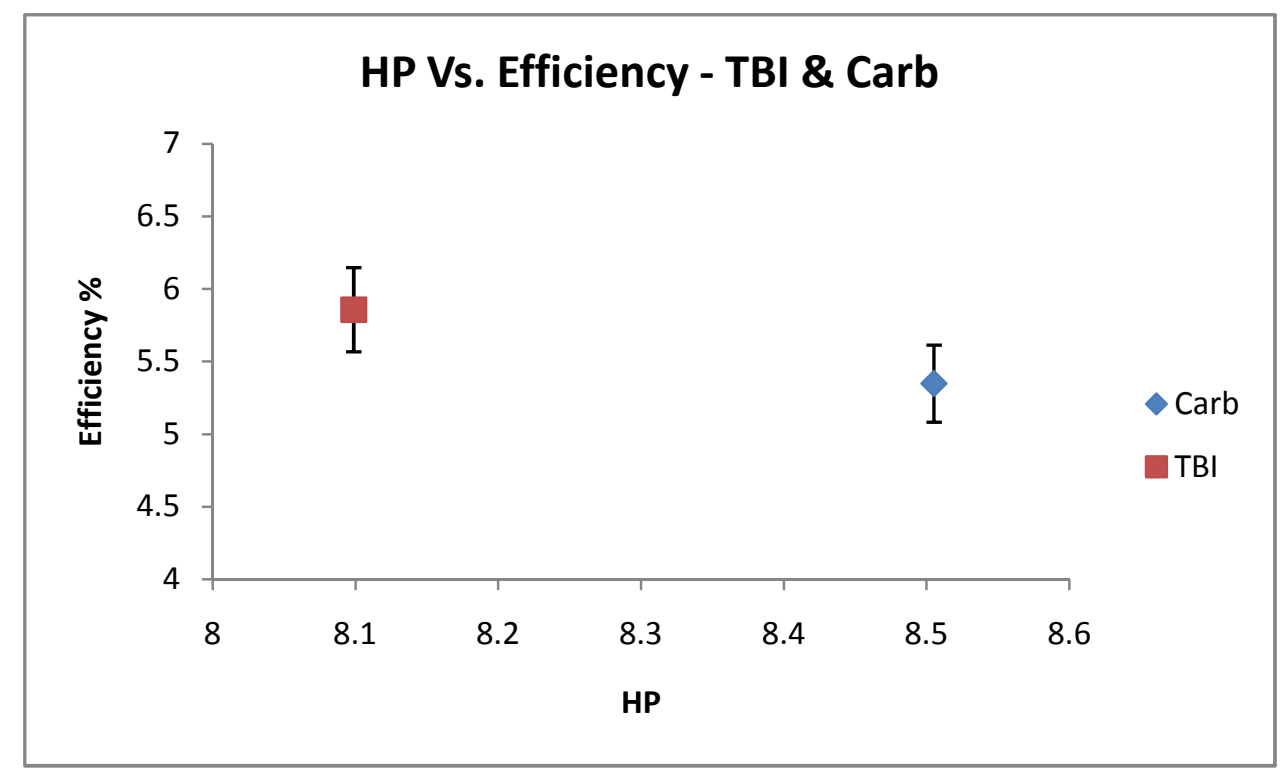

Figure 8.1.3.5 Plot of HP vs. Efficiency

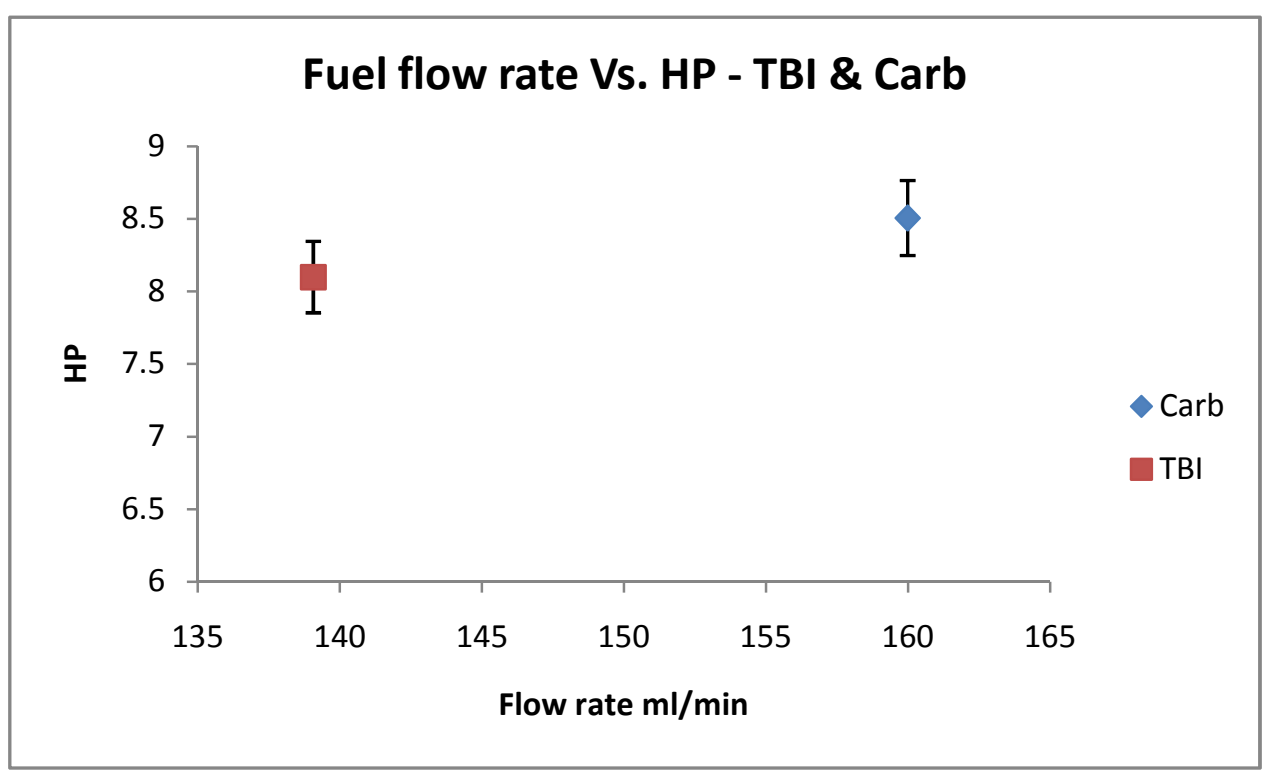

Figure 8.1.3.6 Plot of Fuel flow rate vs. HP 
Inference

- Both the data sets were observed with a 26x10 propeller

- No significant difference is observed in Efficiency, HP or SPED. This is due to the fact that, both the data sets were observed at the same pressure and temperature

- As long as the engine can be tweaked to its best performance of the carburetor, it is possible to duplicate the performance produced when running on EFI.

- A significant difference can be observed if a pressure difference is brought into the test conditions to validate the benefit of EFI.

- The fuel consumption is observed to be less on the TBI when compared to carburetor.

The manufacturer suggests that the BME 150-2 stroke 2 cylinder gasoline engine produces a maximum output of $16.5 \mathrm{HP}$ at $6000 \mathrm{RPM}$. This output power was estimated using, “Aero Design Propeller Selector" program. The program estimates output power and efficiency for a given engine based on RPM, propeller pitch and diameter. Similar method of estimation was used for BME 116-2 stroke 2 cylinder engine and its maximum output was $12 \mathrm{HP}$.

Theoretical max output power can be estimated based on bore size, stroke length, compression ratio, temperature and pressure at inlet manifold. The output power is calculated using the following expressions,

$$
\text { Power }=\frac{(B M E P) V_{d} N}{n}
$$


Here, $\mathrm{n}=1$ for 2 strokes, $\mathrm{N}$ is RPM and $\mathrm{V}_{\mathrm{d}}$ is displacement, 149 cc for BME150 and $116.3 \mathrm{cc}$ for $\mathrm{BME}$ 116. BMEP is calculated using compression ratio (6.60 for BME150 and 5.78 for BME116), bore and stroke length of 5.74 for BME 150 and 5.291 for BME 116, temperature and pressure at inlet. Using these expressions the theoretical output power for BME 150 and BME 116 was found to be 11.12 and $8.11 \mathrm{HP}$ respectively.

Results from dynamometer shows that the BME 150 and the BME 116 produces a maximum output of 9.71 and $7.46 \mathrm{HP}$ respectively. There is a difference of $12 \%$ and $8 \%$ between the theoretical and observed values for the BME 150 and 116 engines.

\begin{tabular}{|c|ccc|}
\hline Engine & Manu. claim & Theoretical & Observed \\
\hline BME 150 & 16.5 & 11.2 & 9.71 \\
BME 116 & 12 & 8.11 & 7.46 \\
\hline
\end{tabular}

\subsection{Payload vs. Range analysis}

Payload vs. Range plots were made for BME 150 and BME 116 engine, assuming both the engines were used on a Tiger shark class UAV. The parameters that were involved in the analysis include, Mach no, aspect ratio, e (span efficiency factor), $\mathrm{C}_{\mathrm{do}}, \mathrm{S}$ (plan form area), gross take-off weight (GTOW), empty weight (EW).

The above mentioned parameters are constant for a Tiger shark class UAV and the only variable parameter here is the BSFC. This is calculated individually for each 
engine and the payload vs. range plots was drawn. The values of the parameters that are assumed to be common are listed

$M=0.16$

$\mathrm{AR}=8.75$

$\mathrm{e}=0.92$

$\mathrm{C}_{\mathrm{do}}=0.0137$

$\mathrm{S}\left[\mathrm{ft}^{2}\right]=35$

GTOW $[\mathrm{lbs}]=300$

EW [lbs] 150

Max altitude $=5000 \mathrm{ft}$

For BME 150 with a BSFC of 1.56

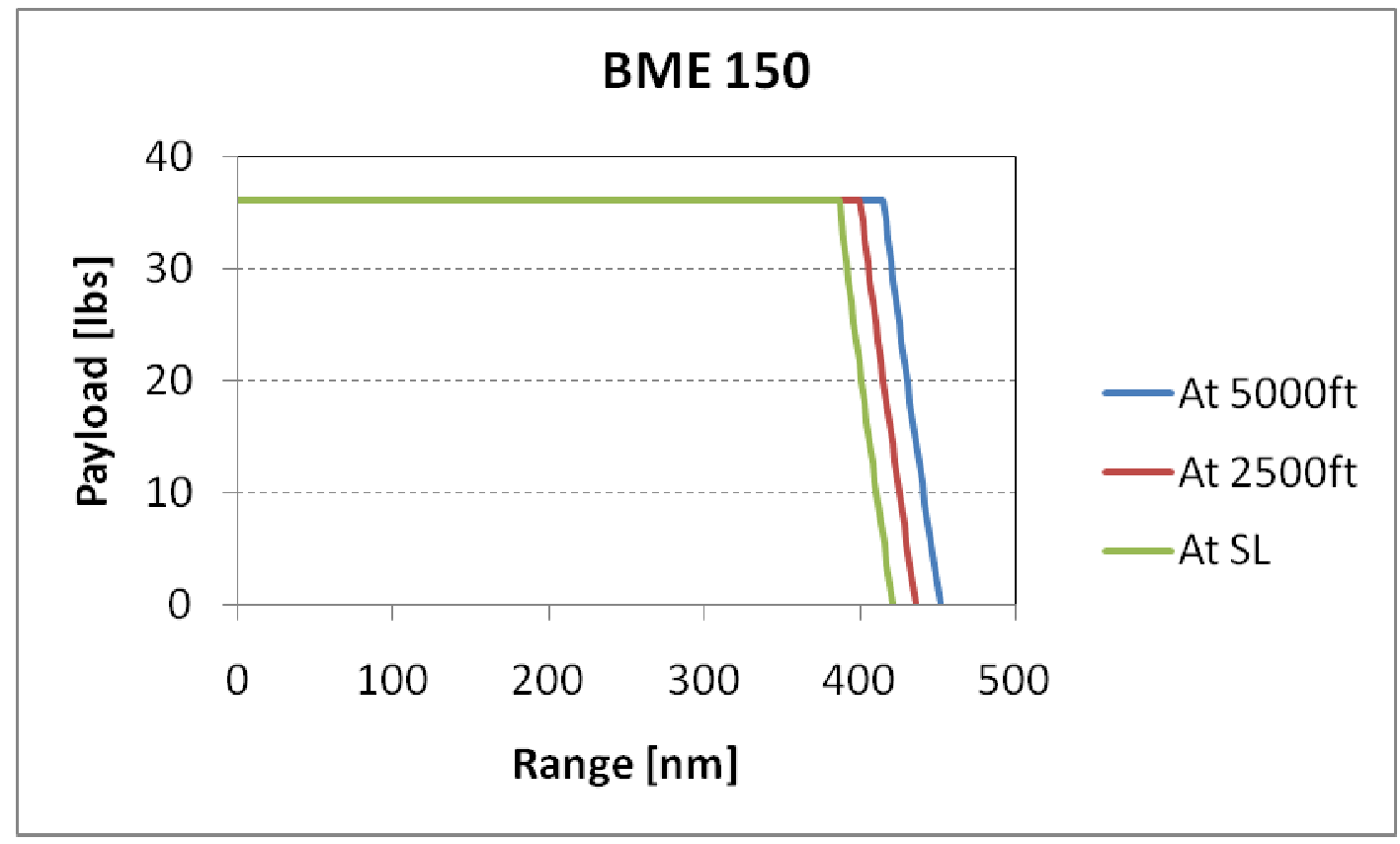

Figure 8.2.1 Plot of Payload vs. Range for BME 150 
For BME 116 with a BSFC of 1.94

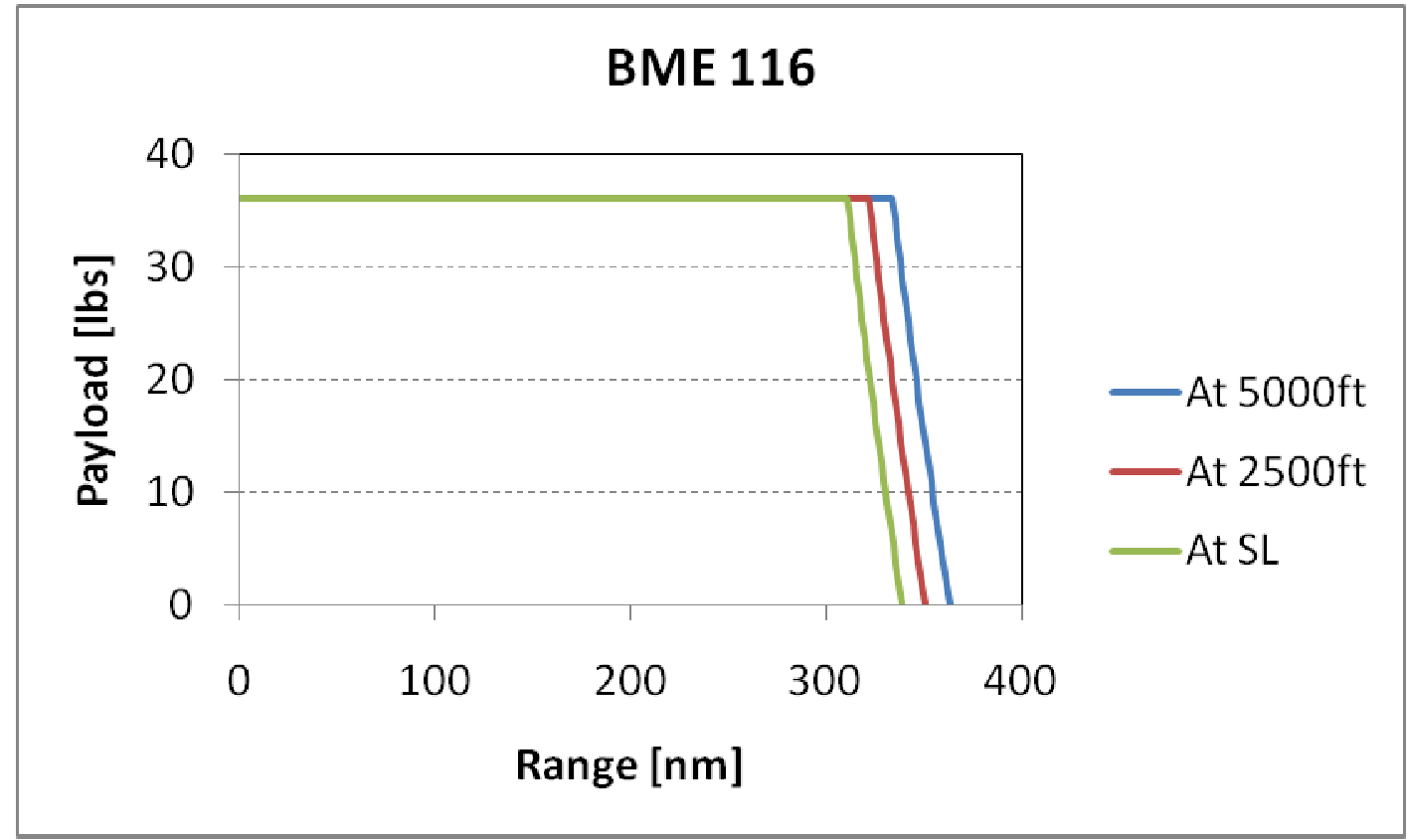

Figure 8.2.2 Plot of Payload vs. Range for BME 116

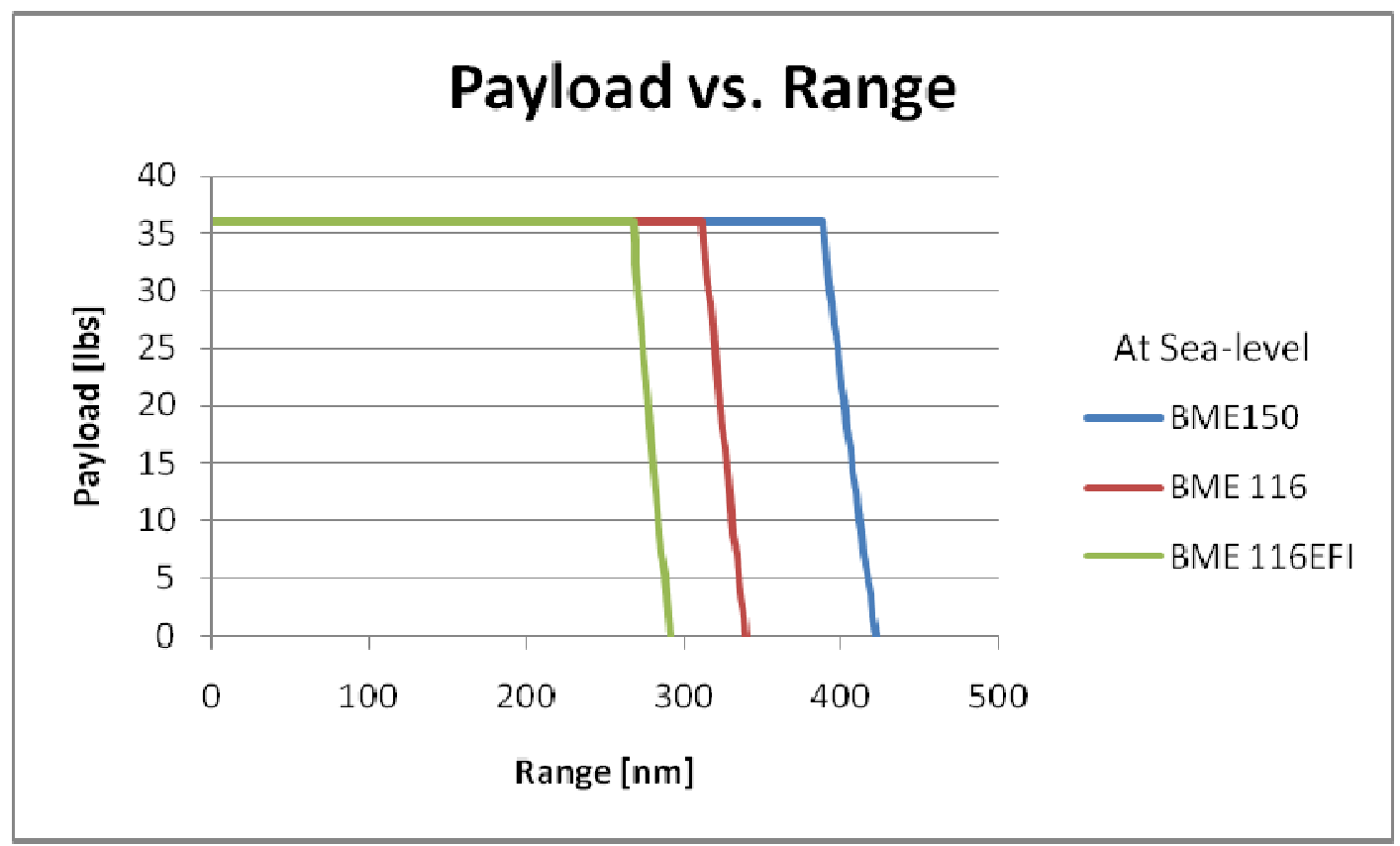

8.2.3 Plot of Payload vs. Range for BME150, 116 and 116TBI 
Range for the aircraft depends on Break Specific Fuel Consumption calculated using the dynamometer. It is directly affected by the amount of fuel consumed, the faster the fuel flows, the lower the range goes. Air densities at sea-level, 2500ft and 5000ft are used to determine the range and payload at every level.

The figure 8.2.3 compares all the three engines against each other. With BSFC of 1.56 the BME 150 clearly has better range characteristics than the BME 116 with a BSFC of 1.94 or the BME 116TBI with a BSFC of 2.26. This high value of BSFC for BME 116TBI can be accounted to very minimum test runs, with more runs, better engine mapping allows the micro-squirt to tweak the engine to its peak performance. Also, the test was run at atmospheric pressure and a significant difference could only be observed when the experiment was performed at altitudes or with a pressure difference. This result can also be supported from the output HP and efficiency numbers observed with the help of dynamometer. 


\section{CHAPTER IX}

\section{CONCLUSION}

A comprehensive list of all the propulsion system that was available in the market today is made available, this provides ground for selecting any class of engine within 5100HP range based on fuel required, output power, efficiency and SPED. The database

provides information on $\mathrm{P} / \mathrm{W}$ ratio, SPED, $\eta$ etc for every engine and classifies engine based on engine class, as a 2-stroke, 4-stroke, Wankel, also based on application, as an aircraft engine or a ground type. This type of classification opens up the application of this database to other major sectors including automobile industry.

Information like $\mathrm{HP}, \mathrm{SPED}, \mathrm{SFC}, \mathrm{P} / \mathrm{W}$ ratio and power-density of the engines from the database were put-together to compare and select the best propulsion system in the target power range. 


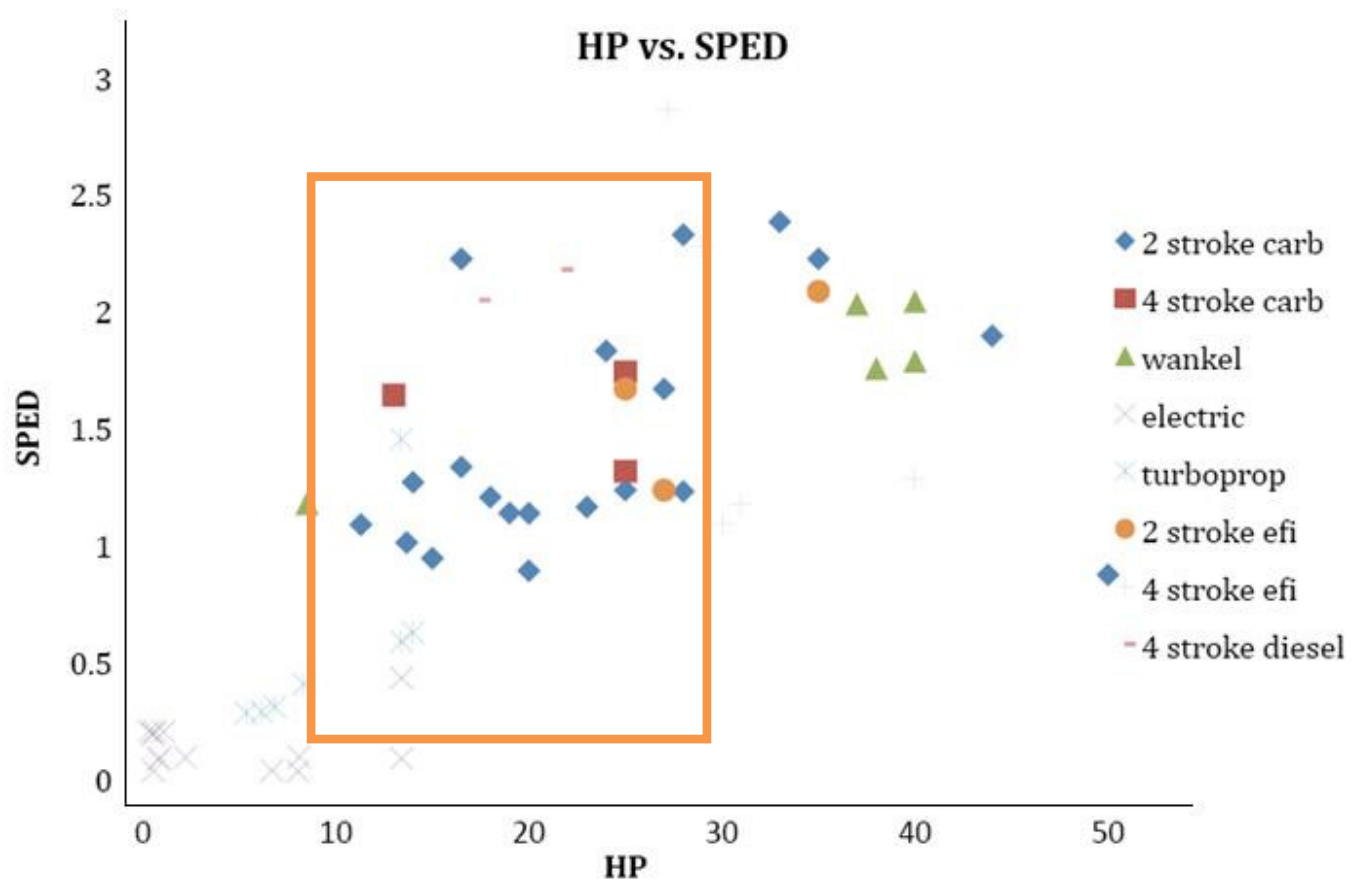

Figure 9.1 Plot of HP vs. SPED

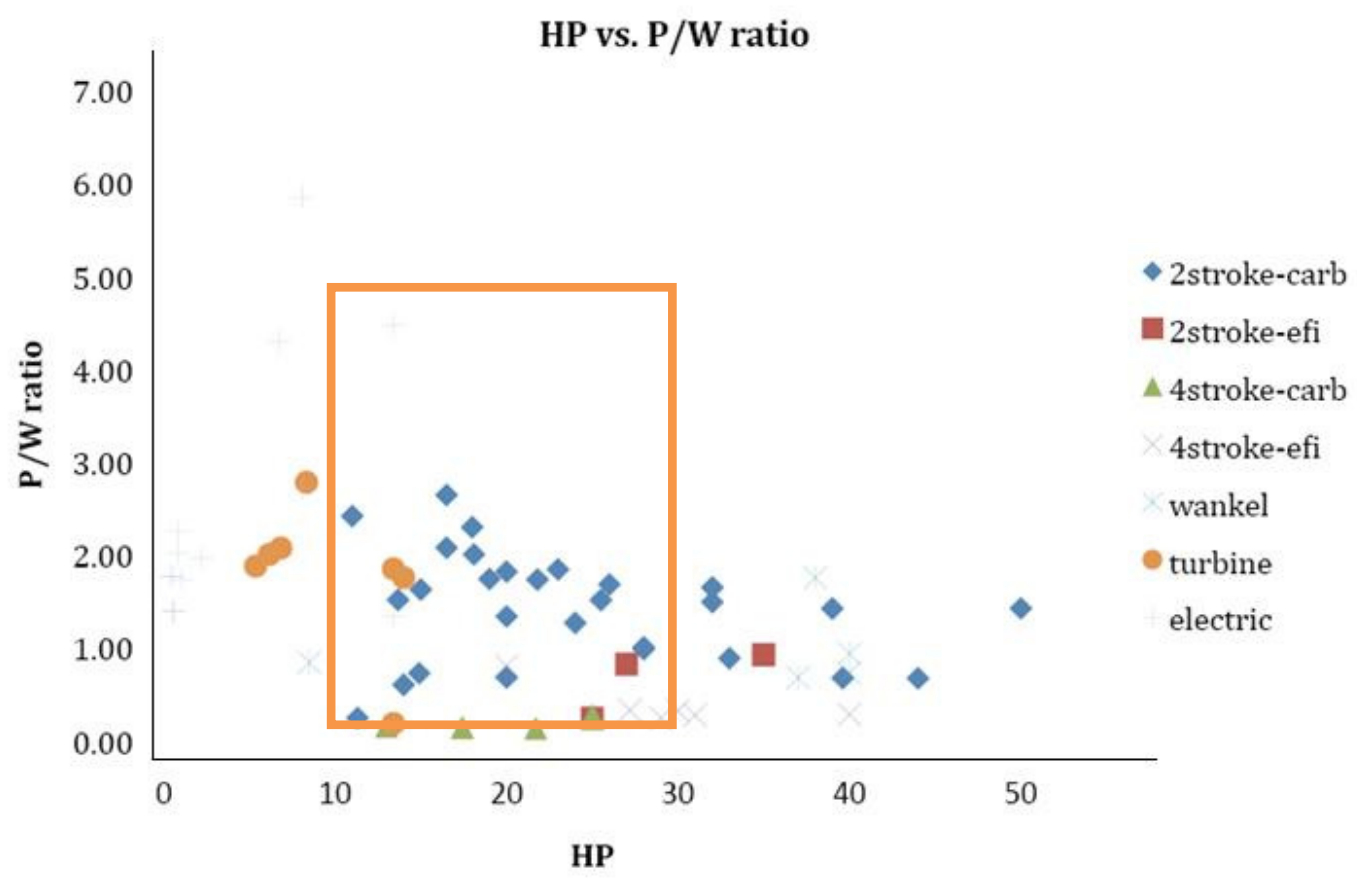

Figure 9.2 Plot of HP vs. Efficiency 


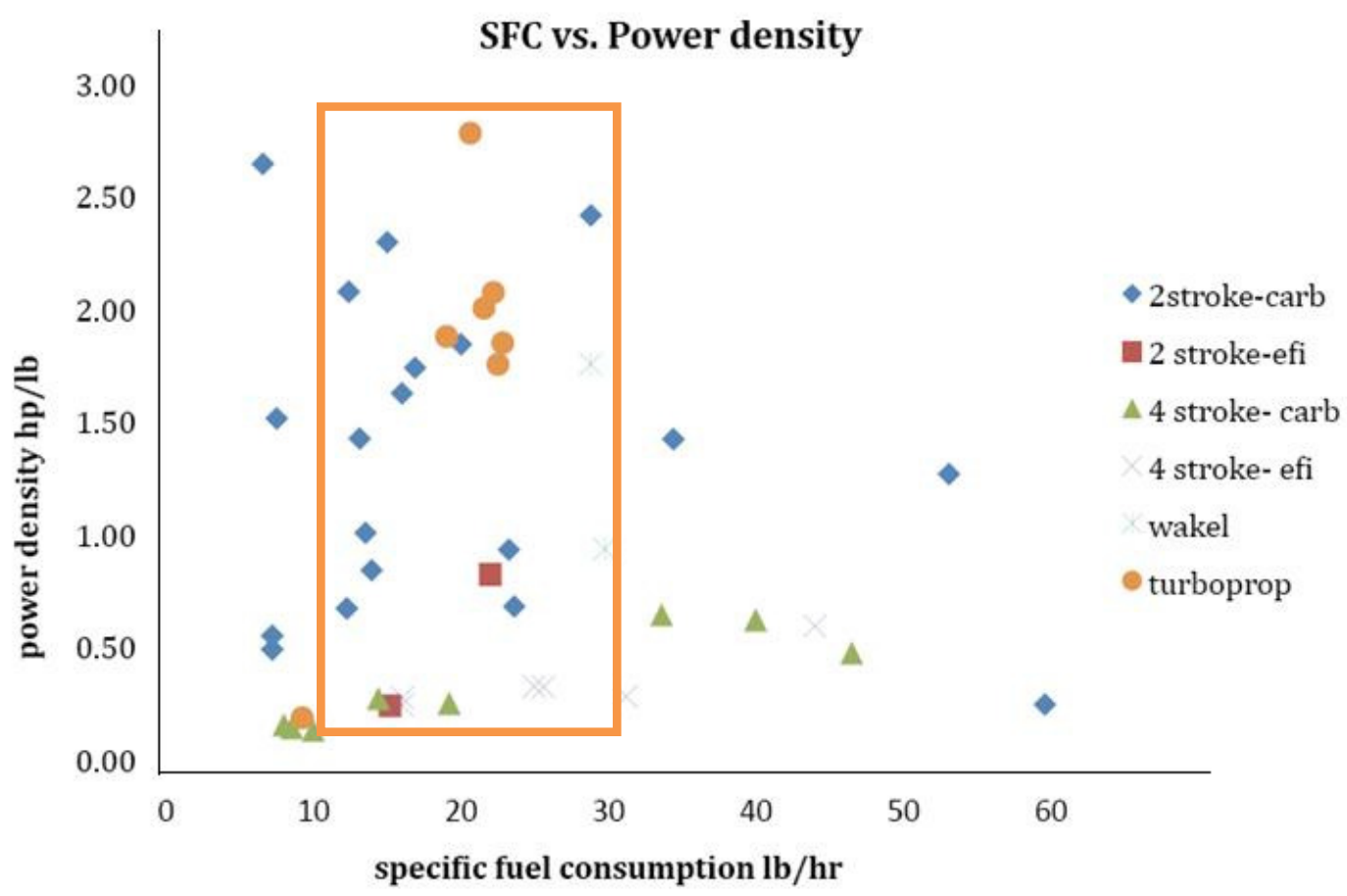

Figure 9.3 Plot of Specific fuel consumption vs. Power density

The plots of HP vs. SPED, HP vs. P/W ratio and SFC vs. Power density are shown on the previous page and the target power range can be seen within the boxed region. It is observed that on majority 2-strokes outperform other type of propulsion systems. These plots clearly indicate, 2-stroke engines are a) light, b) have higher SPED values, c) have high $\mathrm{P} / \mathrm{W}$ ratio compared to other type of propulsion system in the target power range.

It can be seen that in the case of BME engines, the manufacturer used the Aero design propeller selector for estimating output HP. This method is a crude estimation of engine output. The propeller pitch and diameter along with the airspeed doesn't replicate the actual torque on the engine and cannot duplicate peak performance of the engine. 
The theoretical output power estimated using BMEP, compression ratio and other factors is comparatively more accurate and gives a clear picture of engine performance. With pressure and temperature at inlet manifold known and using the compression ratio we can precisely find break mean effective pressure and also the output HP. The results from the dynamometer agree with the theoretical values, difference of $12 \%$ for BME 150 and $8 \%$ for BME 116 . The possible explanation behind this could be mechanical losses; no system is $100 \%$ efficient, also uncertainty in the dynamometer setup contributes to reasonable extent of the difference observed.

Only a dynamometer that can measure torque, RPM and fuel flow, thereby facilitating calculation of HP, efficiency and SPED would help validate the results from the database.

The dynamometer constructed helped resolve this issue, and provides output of HP, RPM and fuel flow, temperature at cylinder head and exhaust. With minimum uncertainty in the setup, the dynamometer proves to be a useful means of testing any engine within the 50HP range.

The BME 150 and BME 1162 stroke 2 cylinder engines tested on the dynamometer were compared against each other. The BME 150 is found to be a better engine between the two with respect to SPED and Efficiency values. SPED values of 0.87 and $0.54, \eta$ of $11.2 \%$ and $6.91 \%$ for BME 150 and BME 116 respectively, clearly show that BME 150 is better..

The BME 116 carburetor engine was retrofitted with a TBI fuel injection system, with Micro-Squirt II as the ECU (Engine Control Unit). This modification was carried out to see if there could be any improvements in the output power and efficiency of the 
engine. Although, not much of a difference was observed in performance, a fair difference was observed with fuel consumption on TBI and carburetor. I believe with more test runs at different pressure and different inlet temperature conditions significant improvements can be observed. The TBI fuel injection system is highly beneficial and would produce better performance and fuel consumption at higher altitudes.

The test results from the dynamometer for BME 150 and BME 116 shows significant disparity in performance from manufacturer's claim with respect to rated output and efficiency. It was learnt that the specifications provided by the manufacturer are based on theoretical calculations and testing the engines on a dynamometer would provide the actual performance detail. 


\section{CHAPTER X}

\section{FUTURE DEVELOPMENTS}

- Due to the short period of time that was available, a very few data points were recorded. The study was mainly focused on performing the study.

- With more time, a more accurate dynamometer integrated with Lab-view could be developed to perform wide range of tests

- More engines needs to be tested, over a wide range of HP rating

- More results on EFI engines are required

- A chamber for creating pressure difference needs to be built that would facilitate validation of EFI and to compare results between EFI \& Carburetor.

- Methods to reduce weight, improve power and Efficiency and test/validate them on the dynamometer

- Methods to reduce sound from the engine and a more in-built system to measure sound on the dynamometer can be done and integrated with lab-view to provide sound-map for each engine tested.

- The ultimate goal is indeed to configure an engine that is more efficient, has high power and less weight and build an UAV in the Tiger-Shark class. 


\section{APPENDIX}

\section{Rotameter Flow rate calibration chart:}

\begin{tabular}{|c|c|c|c|c|c|}
\hline Rotameter reading & Discharge & Rotameter reading & Discharge & Rotameter reading & Discharge \\
\hline & $\mathrm{ml} / \mathrm{min}$ & & $\mathrm{ml} / \mathrm{min}$ & & $\mathrm{ml} / \mathrm{min}$ \\
\hline 10 & 24.32724 & 41 & 147.4037 & 71 & 275.3945 \\
\hline 11 & 28.038397 & 42 & 151.5877 & 72 & 279.6903 \\
\hline 12 & 31.770478 & 43 & 155.7809 & 73 & 283.9839 \\
\hline 13 & 35.523105 & 44 & 159.983 & 74 & 288.2751 \\
\hline 14 & 39.2959 & 45 & 164.1935 & 75 & 292.5633 \\
\hline 15 & 43.088485 & 46 & 168.4121 & 76 & 296.8483 \\
\hline 16 & 46.900482 & 47 & 172.6384 & 77 & 301.1296 \\
\hline 17 & 50.731513 & 48 & 176.872 & 78 & 305.4069 \\
\hline 18 & 54.5812 & 49 & 181.1125 & 79 & 309.6798 \\
\hline 19 & 58.449165 & 50 & 185.3596 & 80 & 313.948 \\
\hline 20 & 62.33503 & 51 & 189.6129 & 81 & 318.2109 \\
\hline 21 & 66.238417 & 52 & 193.872 & 82 & 322.4684 \\
\hline 22 & 70.158948 & 53 & 198.1365 & 83 & 326.7199 \\
\hline 23 & 74.096245 & 54 & 202.406 & 84 & 330.9651 \\
\hline 24 & 78.04993 & 55 & 206.6802 & 85 & 335.2037 \\
\hline 25 & 82.019625 & 56 & 210.9588 & 86 & 339.4352 \\
\hline 26 & 86.004952 & 57 & 215.2412 & 87 & 343.6593 \\
\hline 27 & 90.005533 & 58 & 219.5272 & 88 & 347.8755 \\
\hline 28 & 94.02099 & 59 & 223.8163 & 89 & 352.0836 \\
\hline 29 & 98.050945 & 60 & 228.1082 & 90 & 356.2832 \\
\hline 30 & 102.09502 & 61 & 232.4025 & 91 & 360.4738 \\
\hline 31 & 106.15284 & 62 & 236.6988 & 92 & 364.655 \\
\hline 32 & 110.22402 & 63 & 240.9968 & 93 & 368.8266 \\
\hline 33 & 114.30819 & 64 & 245.2961 & 94 & 372.9881 \\
\hline 34 & 118.40496 & 65 & 249.5962 & 95 & 377.1392 \\
\hline 35 & 122.51397 & 66 & 253.8968 & 96 & 381.2794 \\
\hline 36 & 126.63482 & 67 & 258.1976 & 97 & 385.4085 \\
\hline 37 & 130.76715 & 68 & 262.4982 & 98 & 389.5259 \\
\hline 38 & 134.91058 & 69 & 266.7981 & 99 & 393.6314 \\
\hline 39 & 139.06473 & 70 & 271.097 & 100 & 397.7246 \\
\hline 40 & 143.22921 & & & & \\
\hline
\end{tabular}


2. Digital Flow meter calibration chart:

\begin{tabular}{|c|c|c|c|c|c|}
\hline \multirow[t]{2}{*}{$\begin{array}{l}\text { Flow meter } \\
\text { scale }\end{array}$} & Discharge & $\begin{array}{l}\text { Flow meter } \\
\text { scale }\end{array}$ & Discharge & $\begin{array}{l}\text { Flow meter } \\
\text { scale }\end{array}$ & Discharge \\
\hline & $\mathrm{ml} / \mathrm{min}$ & \multicolumn{2}{|r|}{$\mathrm{ml} / \mathrm{min}$} & \multicolumn{2}{|r|}{$\mathrm{ml} / \mathrm{min}$} \\
\hline 1 & 10.6803 & 36 & 44.0983 & 71 & 77.5163 \\
\hline 2 & 11.6351 & 37 & 45.0531 & 72 & 78.4711 \\
\hline 3 & 12.5899 & 38 & 46.0079 & 73 & 79.4259 \\
\hline 4 & 13.5447 & 39 & 46.9627 & 74 & 80.3807 \\
\hline 5 & 14.4995 & 40 & 47.9175 & 75 & 81.3355 \\
\hline 6 & 15.4543 & 41 & 48.8723 & 76 & 82.2903 \\
\hline 7 & 16.4091 & 42 & 49.8271 & 77 & 83.2451 \\
\hline 8 & 17.3639 & 43 & 50.7819 & 78 & 84.1999 \\
\hline 9 & 18.3187 & 44 & 51.7367 & 79 & 85.1547 \\
\hline 10 & 19.2735 & 45 & 52.6915 & 80 & 86.1095 \\
\hline 11 & 20.2283 & 46 & 53.6463 & 81 & 87.0643 \\
\hline 12 & 21.1831 & 47 & 54.6011 & 82 & 88.0191 \\
\hline 13 & 22.1379 & 48 & 55.5559 & 83 & 88.9739 \\
\hline 14 & 23.0927 & 49 & 56.5107 & 84 & 89.9287 \\
\hline 15 & 24.0475 & 50 & 57.4655 & 85 & 90.8835 \\
\hline 16 & 25.0023 & 51 & 58.4203 & 86 & 91.8383 \\
\hline 17 & 25.9571 & 52 & 59.3751 & 87 & 92.7931 \\
\hline 18 & 26.9119 & 53 & 60.3299 & 88 & 93.7479 \\
\hline 19 & 27.8667 & 54 & 61.2847 & 89 & 94.7027 \\
\hline 20 & 28.8215 & 55 & 62.2395 & 90 & 95.6575 \\
\hline 21 & 29.7763 & 56 & 63.1943 & 91 & 96.6123 \\
\hline 22 & 30.7311 & 57 & 64.1491 & 92 & 97.5671 \\
\hline 23 & 31.6859 & 58 & 65.1039 & 93 & 98.5219 \\
\hline 24 & 32.6407 & 59 & 66.0587 & 94 & 99.4767 \\
\hline 25 & 33.5955 & 60 & 67.0135 & 95 & 100.4315 \\
\hline 26 & 34.5503 & 61 & 67.9683 & 96 & 101.3863 \\
\hline 27 & 35.5051 & 62 & 68.9231 & 97 & 102.3411 \\
\hline 28 & 36.4599 & 63 & 69.8779 & 98 & 103.2959 \\
\hline 29 & 37.4147 & 64 & 70.8327 & 99 & 104.2507 \\
\hline 30 & 38.3695 & 65 & 71.7875 & 100 & 105.2055 \\
\hline 31 & 39.3243 & 66 & 72.7423 & 101 & 106.1603 \\
\hline 32 & 40.2791 & 67 & 73.6971 & 102 & 107.1151 \\
\hline 33 & 41.2339 & 68 & 74.6519 & 103 & 108.0699 \\
\hline 34 & 42.1887 & 69 & 75.6067 & 104 & 109.0247 \\
\hline 35 & 43.1435 & 70 & 76.5615 & 105 & 109.9795 \\
\hline
\end{tabular}




\begin{tabular}{|c|c|c|c|c|c|}
\hline \multirow[t]{2}{*}{$\begin{array}{l}\text { Flow meter } \\
\text { scale }\end{array}$} & Discharge & $\begin{array}{l}\text { Flow meter } \\
\text { scale }\end{array}$ & Discharge & $\begin{array}{l}\text { Flow meter } \\
\text { scale }\end{array}$ & Discharge \\
\hline & $\mathrm{ml} / \mathrm{min}$ & & $\mathrm{ml} / \mathrm{min}$ & & $\mathrm{ml} / \mathrm{min}$ \\
\hline 106 & 110.9343 & 141 & 144.3523 & 176 & 177.7703 \\
\hline 107 & 111.8891 & 142 & 145.3071 & 177 & 178.7251 \\
\hline 108 & 112.8439 & 143 & 146.2619 & 178 & 179.6799 \\
\hline 109 & 113.7987 & 144 & 147.2167 & 179 & 180.6347 \\
\hline 110 & 114.7535 & 145 & 148.1715 & 180 & 181.5895 \\
\hline 111 & 115.7083 & 146 & 149.1263 & 181 & 182.5443 \\
\hline 112 & 116.6631 & 147 & 150.0811 & 182 & 183.4991 \\
\hline 113 & 117.6179 & 148 & 151.0359 & 183 & 184.4539 \\
\hline 114 & 118.5727 & 149 & 151.9907 & 184 & 185.4087 \\
\hline 115 & 119.5275 & 150 & 152.9455 & 185 & 186.3635 \\
\hline 116 & 120.4823 & 151 & 153.9003 & 186 & 187.3183 \\
\hline 117 & 121.4371 & 152 & 154.8551 & 187 & 188.2731 \\
\hline 118 & 122.3919 & 153 & 155.8099 & 188 & 189.2279 \\
\hline 119 & 123.3467 & 154 & 156.7647 & 189 & 190.1827 \\
\hline 120 & 124.3015 & 155 & 157.7195 & 190 & 191.1375 \\
\hline 121 & 125.2563 & 156 & 158.6743 & 191 & 192.0923 \\
\hline 122 & 126.2111 & 157 & 159.6291 & 192 & 193.0471 \\
\hline 123 & 127.1659 & 158 & 160.5839 & 193 & 194.0019 \\
\hline 124 & 128.1207 & 159 & 161.5387 & 194 & 194.9567 \\
\hline 125 & 129.0755 & 160 & 162.4935 & 195 & 195.9115 \\
\hline 126 & 130.0303 & 161 & 163.4483 & 196 & 196.8663 \\
\hline 127 & 130.9851 & 162 & 164.4031 & 197 & 197.8211 \\
\hline 128 & 131.9399 & 163 & 165.3579 & 198 & 198.7759 \\
\hline 129 & 132.8947 & 164 & 166.3127 & 199 & 199.7307 \\
\hline 130 & 133.8495 & 165 & 167.2675 & 200 & 200.6855 \\
\hline 131 & 134.8043 & 166 & 168.2223 & & \\
\hline 132 & 135.7591 & 167 & 169.1771 & & \\
\hline 133 & 136.7139 & 168 & 170.1319 & & \\
\hline 134 & 137.6687 & 169 & 171.0867 & & \\
\hline 135 & 138.6235 & 170 & 172.0415 & & \\
\hline 136 & 139.5783 & 171 & 172.9963 & & \\
\hline 137 & 140.5331 & 172 & 173.9511 & & \\
\hline 138 & 141.4879 & 173 & 174.9059 & & \\
\hline 139 & 142.4427 & 174 & 175.8607 & & \\
\hline 140 & 143.3975 & 175 & 176.8155 & & \\
\hline
\end{tabular}




\section{Propulsion system survey:}

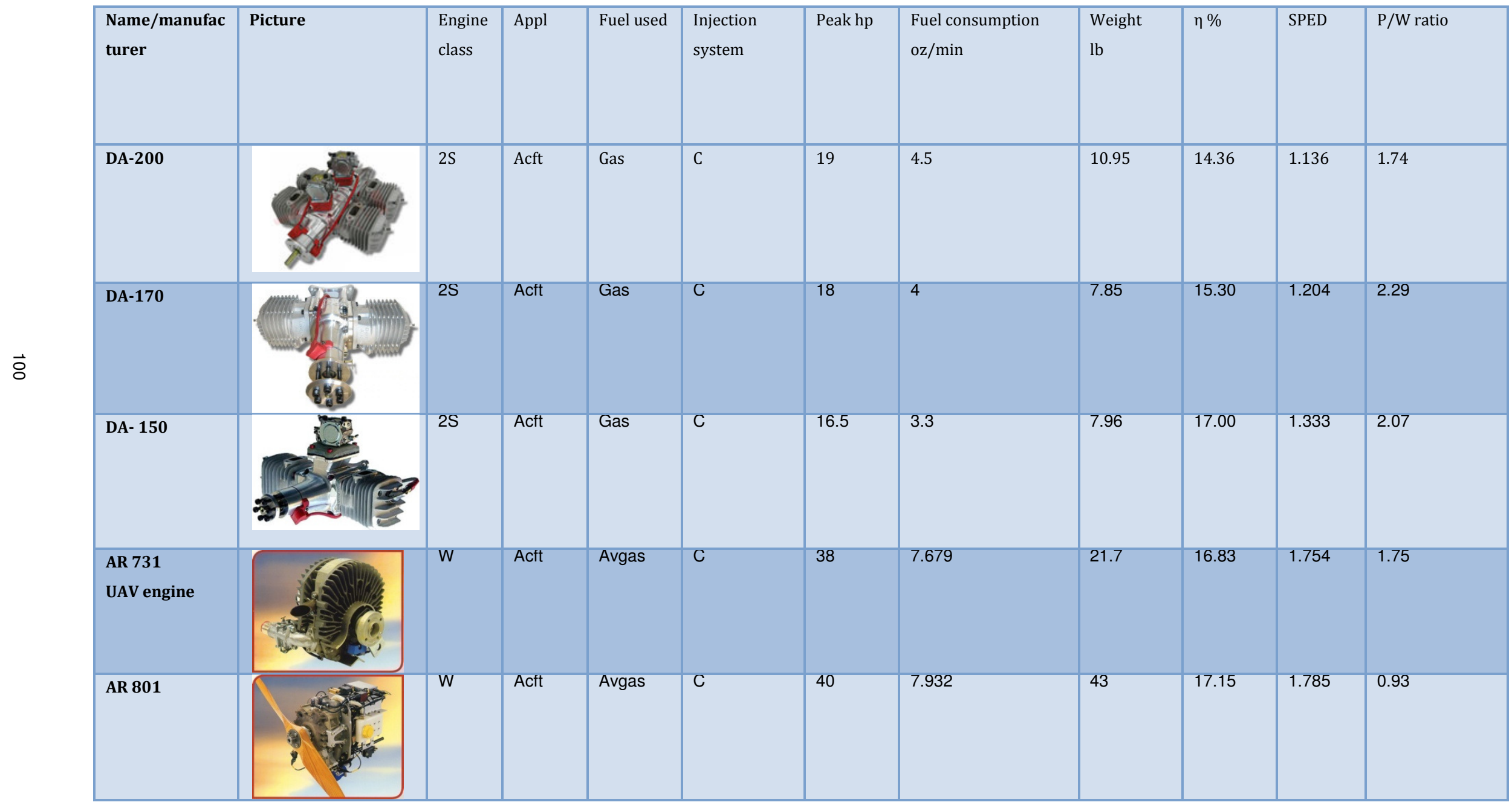




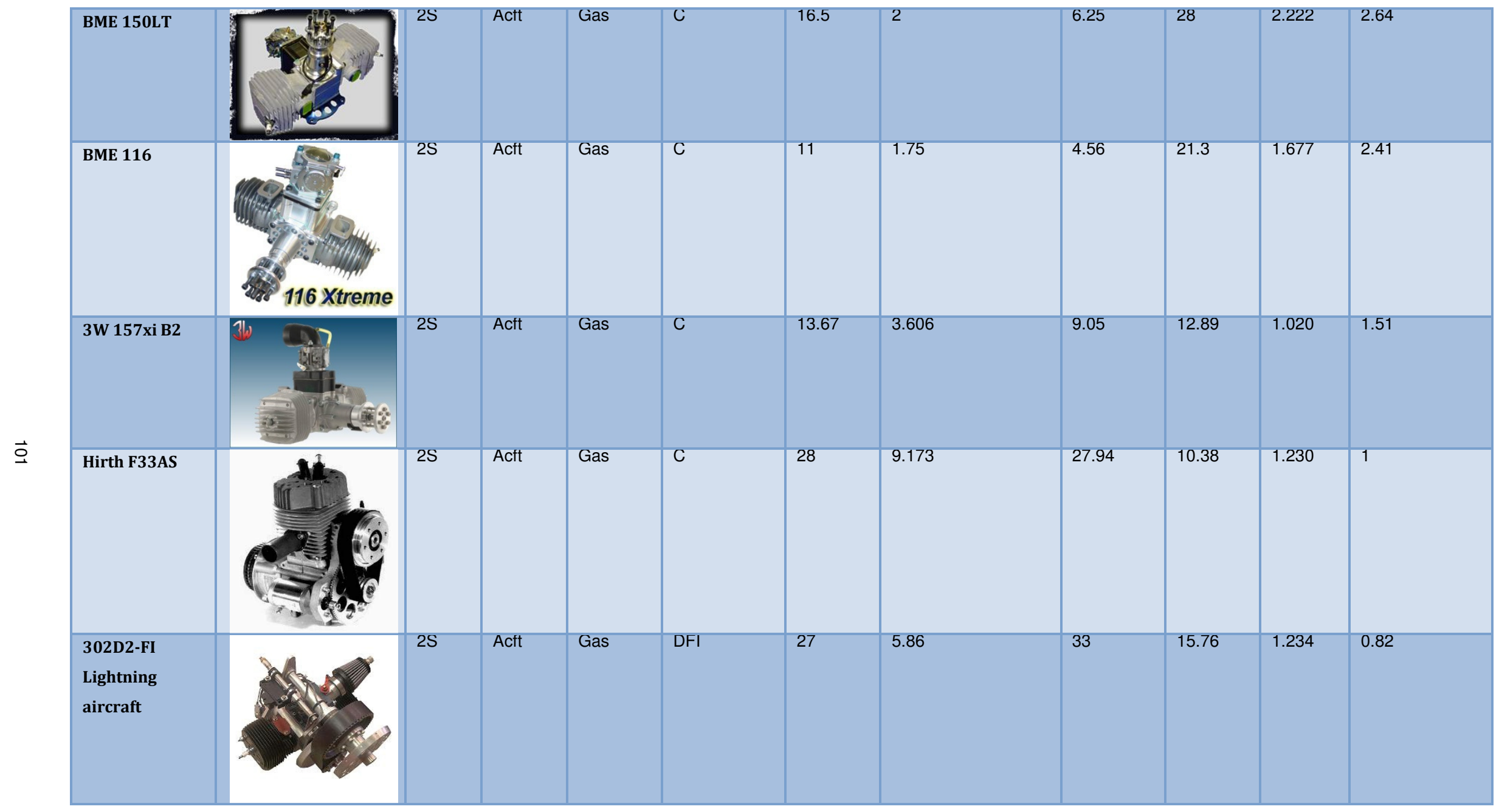




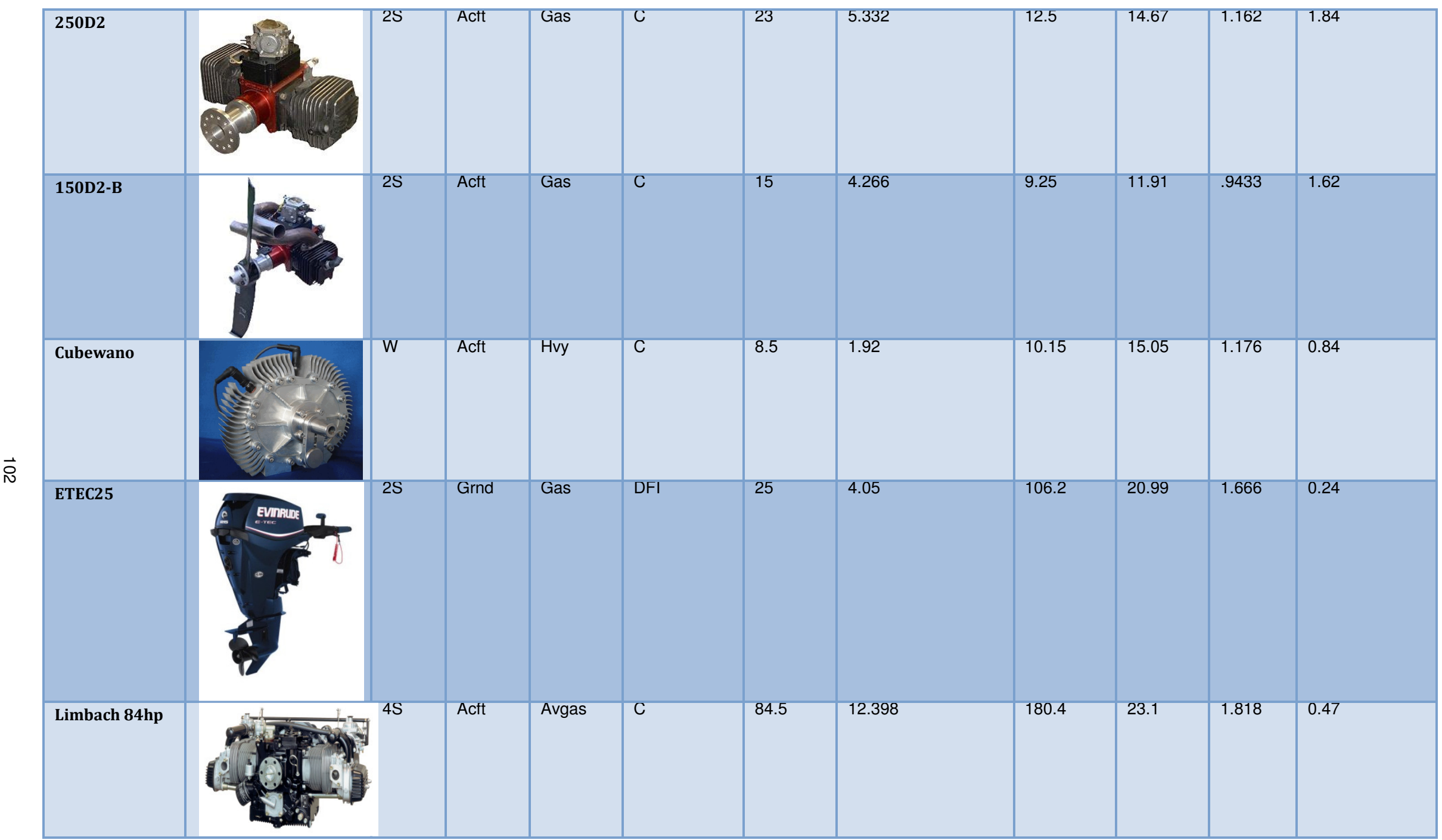




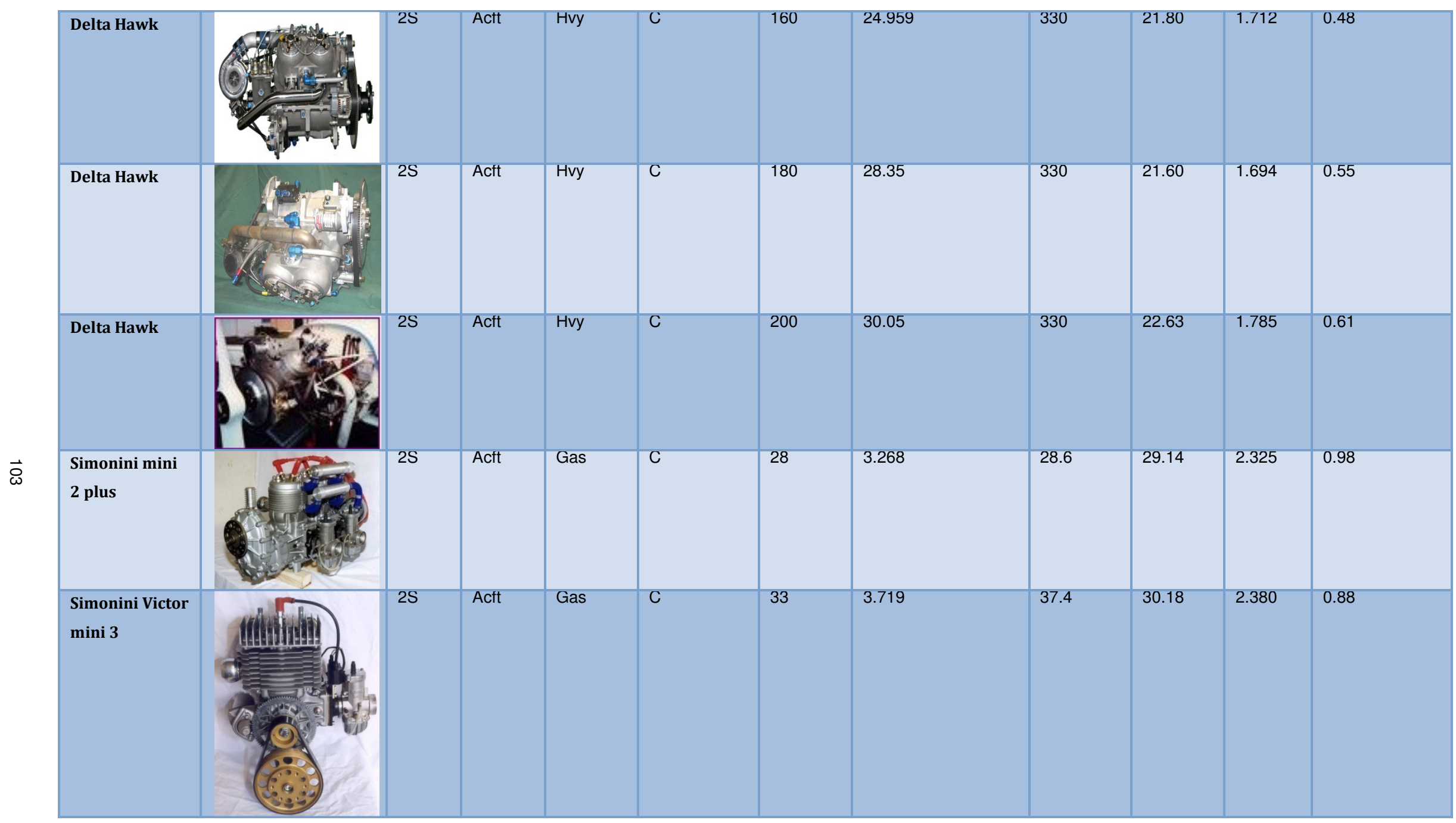




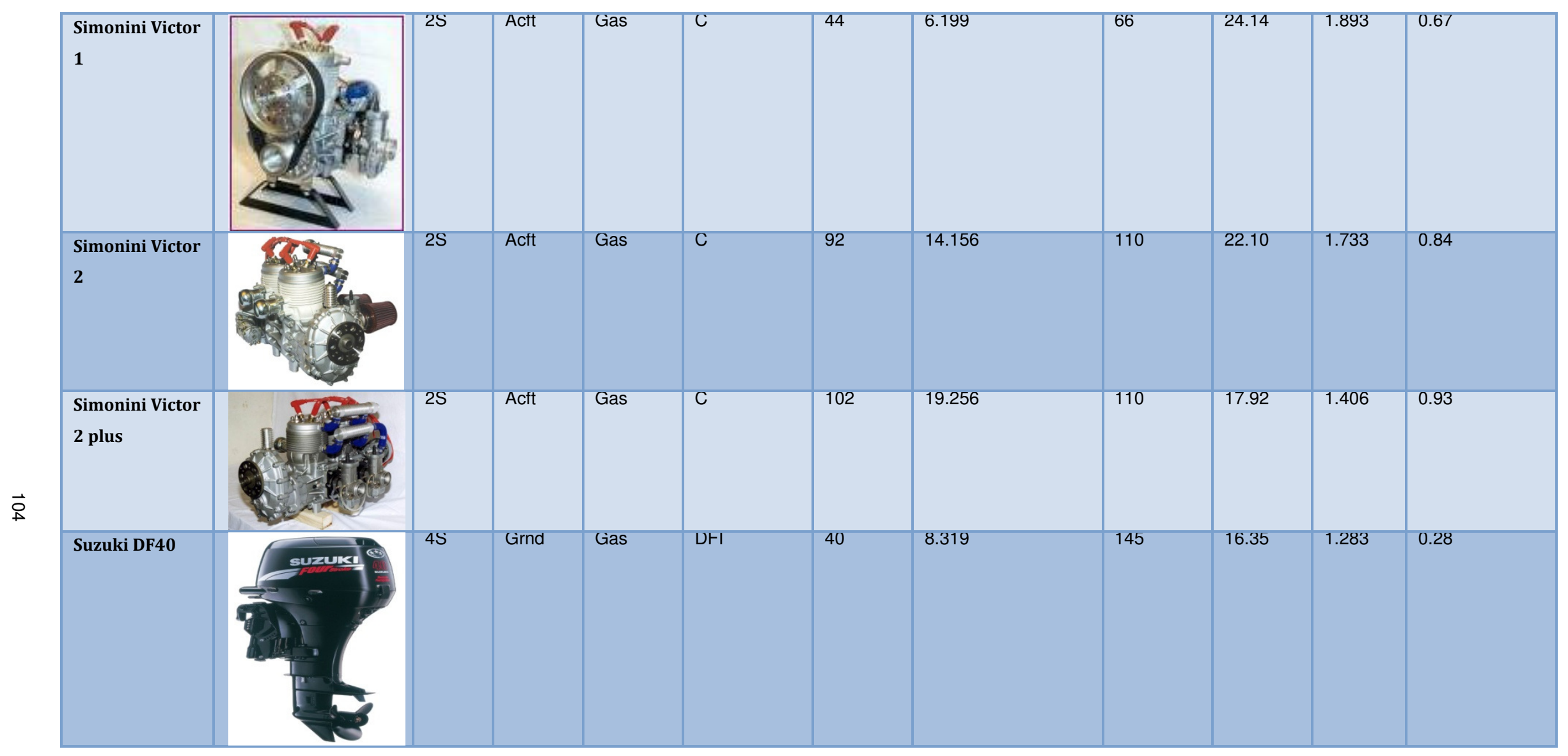




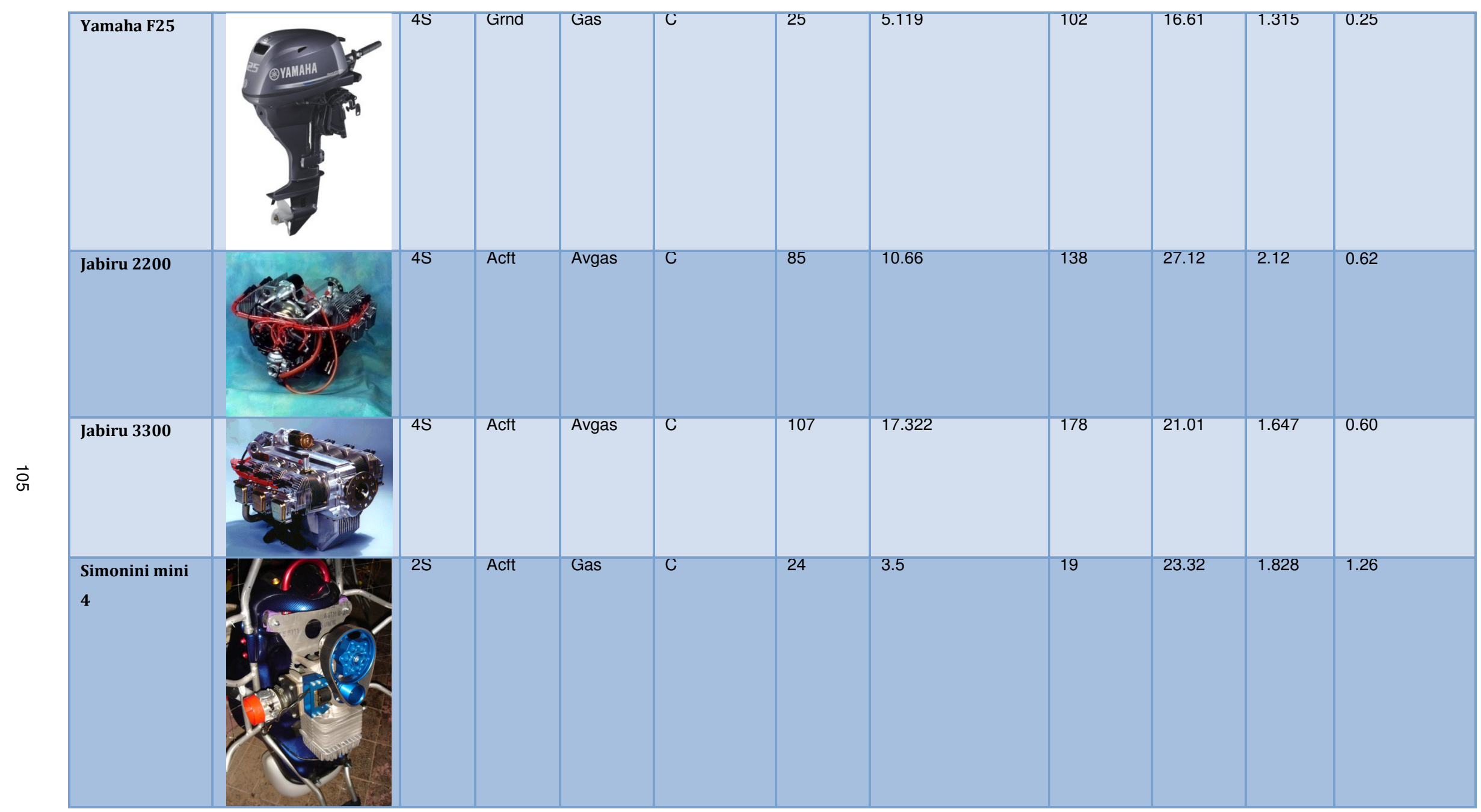




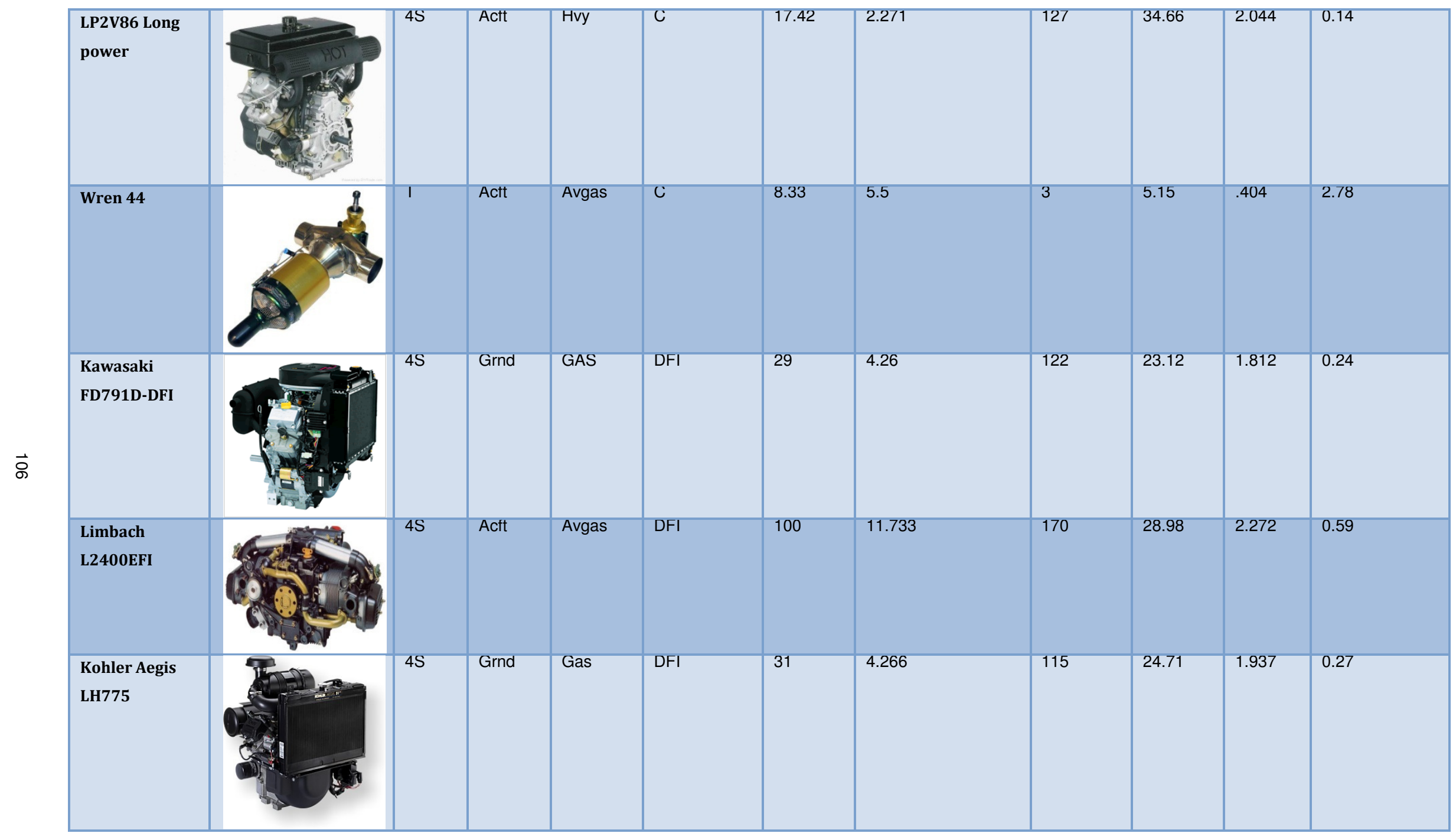




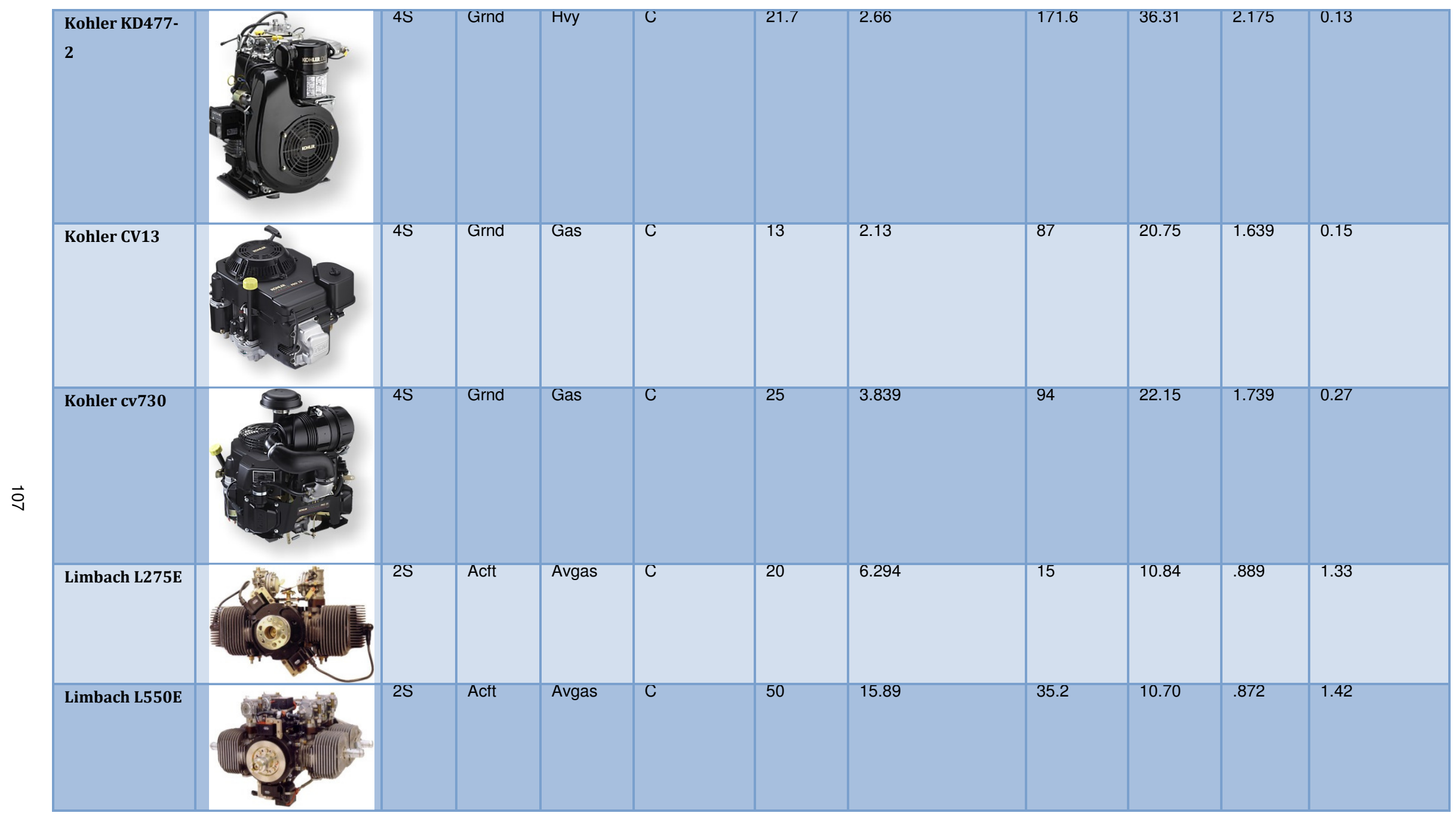




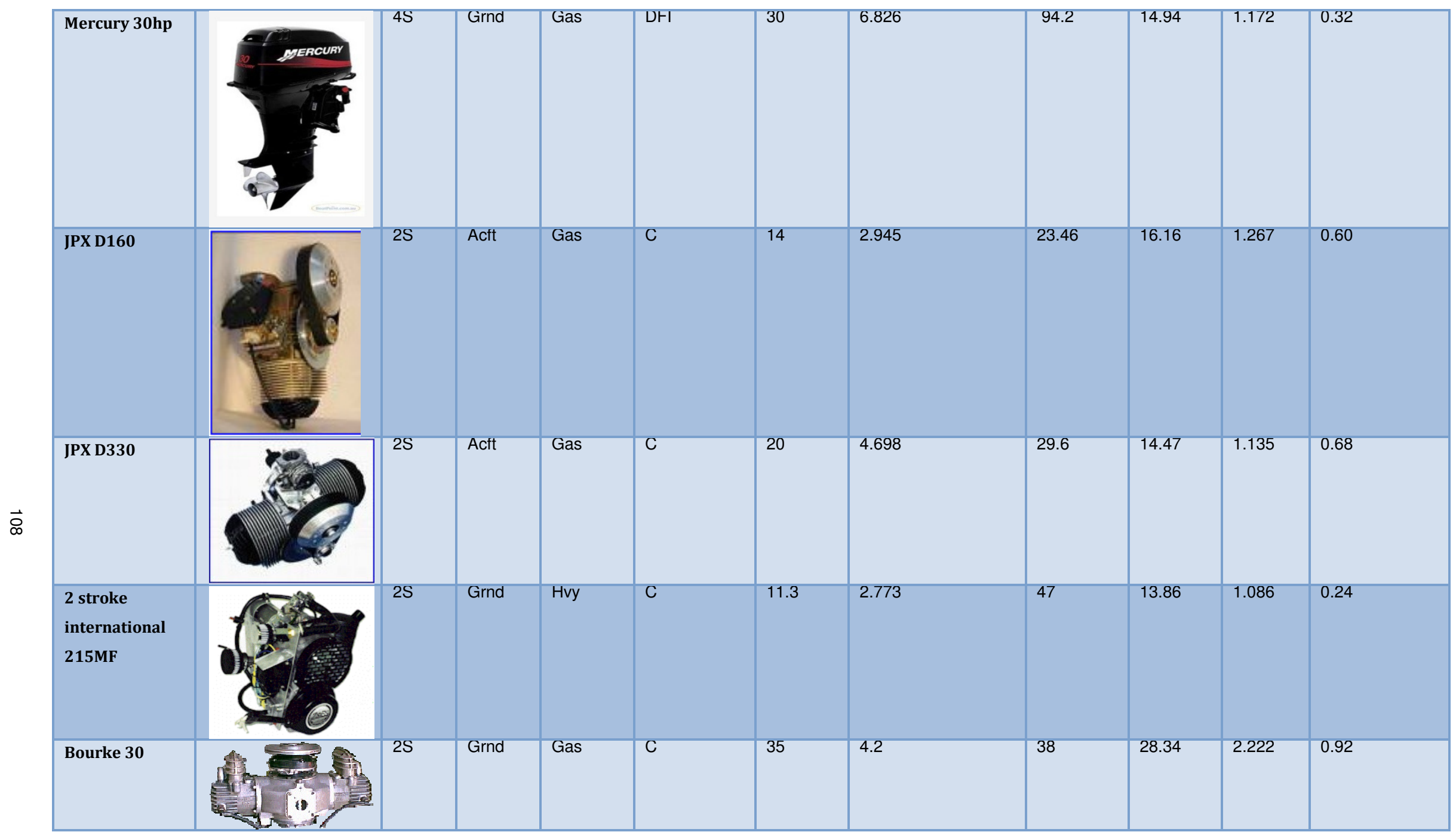




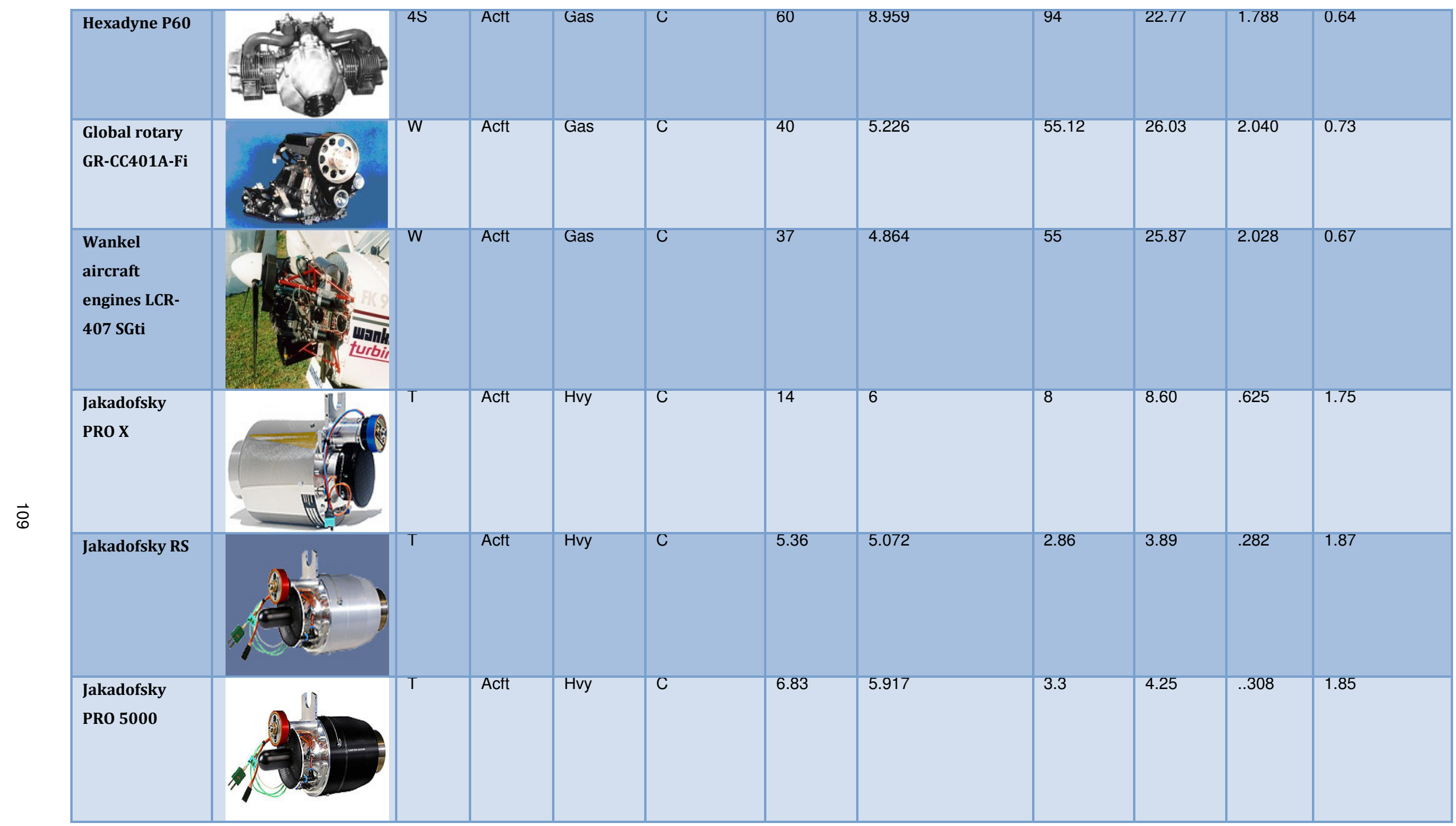




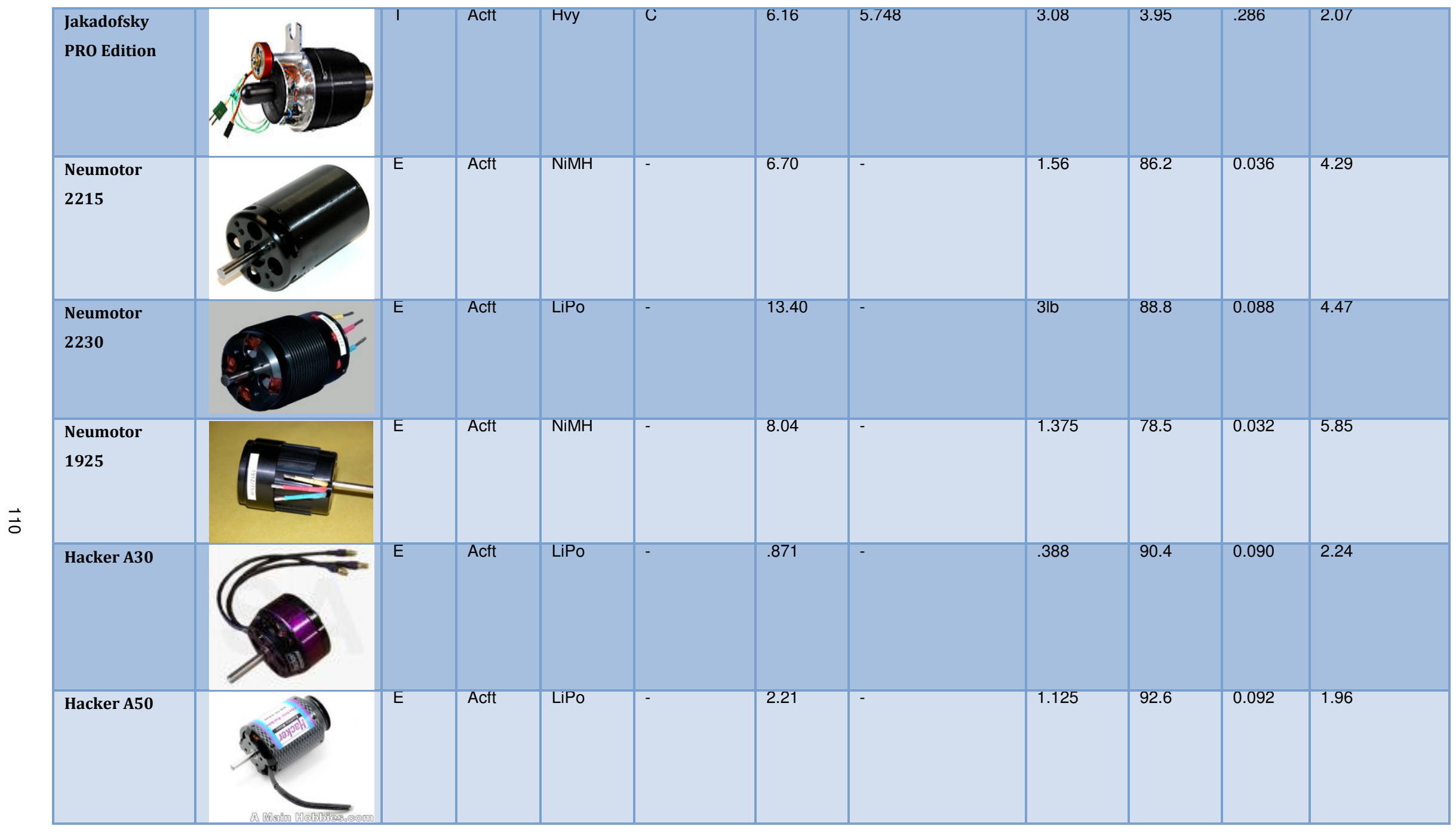




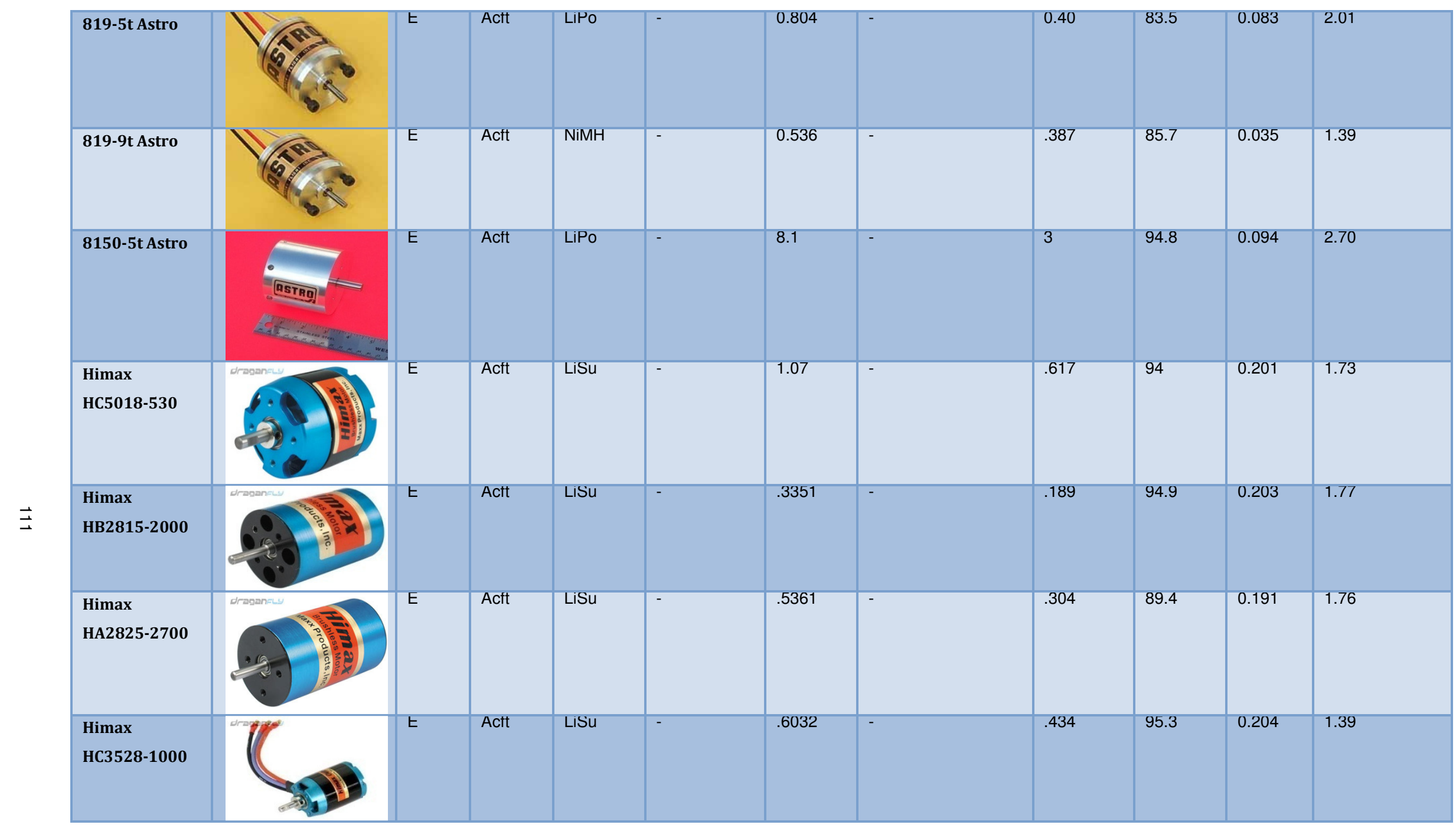




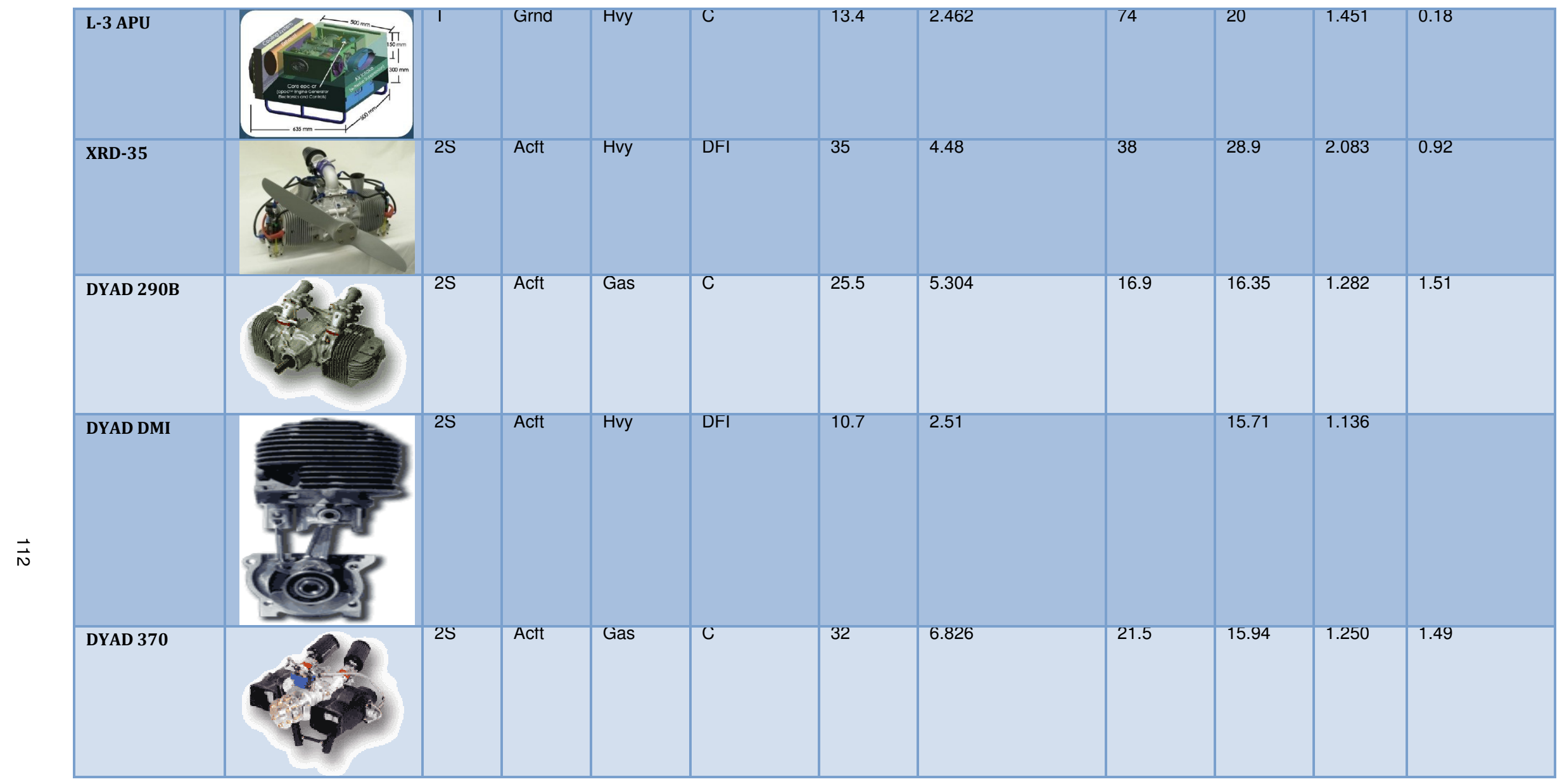




\section{REFERENCE}

Korakianitis, T., Meyer, L., Boruta, M., \& McCormick, H. (2009). Performance of a single nutating disk engine in the 2 to $500 \mathrm{~kW}$ power range. Applied Science, 86(10), 2213-2221. doi: 10.1016/j.apenergy.2009.01.006

Meitner, P. L., Boruta, M., \& Jerovsek, J. (2006). The Nutating Engine - Prototype Engine Progress Report and Test Results (Report No. NASA TM-2006-214342 ARLMR-0641). Washington, DC: National Aeronautics and Space Administration. Received from http://gltrs.grc.nasa.gov/reports/2006/TM-2006-214342.pdf

Menon, S., Moulton, N., \& Cadou, N. (2007). Development of a Dynamometer for measuring Small Internal-Combustion Engine Performance. Journal of Propulsion and Power, 23(1), 194-202. doi: 10.2514/1.19825

Raine, R. R., Moyle, K., Otte, G., Robertson, J. (2002). A Cost-Effective Teaching and Research Dynamometer for Small Engines. International Journal of Engineering Education, 18(1), 50-57. doi: 0949-149X/91

Reinhardt, J. R., James, J. J., \& Flanagan, E. M. (1999). Future Employment of UAVs. Joint Force Quarterly, Summer 1999 (22), 36-41. Retrieved from http://www.dtic.mil/doctrine/jel/jfq_pubs/0822b.pdf

Skin, Y., Change, S., \& Koo, S. (2005). Performance test and simulation of a reciprocating engine for long endurance miniature unmanned aerial vehicles. Proceedings of the I MECH E Part D Journal of Automobile Engineering, 219, 573-581. doi: 10.1243/095440705X11013

United States Army Intelligence Center. (2000). Tactical Unmanned Aerial Vehicle (TUAV)Concept of Operations. Arizona, For Huachuca: Author. Retrieved from http://www.fas.org/irp/program/collect/docs/TUAV-CONOPS.htm

United States Department of Defense - Office of the Secretary of Defense. (2005). Unmanned Aircraft Systems Roadmap 2005-2030. Washington, DC: Author. Retrieved from <http://www.fas.org/irp/program/collect/uav_roadmap2005.pdf>

Annen, Kurt D., David B. Stickler, and Jim Woodroffe. "High energy density electric power for UAV/UGV propulsion using a miniature IC engine (MICE)." 2nd AIAA "Unmanned Unlimited" Systems, Technologies, and Operations (2003).

Astroflight. Bob Boucher. 02 July $2009<$ http://www.astroflight.com>. 
Dahm, Werner, Jun Ni, Kevin Mijit, James Mayor, George Qiao, Stephen W. Dyer, Anish G. Menjamin, Yongxian Gu, Yong Lei, and Melody L. Papke. "Micro Internal Combustion Swing Engine (MICSE) for Portable Power Generation Systems." AIAA Aerospace Sciences Meeting (2002).

Demler, Roger. "Power for the Soldier: Small Engine Prospects." Foster-Miller Inc.

Fu, Kelvin, Aaron J. Knoblock, Fabian C. Martinez, David C. Walther, Carlos Fernandez-Pello, Al P. Pisano, Dorian Liepmann, Kenji Miyaska, and Kaoru Maruta. "Design and experimental results of small scale rotary engines." ASME International Mechanical Engineering Congress and Exposition (2001).

Gerendas, Miklos, and Ralph Pfister. "Development of a Very Small Aero-Engine." ASME

International Gas Turbine and Aeroengine Technical Congress and Exposition (2000).

Glassock, Richard, Jane Hung, Luis F. Gonzalez, and Rodney A. Walker. "Design, Modelling and Measurement of Hybrid Powerplant for Unmanned Aerial Systems (UAS)." 5th

Australasian Congress on Applied Mechanics (2007).

Glassock, Richard R. "Multimodal Hybrid Powerplant for Unmanned Aerial Systems (UAS)

Robotics." Australian Research Centre for Aerospace Automation.

Greenman, Matthew D. Design and Construction of a Miniature Internal Combustion Engine.

Diss. Massachusetts Institute of Technology, 1996.

"High Performance Free-Piston Stirling Engines."

"High Power Lithium Ion ANR26650M1." A123Systems.

"Lithium Sulfur Rechargeable Battery Data Sheet." SION power inc.

Load Cell, Flow meter \& related instruments. <http://omega.com>.

Martini, William R. STIRLING ENGINE DESIGN MANUAL. 1978.

Menon, Shyam K. Performance measurement and scaling in small internal combustion engines.

Thesis. 2006.

Menon, Shyam, Nathan Moulton, and Christopher Cadou. "Development of a Dynamometer for 
Measuring Small Internal-Combustion Engine Performance." JOURNAL OF PROPULSION AND POWER 23 (2007): 194-202.

"[Micro and Precision Engineering Research Group] Microturbine for electric power generation." [Departement Werktuigkunde] Home page Department Mechanical Engineering. 02 July $2009<$ http://www.mech.kuleuven.be/micro/topics/turbine/>.

Raine, Robert R., Keri Morle, and Gordon Otte. "A Cost-Effective Teaching and Research Dynamometer for Small Engines." Int. J. Engng Ed 18 (2002): 50-57.

Sookdeo, Troy. Performance measurement, simulation and analysis of the cox-tee-dee 0.010, the world's smallest production internal combustion engine. Thesis. 2006.

Taylor, Charles F. The Internal-combustion Engine In Theory And Practice. Vol. 1. 
VITA

Ashwin Ravi

Candidate for the Degree of

Master of Science

Thesis: UAV POWER PLANT PERFORMANCE EVALUATION

Major Field: Mechanical \& Aerospace Engineering

Biographical:

Education:

Completed the requirements for the Master of Science in Mechanical \& Aerospace Engineering at Oklahoma State University, Stillwater, Oklahoma in May, 2010.

Experience:

Graduate Teaching Assistant, spring 2009 to spring 2010, Department of Mechanical \& Aerospace Engineering, Oklahoma State University. Graduate Research Assistant, summer and fall 2009.

Professional Memberships: AIAA 
UAV's are proven to be cost effective when compared to manned aircraft and minimize the risk related to a pilot's life. The primary focus of my research was on identifying and evaluating state of the art propulsion technologies for Tiger-Shark class UAV. This would help us in identify areas of future improvement in Power, Weight \& Efficiency. For this purpose, a detailed survey of all the propulsion technologies in the 5-100HP range was conducted and a dynamometer was built to perform a firsthand comparison and evaluation of engine performance. Based on the survey, it was observed that 2-stroke engines are superior in terms of their high energy density P/W ratio. Since, the survey results were based on manufacturer data which were obtained using different methods and under varying test conditions, it is highly mandatory to validate these data to support any conclusion obtained from it. The dynamometer that we built is capable of testing any IC engine in the range of 5-30 HP. With the limited time frame available, two engines were chosen for the preliminary test runs on the dynamometer namely, "BME 150 LT", "BME 116 Xtreme"- two-stroke carburetor engine. Later on, the BME 116 engine was retro-fitted with EFI system and results from all three engine configurations were compared. There is not a significant difference observed between the EFI \& Carburetor type of BME116, the BME 116 EFI is more suitable for the target UAV class power range. Future work include, testing of wide range of engines, with \& without EFI. 